\author{
Mon og r a p h \\ urn:1sid:zoobank.org:pub:A60F479C-8055-4AC9-8F49-44311CA6EA0B
}

\title{
Revision of the species confused with “Nereis falsa" de Quatrefages, 1866 (Annelida, Nereididae)
}

\author{
Sergio I. SALAZAR-VALLEJO ${ }^{\circledR 1, *}$, Jesús Angel DE LEÓN-GONZÁLEZ ${ }^{\circledR 2}$ \\ \& Víctor M. CONDE-VELA @3 \\ ${ }^{1,3}$ El Colegio de la Frontera Sur, Departamento Sistemática y Ecología Acuática, \\ Chetumal, Quintana Roo, Mexico. \\ ${ }^{2,3}$ Universidad Autónoma de Nuevo León, Facultad de Ciencias Biológicas, \\ Laboratorio Biosistemática, San Nicolás de los Garza, N.L., Mexico. \\ *Corresponding author: savs551216@hotmail.com, ssalazar@ecosur.mx \\ ${ }^{2}$ Email: jesus.deleongn@uanl.edu.mx \\ ${ }^{3}$ Email: victorconde2323@gmail.com \\ ${ }^{1}$ urn:1sid:zoobank.org:author:7D3C2D7E-5D08-45F7-A1E4-84A1563EA14F
${ }^{2}$ urn:lsid:zoobank.org:author:F347D71F-DDEA-4105-953F-4FE71A5D6809
${ }^{3}$ urn:1sid:zoobank.org:author:44DFD70C-BA95-46B1-B12D-0E9D800D024A
}

\begin{abstract}
Nereis falsa de Quatrefages, 1866 has been regarded as a cosmopolitan species, and several species described from different localities have been regarded as junior synonyms of $N$. falsa. The present study is an attempt to resolve the taxonomic confusion in $N$. falsa, which seems to contain several distinct species due to previous inappropriate synonymy, widely distributed in the Atlantic and eastern Pacific Oceans. For this purpose, the authors first propose the resurrection of the synonymy of $N$. falsa with Hediste diversicolor that was concluded during the $19^{\text {th }}$ century but disregarded later. After the fixation of the identity of $N$. falsa sensu stricto, the authors re-evaluate the proper taxonomic status of species which have previously been confused with $N$. falsa. Type, topotype and non-type specimens were examined; most species are redescribed, and others are reinstated. Nereis splendida Grube, 1840 is a valid Mediterranean species, and a neotype is proposed; it includes the Mediterranean populations of what is currently regarded as $N$. falsa. Consequently, N. falsa is transferred to Hediste Malmgren, 1867 , and some taxonomic comments are added for the latter genus and a key to species is also included. Nereis callaona Grube \& Kröyer in Grube, 1857, N. marginata Grube \& Örsted in Grube, 1857 and N. riisei Grube \& Örsted in Grube, 1857 are restricted to tropical American shores and are all redescribed. Nereis pelagica lunulata Ehlers, 1901, formerly regarded as a junior synonym of $N$. falsa by Fauvel (1941), is redescribed and elevated in rank to species level. Nereis lucipeta Ehlers, 1908, formerly regarded as a junior synonym of $N$. splendida by Ehlers (1913) and of N. falsa by Fauvel (1919), is reinstated. Nereis occidentalis Hartman, 1945 is also redescribed. Furthermore, N. ambigua Treadwell, 1937, formerly regarded as a junior synonym of $N$. riisei by Monro (1933), deserves to be reinstated. Western Africa specimens recorded as $N$. falsa are newly described as $N$. mezianei sp. nov.
\end{abstract}

Keywords. Taxonomy, Hediste, neotype, new species, redescriptions.

Salazar-Vallejo S.I., de León-González J.A. \& Conde-Vela V.M. 2021. Revision of the species confused with "Nereis falsa" de Quatrefages, 1866 (Annelida, Nereididae). European Journal of Taxonomy 779: 1-70. https://doi.org/10.5852/ejt.2021.779.1579 


\section{Introduction}

Nereis falsa de Quatrefages, 1866 has been regarded as a cosmopolitan species (Salazar-Vallejo et al. 2017). After Fauvel (1923), it has been recognized that $N$. falsa belongs to one of the species groups of Nereis species having anterior notopodia with two ligules, pharyngeal area $\mathrm{V}$ without paragnaths, area VI with 4 (5) large paragnaths in a diamond and areas VII-VIII with 2-3 rows of conical paragnaths, and posterior notopodial ligules tapered, not foliose. It has also been indicated that $N$. falsa might include several distinct species from different localities all over the world (Salazar-Vallejo et al. 2017), such that it could be regarded as a species complex. De Sousa-Paula et al. (2021:2) defined a species complex as "an informal assemblage of taxa whose members are related phylogenetically and share morphological similarities." Fauvel was relying on morphological resemblances when accumulating some species group names under $N$. falsa, but in case differences in some fine diagnostic features are found, the included species cannot be regarded as phylogenetically related. To clarify this problematic group, a revision of type or topotype specimens under a standardized approach, together with an improved understanding of the supposed affinities, might suffice to clarify the differences, if some morphological ones can be noted.

Rathke (1837a) recorded and illustrated, with hesitation, a nereidid species as Lycoris pulsatoria? from the Black Sea; its parapodia were shown as having three notopodial ligules. In a separate publication, its anatomy and physiology were thoroughly described (Rathke 1837b), and with this information Örsted (1843: 23) regarded it as a junior synonym of Nereis diversicolor Müller, 1776. The original description for the latter species was very brief (Müller 1776: 217), but the author provided a much more detailed one a few years afterward (Müller 1800: 104-118, pl. 6 figs 1-6). Regretfully, although de Quatrefages (1866b: 778) had Örsted's publication, he overlooked the synonymy of L. pulsatoria? with $N$. diversicolor, and proposed Nereis falsa for L. pulsatoria? Rathke, 1837 . This means, assuming that Örsted was correct, that $N$. falsa is a junior synonym of $N$. diversicolor. The same conclusion was reached by von Marenzeller (1874: 468-469, footnotes), and this made Bobretzky change his mind. He had recorded N. falsa for the Black Sea (Bobretzky 1870: 210-211, pl. 10 figs 24-25), but later regarded $N$. falsa as a junior synonym of $N$. diversicolor (Bobretzky 1882: 192-193). Consequently, during the $19^{\text {th }}$ century three experts, Örsted, von Marenzeller and Bobretzky, had pointed out that $N$. falsa was a junior synoym of $N$. diversicolor. However, this was not based on a study of the type material, which seems to be lost (Salazar-Vallejo et al. 2017).

In the early $20^{\text {th }}$ century, the encyclopedic monographs of McIntosh became very influential. In the one dealing with nereidids, he cited the publications by Örsted and von Marenzeller, but he did not include $N$. falsa as a junior synonym of $N$. diversicolor (McIntosh 1910: 312-324), and a similar perspective was provided by Heinen (1911: 46-49). Fauvel (1913: 63) disregarded earlier synonyms. There are no references in Fauvel's paper, but he listed both, Örsted and von Marenzeller, in his next publication on the same specimens (Fauvel 1914: 407-408) and used the name $N$. falsa for some Mediterranean nereidids. This was incorrect and must be clarified; to emphasize this, quotation marks are used in the present paper to indicate the questionable status of the species group name $N$. falsa for specimens from the Mediterranean and nearby marine environments (see below).

Some polychaete species are currently regarded as widespread, or even cosmopolitan. Hutchings \& Kupriyanova (2018) have recently summarized the historical reasons for this perspective and pointed out that most species regarded as such should be studied in detail to clarify their status. Especially because, in addition to a few species that were transported associated with Japanese giant oysters or were transported as biofouling on ships hulls or in ballast water, many records were the by-product of erroneous taxonomical procedures. Salazar-Vallejo et al. (2017) reviewed the situation in the widespread nereidid polychaete Nereis falsa de Quatrefages, 1866, and they proposed some steps to solve this specific case. The present contribution is an effort to assess this problematic species, and to improve our understanding of the current situation, some remarks are needed dealing with cosmopolitan species, 
the identification of nereidid taxa, the role of some abnormalities for proposing new groups and the relevance of the pharyngeal areas as diagnostic features.

A comparative method should be employed to solve the supposed cosmopolitan status of species belonging to the " $N$. falsa" group, using type or topotype specimens of all supposed junior synonyms from each relevant region. For the Mediterranean Sea and the adjacent Eastern Atlantic, two similar species should be included: $N$. splendida Grube, 1840 and N. parallelogramma Claparède, 1868; for Southern Africa and Madagascar there would be one species: N. lucipeta Ehlers, 1908; and for the Northwestern Atlantic only one species: N. occidentalis Hartman, 1945. The Northeastern Pacific records were solved by describing a new species elsewhere (Conde-Vela \& Salazar-Vallejo 2015), whereas both the Southwestern Atlantic and the Southeastern Pacific species (Ehlers 1901a, 1901b; Fauvel 1941; Wesenberg-Lund 1962) deserve clarification (see below).

In this contribution, some species resembling " $N$. falsa" are revised, and the diagnostic features mentioned above are assessed. The main conclusions are that $N$. falsa must be transferred to Hediste, as indicated in classical publications, and that N. splendida Grube, 1840 is confirmed and refers to Mediterranean specimens of what has been regarded as N. falsa. Furthermore, N. lucipeta Ehlers, 1908 is reinstated and N. pelagica lunulata Ehlers, 1901 is reinstated and elevated to species rank. Three other confused species, N. callaona Grube \& Kröyer in Grube, 1857, N. marginata Grube \& Örsted in Grube, 1857 and $N$. riisei Grube \& Örsted in Grube, 1857, are redescribed. Some specimens recorded as N. falsa from Western Africa are newly described as N. mezianei sp. nov.

\section{Material and methods}

\section{Morphological characters}

The identification of nereidid genera and species requires the observation of several characters of the anterior end (pairs of tentacular cirri, number of antennae), of the parapodial ligules and cirri, including chaetal features (Gravier 1934), and the presence and arrangement of pharyngeal accessories like papillae and paragnaths. Most publications include illustrations for these features, and some give additional details about variation, especially on their numbers or size proportions; however, the selection of parapodia used for illustrations has not been consistent, making comparisons difficult, especially because in many species there are modifications of parapodial development along the body. This explains why hard structures, such as paragnaths and chaetae, are usually regarded as more reliable than soft structures like antennae, palps and cirri, because being muscular, they are retractile and fragile. Nevertheless, once their size variation pattern is known, including abnormalities, the latter are helpful in separating similar species.

There are a few studies dealing with variations or abnormalities in nereidid soft structures. Duplicated ventral cirri have been found in some parapodia (Mohammad 1981; Conde-Vela \& Salazar-Vallejo 2015), and Coutinho \& Santos (2014) made one of the most complete studies in two Brazilian species of Perinereis Kinberg, 1865. They found anomalies in an average of $7 \%$ of specimens including differences in the number of tentacular cirri and eyes, fusion of antennae, and lateral duplication of parapodia in single chaetigers. It is interesting that in the compilation and keys for all polychaete genera (Fauchald 1977a: 87), the presence of a single antenna is a diagnostic feature for two monotypic nereidid genera (Dawbinia Benham, 1950 and Unanereis Day, 1962), although their single antenna might be an abnormal fusion of the usually paired ones. A supernumerary antenna was reported and illustrated for Nereis rava Ehlers, 1868 by Fauvel (1914: 170, pl. 13 fig. 1), but a new genus was not proposed for it, whereas the presence of a single antenna was regarded as an abnormality by Hartman (1936: 471) and by Bakken \& Wilson (2005: 537).

After Monro (1933), the identification of species of Nereis having pigmented, glandular parapodia has been problematic. For example, he recorded the Caribbean N. riisei for Pacific localities in Central 
America. Hartman (1940) described some species with glandular parapodia, such as N. pseudonereis, and synonymyzed other species like $N$. ambiguus Treadwell, 1937 with $N$. riisei, probably following Monro. Hartman (1940: 224) also remarked that her N. pseudonereis resembled N. falsa by following Fauvel (1923). Besides the pigmented parapodial glands, these species differ especially in the paragnath pattern in areas VII-VIII; one group of species, including $N$. riisei, is provided with a single row of a few paragnaths, whereas the other species have two bands ventrally, including $N$. pseudonereis (Hartman, 1940) (see below). Reish (1954) concluded that N. pseudonereis was a junior synonym of N. callaona, but the delineation for other species remains confusing.

Paragnaths are arranged along the pharyngeal areas and their types and distribution are traditional generic diagnostic features, although some refinement is needed regarding their shape and usefulness for delineating taxa, because homoplasy is common among nereidids (Bakken \& Wilson 2005; Bakken et al. 2009). Nereis Linnaeus, 1758 has over 210 valid species (Read \& Fauchald 2020). In Nereis, paragnaths are always conical and present in oral and maxillary rings, but their relative abundance and size has been regarded as variable within certain ranges. However, paragnaths in the dorsal areas $\mathrm{V}$ and VI show very little variation (González-Escalante \& Salazar-Vallejo 2003; Conde-Vela \& SalazarVallejo 2015). A similar condition may apply to the paragnaths in areas VII-VIII, at least regarding their arrangement in a single transverse row as opposed to two or more.

\section{Specimen examination}

Specimens were measured with a BioQuip micro-ruler (0.1 mm divisions) or a plastic ruler (in milimetres) for complete body length, or in case of anterior fragments, the total length; width was measured at about chaetiger 7, without chaetae. Specimens were observed and photographed with a digital camera mounted on stereo microscopes or compound microscopes. To compare the size of parapodial structures, we followed the proposals by Conde-Vela \& Salazar-Vallejo (2015) and Conde-Vela (2018). The comparison of size for several features includes an ' $x$ ', referring to the number of times each feature is larger than the other. Anteroventral dissections were made in several specimens to observe the patterns of paragnath arrangement and to count teeth on the jaws. Sometimes specimens were immersed for 1 min or less in an oversaturated methyl green solution in ethanol or for a few seconds in Shirlastain A to enhance the visibility of some features. In the results, some refinement of earlier ideas about morphological features are introduced dealing with the anterior end of nereidids, about the parapodial ligules and glandular masses in Nereis, and about the grouping of species of Nereis based on their pharyngeal features, parapodial ligules and blades of homogomph falcigers. An additional nomenclatural note is added in the morphology section, and some species are later redescribed. Diagnoses and keys are given for atoke specimens. Series of digital photographs were compressed with HeliconFocus, and plates were arranged with PaintShopPro. In some cases, line drawings were made if no camera was available. The formatting of material citations in the descriptions follows Chester et al. (2019). Field data for the Templeton Crocker Expedition stations are after Beebe (1937). Species are presented in chronological order after their description, but a taxonomic comment and a key to the species of Hediste are included after dealing with $N$. splendida and continuing afterwards for other species of Nereis. Descriptions are given focusing on type specimens, and further details are given for better preserved specimens, topotypes or alternatives as separate sections, in order to illuminate variation.

\section{Repositories}

$\mathrm{AMNH}=$ American Museum of Natural History, New York, USA

ECOSUR $=$ El Colegio de la Frontera Sur, Unidad Chetumal, Quintana Roo, Mexico

ICMyL = Instituto de Ciencias del Mar y Limnología, Polychaete Collection, UNAM, Mexico City

LACM = Natural History Museum of Los Angeles County, Allan Hancock Foundation Polychaete Collection, Los Angeles, California, USA 


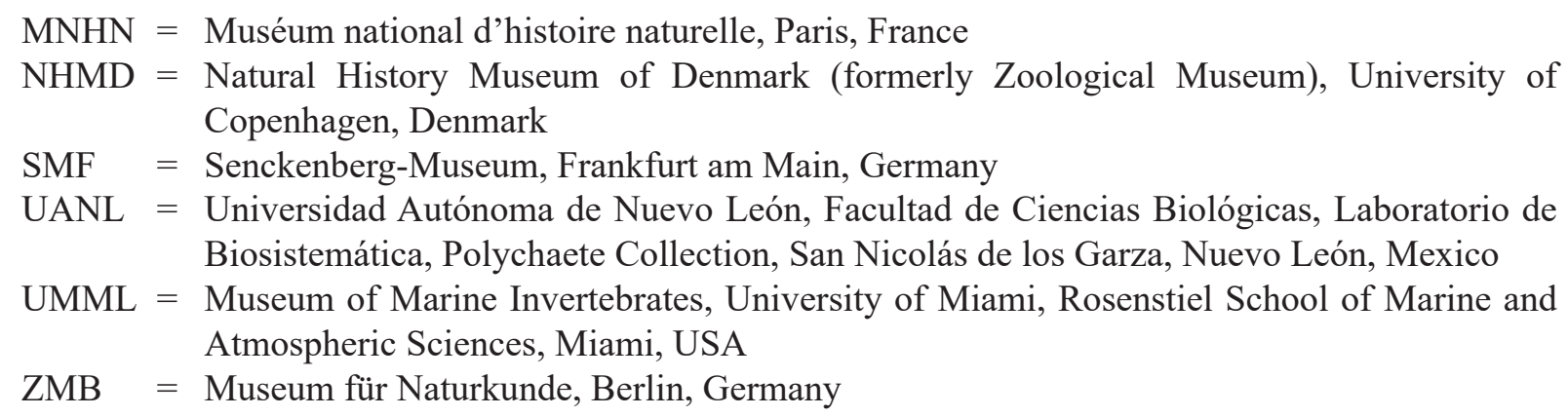

\section{Results}

\section{Morphological features}

\section{Anterior end}

Most traditional diagnostic features are concentrated on the pharynx, parapodia and chaetae (Gravier 1901). However, the prostomium, especially the relative size of eyes together with the modification of the anterior margin of the following segment, can be useful to separate similar species. Thus, a rigorous means to assess the size of eyes is to compare them against the prostomial width at the level of the eyes. Sometimes anterior eyes look reniform, but their shape is taken as circular, and then this size is compared with the width of the ocular prostomial region and can be indicated as a fraction of ocular region width. On the other hand, the first segment has been called peristomium despite the fact that it has been long known that the original first chaetiger has been cephalized (Schroeder \& Hermans 1975: 161). It is herein regarded as the tentacular belt, as defined elsewhere for hesionids (Salazar-Vallejo 2020: 12), with the difference that unlike in larger hesionids, in most nereidids there are two original chaetigers implied. This was concluded by Winchell et al. (2010: 4), although they preferred to use the term achaetous ring, instead. However, because the term ring might be equated with segment, as indicated in the etymology for annelids (or Annulata, animals with rings), an alternative solution is to regard these cephalized segments as a belt. The tentacular belt is often projected anteriorly over the body sides, whereas the anterior margin can be straight or projected anteriorly. As a consequence, the posterior eyes can be partially or completely concealed; furthermore, the anterior margin can sometimes be displaced posteriorly such that the posterior eyes are completely visible, and even the nuchal organs can be seen as well, as shown below for Nereis lucipeta. There has been little emphasis on using features of the tentacular belt as diagnostic, although Hefferan (1900: 129) indicated that its length, in comparison to that of chaetiger 1 , can be used to separate two similar species.

\section{Parapodial ligules}

Two different patterns were recognized in the shape of parapodial ligules along anterior chaetigers. In the first one, present in N. splendida, ligules are blunt, slightly longer than wide (Fig. 1A), whereas median and posterior parapodia have longer, digitate ligules (Fig. 1B), which become conical, more or less pointed in posterior parapodia (Fig. 1C). The second pattern is present in N. mezianei sp. nov., where anterior, median and posterior parapodia have tapered ligules (Fig. 2). Median and posterior chaetigers have parapodial ligules tapered in all species.

\section{Parapodial glands}

The presence, shape and pigmentation of parapodial glands can be used to separate similar species. Augener (1918: 184) and later Fauvel (1936: 35) noted some African specimens with blackish parapodia, and the former gave further details for the parapodia of what he regarded as the type of $N$. splendida, indicating both dorsal and ventral ligules were blackish (Augener 1918: 186), but no further details were given on their shape or relative size. 
Parapodial glands can be separated into three basic patterns: tubular, granulose and solid. Tubular glands have a fine mesh of thin tubules, with varying intensities of pigmentation. Granulose glands are rather irregular, with margins ill-defined and heterogenous cores, but differing from adjacent tissues in density or pigmentation. Solid glands are regular, with well defined margins, especially laterally, and homogeneous cores.

Tubular glands are present in Nereis mezianei sp. nov., a species formerly recorded as $N$. falsa by Fauvel (1936). The glands have a dark pigmentation, giving a dark or even blackish appearance to parapodial ligules, but they are not present inside cirri. The pigmentation is less intense in anterior chaetigers (Fig. 2A), and becomes darker in median (Fig. 2D) and posterior chaetigers (Fig. 2G). These glands extend along most of the available space in notopodial and ventral ligules; its tubes are rather smooth in anterior chaetigers (Fig. 2B-C). In median and posterior chaetigers these glands become more complex, with an expanded convolute basal area, penetrating inside the parapodial lobe beyond the widest ligule base. In all ligules, tubes extend along them but become regularly corrugated or monilate (Fig. 2E, H), and even in neuropodial ligules these glandular tubes extend distally, reaching the ligular tips (Fig. 2F, I), although distal areas are less heavily pigmented. Tubular glands are also present in N. occidentalis.

Granulose parapodial glands are present in $N$. callaona, $N$. lucipeta and $N$. lunulata stat. nov. Solid parapodial glands are shown by specimens of $N$. marginata, $N$. splendida and $N$. riisei. However, some transitional forms are shown by non-type specimens of N. marginata and N. riisei.

\section{Nereis species groups}

Pharyngeal paragnath patterns in areas VII-VIII, the shape and development of parapodial ligules and features of the homogomph falcigers can be used to separate species of Nereis into several groups (Table 1). Homogomph falciger blades can be smooth or finely denticulate with blunt tips, have abundant denticles with tips acute or incurved, or only a few large denticles. Parapodial ligules can be blunt, slightly longer than wide, or elongate, tapered, and upper notopodial ligules can be basally hypertrophied in posterior chatigers. Pharyngeal areas VII-VIII can have a single row of paragnaths, have a band with abundant paragnaths or be smooth. The largest keys available for species of Nereis (Wu et al. 1985: 94-95; Khlebovich 1996: 124-126) emphasized pharyngeal paragnath patterns over parapodial or chaetal features. These proposals for grouping species (Table 1) are working hypothesis deserving further analysis, but that is beyond our current objectives. However, Table 1 shows that some
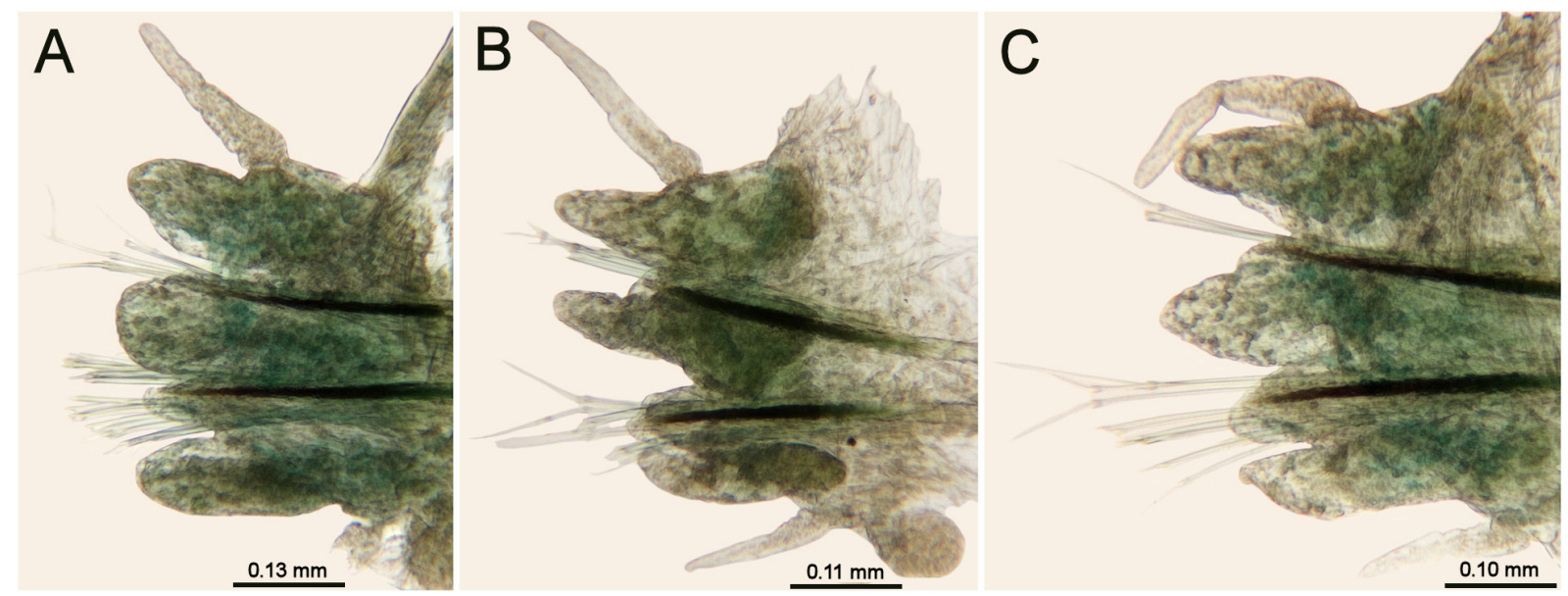

Fig. 1. Nereis splendida Grube, 1840, non-type juvenile (MNHN 423-531), after methyl green staining. A. Chaetiger 9, right parapodium, anterior view. B. Chaetiger 25, right parapodium, anterior view. C. Chaetiger 46, right parapodium, anterior view. 
of the species formerly regarded as junior synonyms of $N$. splendida actually belong to different groups of species.

\section{Nomenclatural note about nereidids described in Annulata örstediana}

Grube (1857) proposed 11 new Nereis species and placed them into three subgenera: 1) Nereis, as restricted by Örsted, 1843, with $N$. debilis Grube \& Örsted in Grube, 1857, N. krebsii Grube \& Örsted in Grube, 1857, N. marginata Grube \& Örsted in Grube, 1857, N. puncturata Grube \& Örsted in Grube, 1857, N. rigida Grube \& Örsted in Grube, 1857, N. riisei Grube \& Örsted in Grube, 1857 and N. vallata Grube \& Kröyer in Grube, 1857;2) Nereilepas de Blainville, 1828 including N. callaona Grube \& Kröyer in Grube, 1857 and N. variegata Grube \& Kröyer in Grube, 1857; and 3) Heteronereis Örsted, 1843 with N. caudipunctata Grube \& Örsted in Grube, 1857 and N. pannosa Grube \& Kröyer in Grube, 1857.

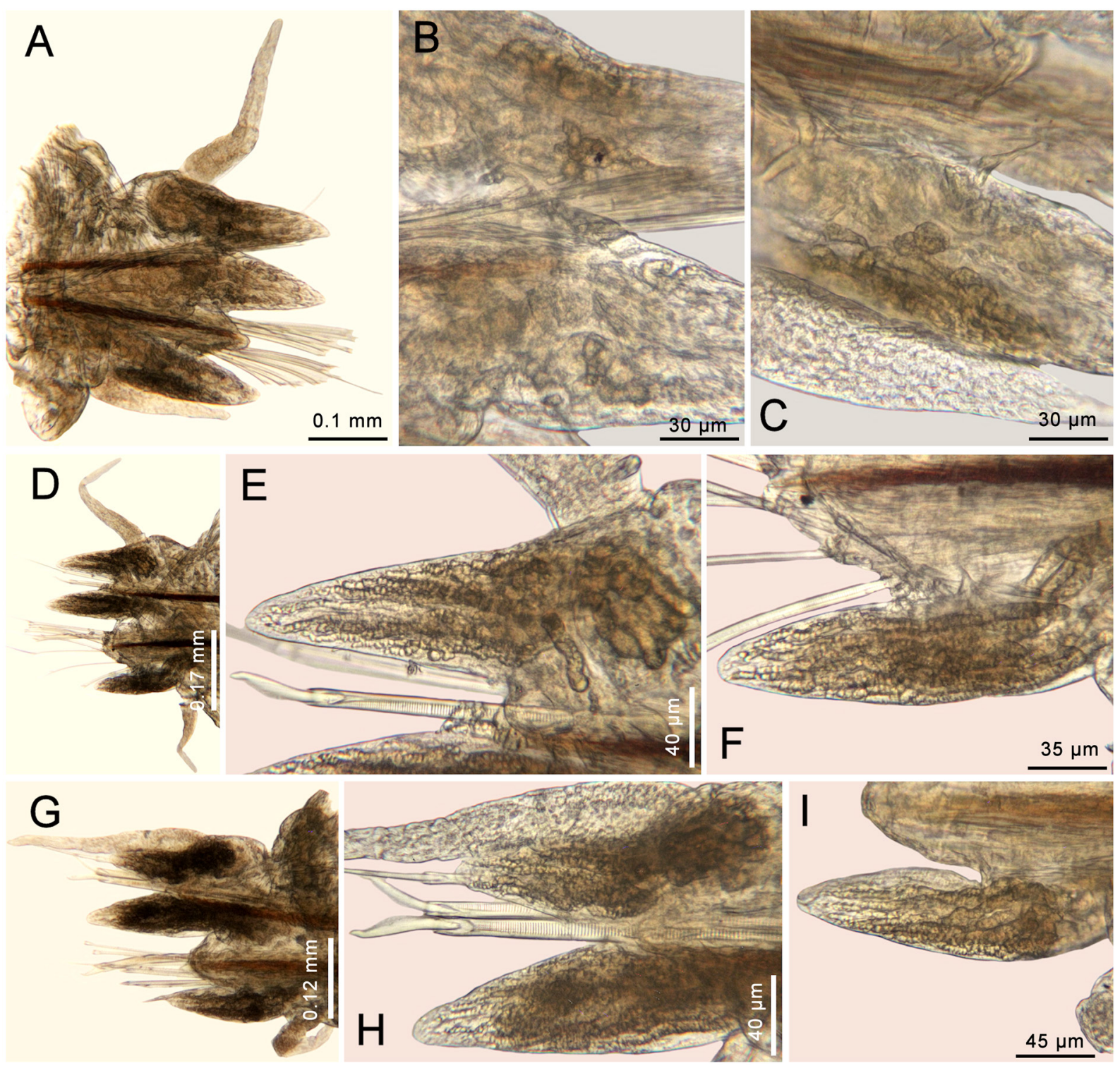

Fig. 2. Nereis mezianei sp. nov., non-type juvenile (MNHN 372-45). A. Chaetiger 9, left parapodium, anterior view. B. Same, base of notopodial ligules. C. Same, base of ventral ligule. D. Chaetiger 25, left parapodium, posterior view. E. Same, dorsal ligule. F. Same, ventral ligule. G. Chaetiger 46, left parapodium, posterior view. H. Same, notopodial ligules. I. Same, ventral ligule. 
Table 1. Species groups of Nereis Linnaeus, 1758 and representative species based on descriptions or redescriptions (original).

I Blades of homogomph falcigers finely denticulate to smooth

A Posterior parapodia with dorsal ligules expanded

1 Pharyngeal areas VII-VIII with a wide band of paragnaths of progressive size (N. vexillosa Grube, 1851)

2 Pharyngeal areas VII-VIII with a wide band of paragnaths of mixed sizes (N. grubei Kinberg, 1866)

B Posterior parapodia with dorsal ligules not markedly expanded

1 Parapodial ligules blunt, slightly longer than wide; pharyngeal areas VII-VIII with irregular, continuous rows of paragnaths of different sizes ( $N$. pelagica Linnaeus, 1758)

2 Parapodial ligules tapered, markedly longer than wide; pharyngeal areas VII-VIII with discontinuous rows of paragnaths ( N. zonata Malmgren, 1867)

II Blades of homogomph falcigers denticulate

A Posterior parapodia with dorsal ligules expanded

1 Pharyngeal areas VII-VIII with a single row of large paragnaths (N. nicholsii Kott, 1951)

2 Pharyngeal areas VII-VIII with a wide band of paragnaths of mixed size (N. callaona Grube \& Kröyer in Grube, 1857)

B Posterior parapodia with dorsal ligules not expanded, conical, tapered

1 Pharyngeal areas VII-VIII without paragnaths (N. surugaense Imajima, 1972)

2 Pharyngeal areas VII-VIII with a single row of large paragnaths ( $N$. rava Ehlers, 1868, N. riisei Grube \& Kröyer in Grube, 1857)

3 Pharyngeal areas VII-VIII with 2-3 rows of large paragnaths (N. splendida Grube, 1840)

III Blades of homogomph falcigers dentate

A Posterior parapodia with dorsal ligules not expanded

1 Pharyngeal areas VII-VIII with a single row of large paragnaths (N. jacksoni Kinberg, 1866)

2 Pharyngeal areas VII-VIII with a wide band of progressively decreasing paragnaths (N. triangularis Hutchings \& Turvey, 1982)

B Posterior parapodia with dorsal ligules expanded, strap-like; pharyngeal areas VII-VIII with a single row of large paragnaths (N. denhamensis Augener, 1913)

Furthermore, this arrangement into three genera was followed in his index to all species (Grube 1858: 119). Therefore, all these species were originally placed in Nereis and separated into three subgenera; the subgeneric separation can be traced back to Grube (1850: 296-300). Salazar-Vallejo \& Eibye-Jacobsen (2012) overlooked this arrangement, probably following Hartman's catalogue of the polychaetes of the world (Hartman 1959). Here, Grube's original combinations are used when necessary.

\section{Systematics}

Phylum Annelida Lamarck, 1809

Order Phyllodocida Dales, 1962

Family Nereididae de Blainville, 1818

Genus Hediste Malmgren, 1867

Hediste diversicolor (Müller, 1776)

Nereis diversicolor Müller, 1776: 217 
Nereis diversicolor - Örsted 1843: 23, figs 66, 68, 73. - Müller 1800: 104-118, pl. 6 figs 1-6. McIntosh 1910: 312-324. - Heinen 1911: 46-49. — Fauvel 1923: 344, fig. 133a-f. — Chambers \& Garwood 1992: 28-31, fig. 41.

Hediste diversicolor - Malmgren 1867: 165-166, pl. 28 fig. 28. - Bakken 2004: 34-35, fig. 11.

Nereis (Hediste) diversicolor - von Marenzeller 1874: 466-469, pl. 7 fig. 3. - Hartmann-Schröder 1996: 201-204, fig. 88.

\section{Remarks}

The taxonomic history of Hediste diversicolor is rather complex and has not been fully resolved. The original description was "body subdepressed, parapodia tapered with chaetae" (Müller 1776: 217), and no Greenlandic name or type locality was indicated; after invoking the ICZN, the Commission has moved to conclude that "the type locality has not been clarified" (Oug et al. 2014: 220). However, recommendation 76A1.3 is to take into account "the original description of the taxon". The second line for the original description includes two references: "Würm. 104, t. 6, Str. S. 1, p. 198, 2?" The first is a previous paper by the author (Müller 1771), whereas the latter is a paper: "Physik og oeconomisk Beskrievelse over fogderiet Söndmör" by Hans Ström (published in Soröe [Sorø, Denmark] in 1762). We could not find the latter, but we found two editions of the former which contain an extended description (Müller 1771: 102-111, pl. 6 figs 1-6) and indications that the specimens were collected in Copenhagen. This information complies with the recommendation, and consequently the type locality should be Copenhagen, Denmark. It was reiterated in the second edition (Müller 1880: 110). Furthermore, specimens identified as $H$. diversicolor from the Baltic Sea include at least two different species, and this has complicated solving what we should regard as this biological species (Virgilio et al. 2009; Tosuji et al. 2019).

Örsted (1843: 23) provided a description of Nereis diversicolor and included illustrations of the anterior end, one jaw and one parapodium (pl. 4 figs 66, 68, 73). From the description, he emphasized that the tentacular cirri could reach segments 5-6, that dorsal cirri were short, parapodial ligules tapered and the notopodia had three ligules. He also indicated that this was a very common species living in sediments along Danish coasts, and in the synonymy he listed the species that Rathke (1837a) had recorded as Lycoris pulsatoria? Örsted relied on the original description by Rathke (1837a) and on the additional detailed account of its anatomy published separately (Rathke 1837b). Because the typical $N$. diversicolor and the recorded specimens of $L$. pulsatoria? have three notopodial ligules, he regarded them as synonymous.

On the other hand, Malmgren (1867: 48-49) used the number of notopodial ligules in his key to genera, and for species having three ligules he proposed Hediste, with $N$. diversicolor as its only species and listing N. sarsi Rathke, 1843, described from Molde, Norway, and N. depressa Frey \& Leuckart, 1847, described from Helgoland, as synonyms. Malmgren did not use the diagnostic anchylosed neurofalcigers in his diagnosis, nor in the species description, and did not illustrate them. Ehlers (1868: 554) added $N$. brevimanus Johnston, 1840, described from Ireland, to the list of synonyms, provided a complete description and indicated that Hediste diversicolor could also be found in fresh-water environments.

\section{Key to species of Hediste Malmgren, 1867}

1. Areas VII-VIII with a single row of denticles (rarely 2-5 supernumerary paragnaths) ..............2

- Areas VII-VIII with two rows of denticles; palpophores continuous, 3-4 $\times$ as long as wide; area II with about 15 paragnaths per side .7

2. Palpophores with a transverse depression (looking bisegmented); longest tentacular cirri reaching chaetigers 2-3; area II with about 15 medium-sized paragnaths per side

H. limnicola (Johnson, 1903) (California)

- Palpophores continuous, $2 \times$ as long as wide .3 
3. Area II with 10 or fewer large paragnaths per side; longest tentacular cirri reaching chaetigers 6-9; areas VII-VIII with 19-26 paragnaths

H. japonica (Izuka, 1908) (Japan)

- Area II with more than 20 tiny paragnaths per side; longest tentacular cirri reaching chaetigers 8-9; areas VII-VIII with 9-35 paragnaths H. atoka Sato \& Nakashima, 2003 (Japan)

- Area II with 10-20 paragnaths .4

4. Areas VII-VIII with 8 paragnaths; longest tentacular cirri reaching chaetiger 5

H. sakhalinensis (Okuda, 1935) (Sakhalin Island, Japan Sea)

- Areas VII-VIII with 11-41 paragnaths

5. Posterior parapodia with median ligule as long as dorsal one; longest tentacular cirri reaching chaetigers $6-12$ H. diadroma Sato \& Nakashima, 2003 (Japan)

- Posterior parapodia with median ligule markedly smaller than dorsal one ...6

6. Longest tentacular cirri reaching chaetiger 6 .H. lighti (Hartman, 1938) (California)

- Longest tentacular cirri reaching chaetiger 2 ......H. rabatensis (Mohammad, 1989) (Morocco)

7. Neuropodial anchylosed falcigers subdistally constricted; tentacular cirri reaching chaetigers 5-7 H. diversicolor (Müller, 1776) sensu Hartmann-Schröder 1996 (Baltic Sea)

- Neuropodial anchylosed falcigers subdistally swollen; tentacular cirri reaching chaetigers 5-9 .... H. diversicolor (Müller, 1776) sensu Khlebovich 1996 (Black Sea; matching N. falsa (de Quatrefages, 1866))

\section{Remarks}

Smith (1959), after comparing the types, concluded that $H$. lighti was a junior synonym of $H$. limnicola. They differ in pigmentation in living specimens, $H$. limnicola being reddish, whereas $H$. lighti is transparent. A more detailed comparison is needed to confirm this synonymy. Day (1967) described Nereis gilchristi based on a single small specimen ( $8 \mathrm{~mm}$ long, 40 chaetigers) collected in South Africa. He indicated that it has only two notopodial ligules in anterior chaetigers, which is an important difference and deserves a separate assessment when assigning it to a genus. The key above should be used cautiously because the status of the type species must be clarified, since there are two cryptic species in the Baltic Sea (Röhner et al. 1997; Virgilio et al. 2006; Audzijonyte et al. 2008), and some Mediterranean and Black Sea forms (Virgilio et al. 2009; Cossu et al. 2012) might necessitate the reestablishment of some names currently regarded as junior synonyms.

\section{Genus Nereis Linnaeus, 1758}

Nereis splendida Grube, 1840

Figs 1, 3-6

Nereis splendida Grube, 1840: 75-76.

Nereis (Nereilepas) parallelogramma Claparède, 1868: 477-478, pl. 9 fig. 7, pl. 10 fig. 2.

Nereis splendida - Grube 1874: 70 (synonymy). — Núñez 2004: 375-378, fig. 139. — Alós et al. 2004: 513 (synonymy).

Nereis falsa - Fauvel 1913: 63; 1916: 81-84, pl. 5 figs 1-11 (synonymy, partim); 1923: 337-338, fig. 129e-m; 1950: 353. - Fauvel \& Rullier 1959: 517-518. - Rullier \& Amoureux 1969: 120. — Gravina et al. 2015: 155, fig. 9 (synonymy) (non de Quatrefages, 1866). 


\section{Diagnosis}

Nereis with tentacular belt $2 \times$ as long as first chaetiger; tentacular cirri reaching chaetiger $4-5$. Jaws with 5-6 denticles; paragnaths arranged as follows: I: 2 in tandem; II: 21-22 in two rows; III: 28-40; IV: 35-36; V: 0; VI: 4-5; VII-VIII: 66 in 2 bands. Posterior parapodia with ventral ligule longer than neuracicular ligules and ventral cirri.

\section{Material examined}

\section{Neotype}

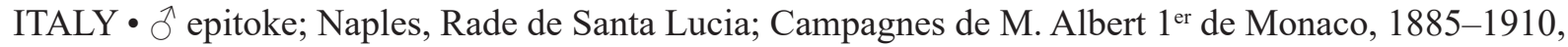
stn 311; electric light; 4 Aug. 1893; MNHN 423-311.

\section{Other material}

Atokes

MEDITERRANEAN SEA $11 \mathrm{spec}$. (22 mm long, $2 \mathrm{~mm}$ wide, 71 chaetigers; anterior and median parapodial ligules blunt, digitate, posterior ones tapered; pharynx fully exposed, area VI: $4+5$ in diamond); MNHN A83b • 4 specs (without posterior regions, $16-31 \mathrm{~mm}$ long, 1.1-3.0 mm wide, 4857 chaetigers; longest tentacular cirri reach chaetigers 3-4; one medium-sized specimen with pharynx fully exposed); Chaine de l'Eider, Monaco, port; Campagnes de M. Albert $1^{\text {er }}$ de Monaco, 1885-1910, stn 531; 13 Sep. 1905; MNHN 423-531 1 spec. (30 mm long, 2 mm wide, 82 chaetigers; pharynx not exposed; longest tentacular cirri reach chaetiger 3; anal cirri as long as last 7-8 chaetigers); same collection data as for preceding; MNHN 495-1.

\section{Epitokes}

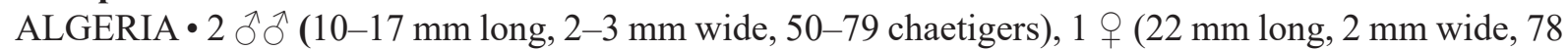
chaetigers); Algiers, entrance to port; 36 $46^{\prime} 00^{\prime \prime}$ N, 030. $04^{\prime} 00^{\prime \prime}$ E; light trap; 20 Aug. 1924; MNHN A83 (lot also includes 1 smaller $\hat{o}$ epitoke of another species).

MOROCCO • 3 万ิ (22.0-24.5 mm long, 3.0 mm wide, 76-78 chaetigers; longest tentacular cirri reaching chaetigers 5-7; jaws with 7 accessory denticles); Rade de El Yadida (formerly Mazaghan); $33^{\circ} 14^{\prime} \mathrm{N}, 08^{\circ} 30^{\prime} \mathrm{W}$; Campagnes de M. Albert $1^{\text {er }}$ de Monaco, 1885-1910, stn 779; electric light; 23

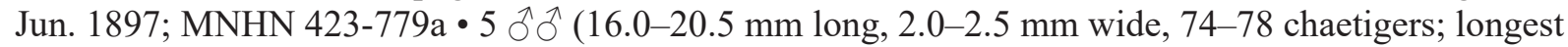
tentacular cirri reaching chaetigers 5-7; jaws with 6-7 accessory denticles); same collection data as for preceding; MNHN 423-779b.

SENEGAL -2 우우 (pre-epitokes, dehydrated, one complete, one anterior fragment; complete one $31 \mathrm{~mm}$ long, $3 \mathrm{~mm}$ wide, 83 chaetigers; longest tentacular cirri reach chaetiger 5-6; chaetiger 47 with ventral cirri shorter than ventral ligule; oocytes loose in coelom from chaetiger 2, each about $150 \mu \mathrm{m}$ in diameter); Dakar; 1947; R. Sourie leg.; MNHN 495-1947a.

\section{Description}

\section{Neotype}

BoDy. Complete, bent laterally, medially collapsed by label, anterior end breaking off at chaetiger 7 , pharynx fully exposed. Length $15 \mathrm{~mm}$, width $3 \mathrm{~mm}, 73$ chaetigers. Dorsum brownish along body, wider transverse bands along non- natatory region, with a paler longitudinal tapered band finishing on chaetiger 18 (Fig. 3A). Divided into two regions: non-natatory region includes chaetigers 1-18; natatory region with parapodia markedly transformed along chaetigers 19-73.

Prostomium. As long as wide, dorsal groove present. Eyes black, enlarged, fused laterally, subequal, slightly smaller than $1 / 3$ of prostomial width. Antennae tapered, divergent, $1 / 3$ as long as prostomium, as 
long as palpophores. Palpophores massive, expanded laterally, as long as wide, palpostyles rounded, small.

TentACUlAR Belt. $2 \times$ as long as first chaetiger, anterior margin not covering posterior eyes (Fig. 3A, C). Tentacular cirri corrugated, longest one reaching chaetiger 8.

Pharynx. Exposed (Fig. 3B-C). Paragnath formula: I: 2, small, in tandem; II: 24-26 in 2-3 oblique rows; III: 38 in oval group; IV: 40-42 in oval groups; V: 0; VI: 4-5 in diamond; VII-VIII: 54, larger, in 2 irregular rows.

PARAPODIA. Not dissected to avoid further damage (see below).

Posterior REGION. Tapered into a blunt cone; pygidium with anus expanded, with 2-3 series of digitate anal cirri (Fig, 3D).

\section{Male epitokes (MNHN A83)}

BoDy. Complete, 10-17 mm long, 2-3 mm wide, 50-79 chaetigers; specimens slightly damaged, almost colorless, with pharynges fully exposed.

Prostomium. As long as wide, dorsal groove present. Eyes blackish, enlarged, rounded, fused laterally, enlarged, anterior eyes about as large as $1 / 3$ prostomial width (Fig. 4A). Antennae $1 / 3$ as long as prostomium, tapered, longer than palps. Palpophores massive, blunt, subcylindrical, about as wide as long, palpostyles directed ventrally, rounded, small.

TENTACUlAR Belt. $2 \times$ as long as first chaetiger, anterior margin not covering eyes. Tentacular cirri corrugated, longest ones reaching chaetiger 5 (Fig. 4A).
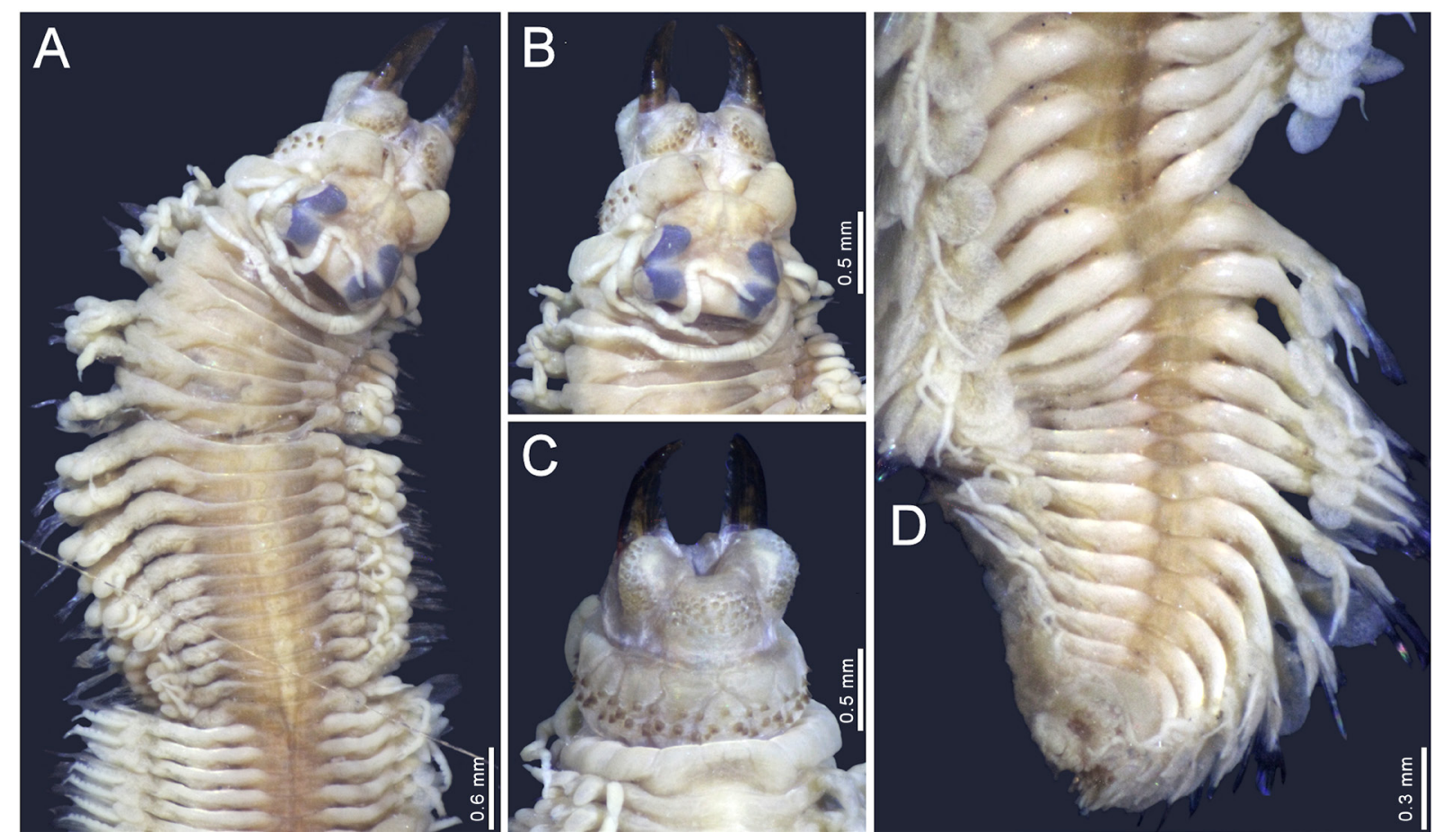

Fig. 3. Nereis splendida Grube, 1840, neotype (MNHN 423-311), male epitoke. A. Anterior region, dorsal view, depressed by cover slip. B. Anterior end, dorsal view. C. Anterior end, ventral view. D. Posterior region, dorsal view. 
Pharynx. Everted, jaws amber-colored, tips brownish, each with 7-8 teeth (Fig. 4A-B). Paragnath formula: I: 2 in tandem; II: $22-24$ in 2-3 oblique rows; III: 36 in oval transverse group; IV: $38-40$ in oval groups; V: 0; VI: 4-5 in diamond; VII-VIII: 38-44, not larger than other ones, in 2 irregular rows.

Pattern of PARAPOdial Ligules. Anterior chaetigers with ligules blunt, longer than wide in first few chaetigers, soon becoming as long as wide; natatory region with ligules tapered, $3-4 \times$ as long as wide.

REGIONS. Body divided into two regions: non-natatory region includes chaetigers 1-19, subdividided into two sections: 1 ) chaetigers 1-8 with dorsal and ventral cirri basally to medially swollen, 2) chaetigers 9-19 with both dorsal and ventral cirri cirriform; and natatory region with markedly transformed parapodia includes chaetigers 20-79 (to end of the body), plus pygidium.

Chattigers 1-2. With neuraiculae only (Fig. 4C), with both noto- and neuraciculae thereafter. Dorsal cirrus cattail-like, $3 \times$ as thick and almost $2 \times$ as long as ventral one, basal swollen section $5 \times$ as wide and $4-5 \times$ as long as distal narrow section. Dorsal ligule digitiform, shorter than neuracicular ligule. Neuracicular ligule subconical, truncate, as long as ventral ligule; ventral ligule digitiform, slightly longer than dorsal one. Ventral cirrus with basal swollen section $4 \times$ as wide and $2 \times$ as long as distal narrow section. Supracicular neurochaetae: 3 homogomph spinigers and 2 heterogomph falcigers with blades $5-6 \times$ as long as wide, spinulose, tendon barely developed; subacicular neurochaetae: 5 homogomph spinigers, with blades long or short, and 3 heterogomph falcigers, one with blade longer than the others.

Chaetigers 9-19 (Fig. 4D). With dorsal cirrus cirriform, full of sperm. Dorsal cirrus slightly longer and wider than ventral ones, basal swollen section $3 \times$ as thick and $2.5 \times$ as long as distal narrow section. Dorsal and median ligules digitiform, tapered, barely longer than wide, about as long as neuracicular
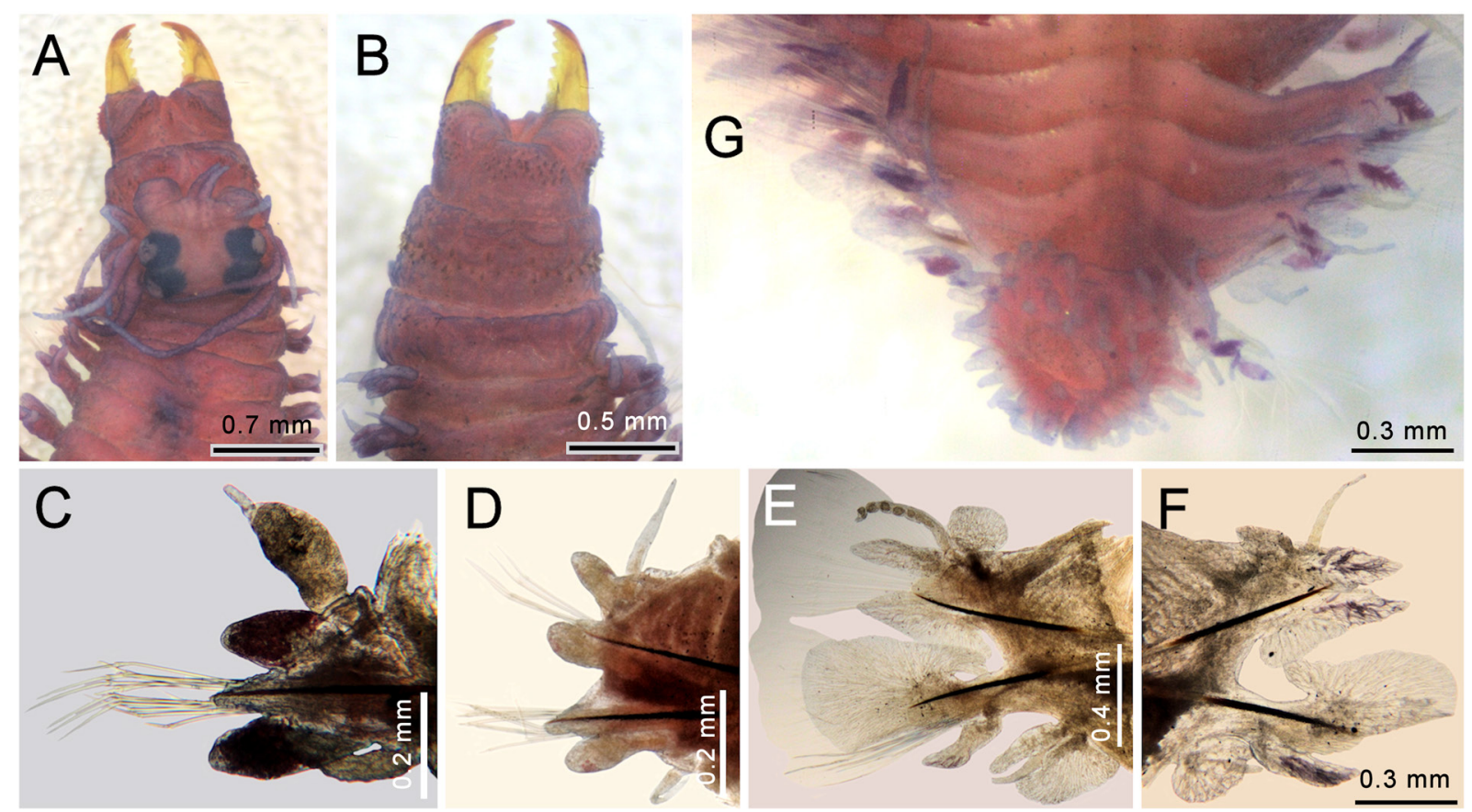

Fig. 4. Nereis splendida Grube, 1840, non-type, largest male epitoke (MNHN A83), after Shirlastain-A staining. A. Anterior region, dorsal view. B. Anterior end, ventral view. C. Chaetiger 2, right parapodium, anterior view. D. Chaetiger 15, right parapodium, anterior view. E. Chaetiger 30, right parapodium, anterior view. F. Chaetiger 74, right parapodium, posterior view (chaetae omitted). G. Posterior region, dorsal view. 
ligule. Neuracicular ligule subconical, $1.5 \times$ as long as ventral ligule; ventral ligule blunt, $1.5 \times$ as long as wide. Ventral cirrus with basal swollen section $2 \times$ as wide and as long as distal narrow section. Notochaetae 4 homogomph spinigers. Supracicular neurochaetae: 2 homogomph spinigers and 2 heterogomph falcigers; subacicular neurochaetae: 6 heterogomph falcigers.

ANTERIOR NATATORY PARAPODIA (Fig. 4E). With large expanded fan lobes basal to dorsal and ventral cirri, and on median and neuracicular ligules (Fig. 4E). Dorsal cirrus wider and longer than ventral cirrus, $2.5 \times$ as long as rounded dorsal lamellae, with spherical, centrally open expanded areas. Dorsal ligule digitiform, tapered, $5-6 \times$ as long as wide, as long as median ligule; median ligule arrowheadshaped, with lamella on ventral side. Neuracicular ligule digitiform; postchaetal lobe transformed into flabelliform lamella, as long as neuracicular ligule; ventral ligule digitate, about $5 \times$ as long as wide, as long as neuracicular ligule, with a small dorsal protuberance near base. Ventral cirrus with upper lamella digitiform, $7-8 \times$ as long as wide, lower lamella flabelliform, about $2 \times$ as long as wide. Noto- and neuropodial natatory chaetae sesquigomph, blades fusiform, $8-10 \times$ as long as wide, one margin finely denticulate, tips tapered, usually eroded.

POSTERIOR NATATORY PARAPODIA (Fig. 4F). With slightly reduced modifications; glandular areas better defined in ligules, being smaller than those present in anterior natatory region. Dorsal cirrus slightly longer, as wide as ventral one, $3-4 \times$ as long as digitiform dorsal lamella. Dorsal and median ligules subconical, subequal, tapered; dorsal ligule $1.2 \times$ as long as wide; median ligule arrowhead-shaped, with lamella on ventral side. Neuracicular ligule digitiform; postchaetal lobe transformed into flabelliform lamella, as long as neuracicular ligule; ventral ligule digitiform, tapered, about 5-6× as long as wide, as long as neuracicular ligule. Ventral cirrus slightly longer than upper and lower lamellae; upper lamella digitiform, lower one flabelliform. Noto- and neuropodial natatory chaetae sesquigomph, blades fusiform, $7-9 \times$ as long as its widest area, very finely denticulate along one margin.

Posterior Region. Abruptly tapered (Fig. 4G). Pygidium expanded into a rosette with several rows of digitiform papillae-like anal cirri, each $2-4 \times$ as long as wide.

\section{Female epitoke (MNHN A83)}

Body. Complete, $22 \mathrm{~mm}$ long, $2 \mathrm{~mm}$ wide, 78 chaetigers, slightly damaged, almost colorless, with pharynx fully exposed.

Prostomium. As long as wide, dorsal groove present. Eyes blackish, enlarged, rounded, anterior ones about as large as $1 / 3$ prostomial width (Fig. 5A). Antennae $1 / 3$ as long as prostomium, slightly longer than palps. Palpophores massive, blunt, subconical, slightly wider than long, palpostyles rounded, small.

TENTACUlAR Belt. $2 \times$ as long as first chaetiger, anterior margin not covering posterior eyes. Tentacular cirri corrugated, longest ones reaching chaetiger 8 (Fig. 5A).

Pharynx. Everted, jaws amber-colored, tips brownish, each with 5-6 teeth (Fig. 5A-B). Paragnath formula: I: 2 in tandem; II: 10-12 in two oblique rows; III: 25 in oval transverse group; IV: 34-36 in oval oblique groups; V: 0; VI: 4 in diamond; VII-VIII: 44, larger, in 2 irregular rows.

PATTERn OF PARAPODial Ligules. Anterior chaetigers with ligules blunt, as long as wide, or slightly longer than wide; median and posterior chaetigers with ligules tapered or digitate, about $2 \times$ as long as wide, or longer.

REGIONS. Body separated into three regions: non-natatory region includes chaetigers 1-25 sub-dividided into two sections: 1) chaetigers $1-5$ with dorsal and ventral cirri basally to medially swollen, 2) chaetigers 6-25 with both dorsal and ventral cirri cirriform; natatory region with markedly transformed parapodia 
includes chaetigers 26-65; and caudal region with slightly transformed parapodia includes chaetigers 66-78 (end of the body).

ChAETigers 1-2. With neuraciculae only (Fig. 5D); with both noto- and neuraciculae thereafter. Dorsal cirrus thicker, slightly longer than ventral cirrus, basal swollen section $4 \times$ as wide and $3 \times$ as long as distal narrow section. Neuracicular ligule subconical, slightly shorter than ventral ligule; ventral ligule digitiform, $1.2 \times$ as wide as long. Ventral cirrus with basal swollen section $3 \times$ as wide and $2 \times$ as long as distal narrow section. Supracicular neurochaetae: 4 homogomph spinigers and 2 heterogomph falcigers with blades $4-5 \times$ as long as wide, spinulose, tendon barely developed; subacicular neurochaetae: 4 heterogomph spinigers and 6 heterogomph falcigers with blades $6-8 \times$ as long as wide, spinulose, tendon barely developed.

Chaetigers 6-25 (Fig. 5E). Full of oocytes, with dorsal cirrus slightly longer and wider than ventral cirrus, $2.5 \times$ as long as dorsal ligule. Dorsal and median ligules digitiform, slightly longer than wide, slightly longer than median ligule. Neuracicular ligule subconical, slightly longer than ventral ligule; ventral ligule digitiform, slightly longer than wide. Notochaetae 4 homogomph spinigers. Supracicular neurochaetae: 4 homogomph spinigers and 3 heterogomph falcigers with blades $2-3 \times$ as long as wide, spinulose, tendon barely developed; subacicular neurochaetae: 4 heterogomph spinigers and 4 heterogomph falcigers with blades $2-3 \times$ as long as wide, spinulose, tendon barely developed.

Natatory PaRAPODia (Fig. 5F). With large expanded fan lobes on neuracicular ligule and at base of ventral cirri; smaller fans along lower surface of median ligules. Dorsal cirrus barely longer and wider
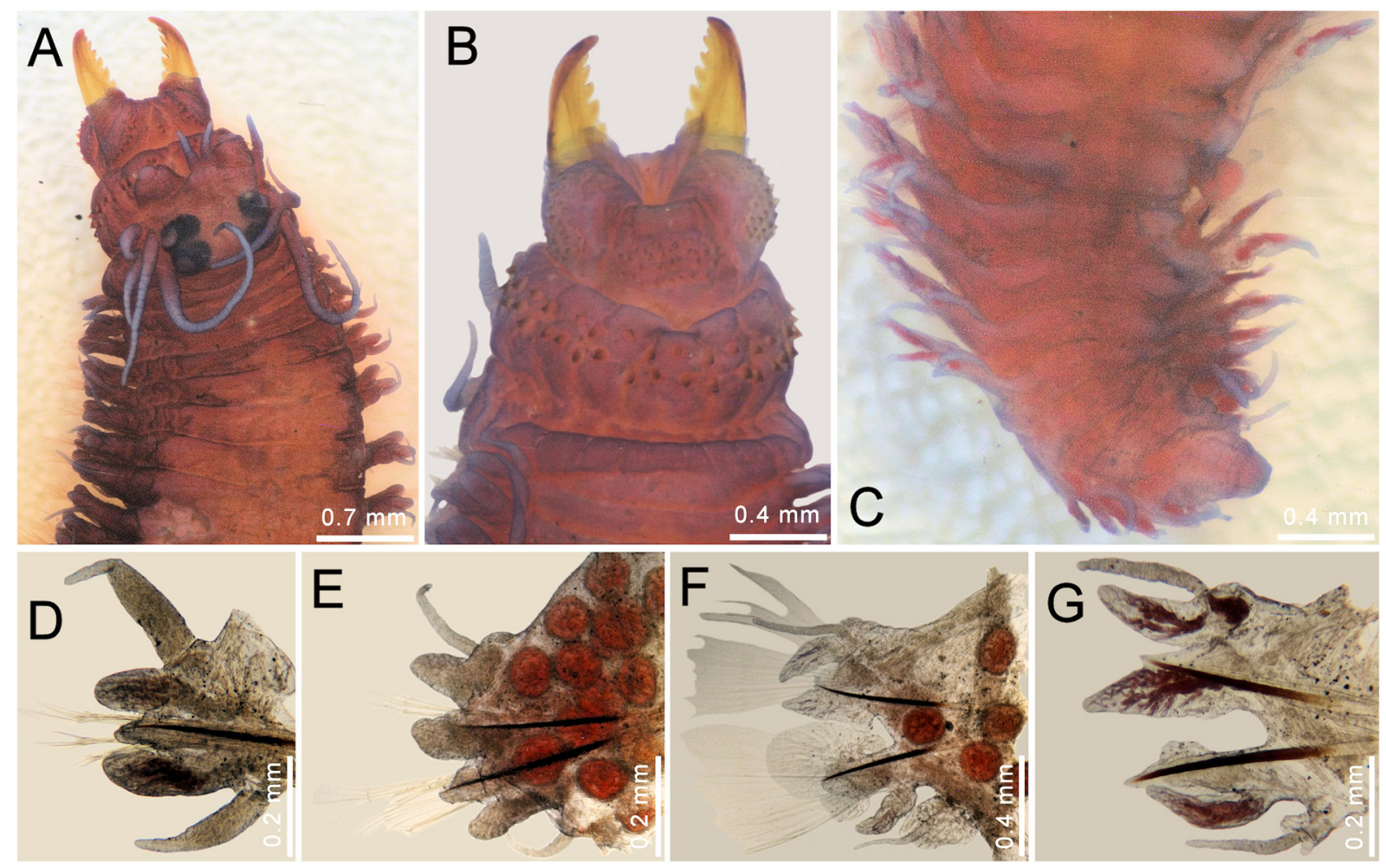

Fig. 5. Nereis splendida Grube, 1840, non-type, female epitoke (MNHN A83), after Shirlastain-A staining. A. Anterior region, dorsal view. B. Anterior end, ventral view. C. Posterior region, dorsal view. D. Chaetiger 2, right parapodium, anterior view. E. Chaetiger 15, right parapodium, anterior view. F. Chaetiger 30, right parapodium, anterior view. G. Chaetiger 73, right parapodium, anterior view (chaetae omitted). 
than ventral cirrus, glandular masses absent. Dorsal ligule subconical, $3 \times$ as long as wide, glandular areas barely visible; median ligule arrowhead-shaped, with lamella on ventral side. Neuracicular ligule digitiform, $1.2 \times$ as long as postchaetal lobe; postchaetal lobe transformed into flabelliform lamella, ventrally bilobated; ventral ligule digitiform, basally swollen, $3-4 \times$ as long as wide. Ventral cirrus with upper lamella digitiform, $4 \times$ as long as wide, lower lamella flabelliform, about $2-3 \times$ as long as wide. Noto- and neuropodial natatory chaetae sesquigomph, blades fusiform, $7-9 \times$ as long as wide, one margin very finely denticulate, tips tapered, usually eroded.

CAUdAL REGION (Fig. 5G). With reduced parapodial transformation; with a small fan lobe over superior surface of neuracicular ligules and glandular areas better developed in parapodial ligules, tubular glands homogeneous, slightly rugose, projected along parapodial ligules and forming a mass basal to dorsal cirri. Dorsal cirrus slightly shorter and wider than ventral cirrus, slightly longer than dorsal ligule. Dorsal ligule digitiform, $2-3 \times$ as long as wide; median ligule subconical, blunt, slightly longer than dorsal ligule, $1.2 \times$ as long as neuracicular ligule. Neuracicular ligule subconical, about $4 \times$ as wide as long; postchaetal lobe transformed into rounded lamella, $0.3 \times$ as long as neuracicular ligule; ventral ligule digitate, $4 \times$ as long as wide, $1.5 \times$ as long as ventral cirrus. Ventral cirrus with upper and lower lamellae digitiform, $2 \times$ as long as wide. Noto- and neuropodial natatory chaetae sesquigomph; blades fusiform, $7-9 \times$ as long as wide, very finely denticulate along one margin.

Posterior END. Tapered (Fig. 5C). Pygidium conical, blunt, without rosette of papillae, anal cirri missing.

Oocytes. Round, granulose, with yolk droplets, each oocyte about $160 \mu \mathrm{m}$ in diameter.

\section{Atokes}

Body. Largest specimen (MNHN 423-531), without posterior region, $31 \mathrm{~mm}$ long, $3.0 \mathrm{~mm}$ wide, 57 chaetigers. Another long specimen (MNHN 495-1) complete, $30 \mathrm{~mm}$ long, $2 \mathrm{~mm}$ wide, 82 chaetigers. Body subcylindrical; dorsum brownish, with a paler middorsal blood vessel, integument darker along anterior chaetigers with some darker oblique lines (Fig. 6A), sometimes blackish (Fig. 6G); other specimens paler. Parapodia paler.

Prostomium. $2 \times$ as long as wide, dorsal groove present. Eyes blackish, of similar size, anterior eyes oval, directed anterolaterally, about $1 / 8$ of prostomial width, slightly more separated than posterior eyes (Fig. 6B). Antennae half as long as prostomium, without gap between them, tips reaching palpostyle tips. Palpophores almost $2 \times$ as long as wide; palpostyles slightly longer than wide (Fig. 6B) or rounded (Fig. 6G).

TENTACUlAR BeLt. $1.5 \times$ as long as first chaetiger; anterior margin straight, not covering posterior eyes. Tentacular cirri smooth to regularly contracted (Fig. 6B), partially dehydrated, without tips (Fig. 6G), longest ones reaching chaetigers $3-4$.

Pharynx. Not everted, observed by previous dissections. Jaws with 6 denticles ( 5 in smallest specimen, MNHN 423-531). Paragnath formula: I: 2 in tandem; II: 21-22 (24-26 in smallest specimen) in 2-3 rows; III: 40 (28 in smallest specimen) in oval group; IV: 35-36 (27-28 in smallest specimen) in oval groups; V: 0; VI: 5 (4 in smallest specimen) in diamond; VII-VIII: 2-3 rows of 66 large paragnaths (same in smallest specimen).

PATTERN OF PARAPODial LIGUles. Anterior and median chaetigers with ligules blunt, about $2 \times$ as long as wide, becoming blunt subconical to digitiform, about $2.5 \times$ as long as wide medially, posterior chaetigers with ligules subconical, blunt; ventral ligules progressively longer than neuracicular ligule in posterior chaetigers. 
ChAETigers 1-2. With neuraciculae only (Fig. 6C); with both noto- and neuraciculae thereafter. Dorsal cirrus slightly longer, as wide as ventral cirrus, $2 \times$ as long as parapodial ligules. Dorsal ligule digitiform, $2 \times$ as long as neuracicular ligule. Neuracicular ligule subconical, longer than wide; ventral ligule digitiform, $1.2 \times$ as long as neuracicular ligule. Supracicular neurochaetae: 7 homogomph spinigers and 4 heterogomph falcigers with blades $5-6 \times$ as long as wide, spinulose, tip incurved; subacicular neurochaetae: 7 heterogomph spinigers and 10 heterogomph falcigers with blades $6-7 \times$ as long as wide, spinulose, tip incurved.

MEDian PARAPODIa (FIg. 6D). With dorsal cirrus longer than dorsal ligule, slightly longer than ventral cirrus. Dorsal and median ligules subequal, as long as wide, as long as neuracicular ligule, subconical to rounded, glandular areas unpigmented, extended along ligular bases. Neuracicular ligule subconical, as long as wide, subequal to ventral ligule; ventral ligule digitiform, $1.3 \times$ as long as ventral cirrus. Notochaetae 12 homogomph spinigers. Supracicular neurochaetae: 6 homogomph spinigers and 3 heterogomph falcigers with blades $3 \times$ as long as wide, spinulose, tip incurved, tendon barely visible, in smaller specimen distinct (Fig. 6I); subacicular neurochaetae: 6 heterogomph spinigers, blades decreasing in size ventrally, and 6 heterogomph falcigers with blades $2-3 \times$ as long as wide, spinulose, tip incurved, tendon visible.

Posterior CHAETigers (Fig. 6E). With dorsal and ventral cirri $6-8 \times$ as long as wide, dorsal cirrus longer than dorsal ligule. Dorsal and median ligules subconical, blunt, slightly longer than wide, $1.2 \times$ as long as neuracicular ligule; glandular areas unpigmented, extended along ligular bases. Neuracicular ligule subconical, blunt, as long as ventral ligule; ventral ligule digitiform, slightly longer than wide, $1.2 \times$ as long as ventral cirrus. Notochaetae: 6 homogomph spinigers and 1 homogomph falciger with blade $4 \times$ as long as wide, spinulose, tip incurved, tendon visible. Supracicular neurochaetae: 7 homogomph
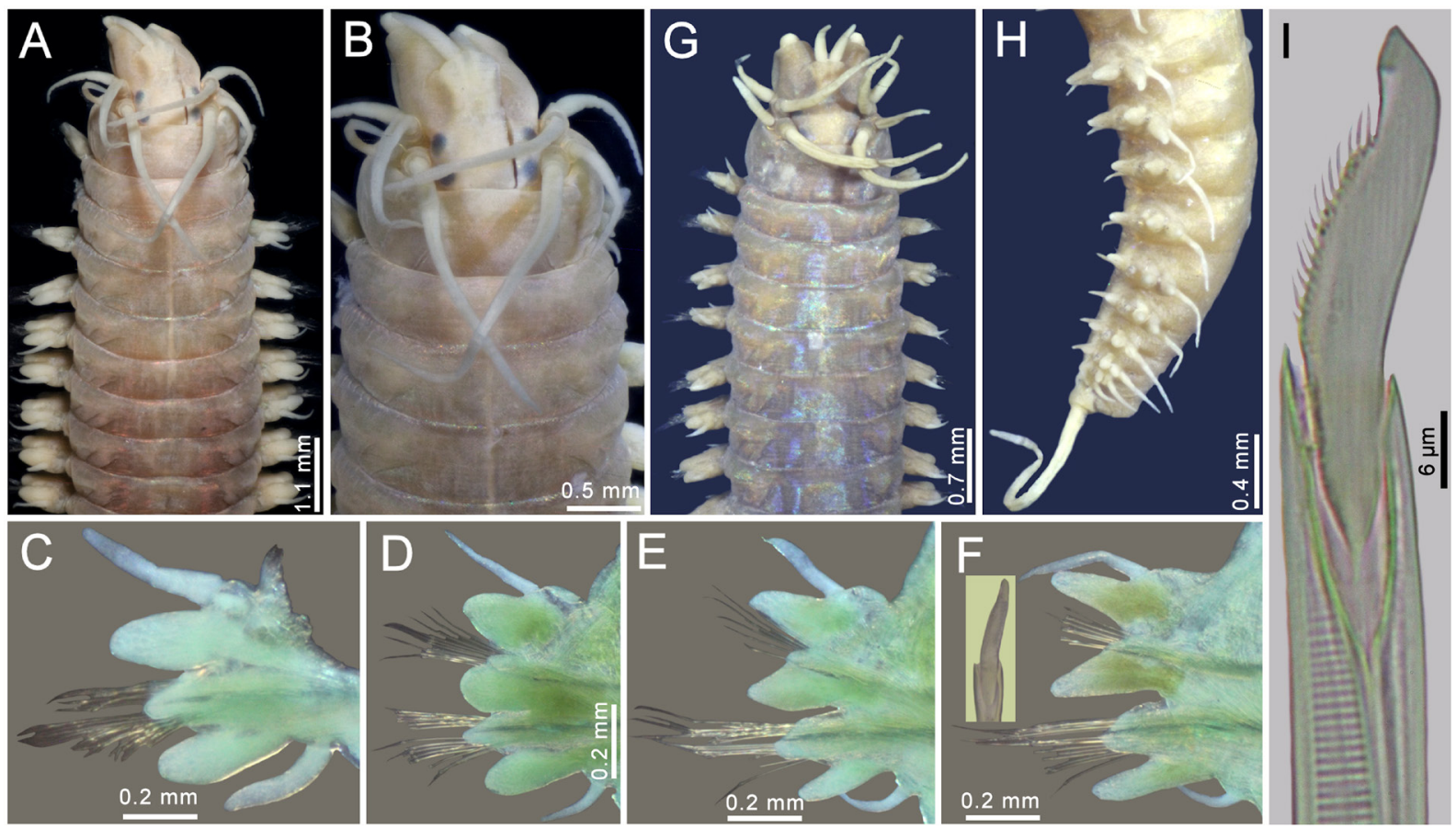

Fig. 6. Nereis splendida Grube, 1840, non-type, atokous specimens. A-F. MNHN 423-531. A. Anterior region, dorsal view. B. Anterior end, dorsal view. C. Chaetiger 2, right parapodium, anterior view. D. Chaetiger 15, right parapodium, anterior view. E. Chaetiger 30, right parapodium, anterior view. F. Chaetiger 55, right parapodium, anterior view (inset: homogomph falciger tip). G-H. MNHN 495-1. G. Anterior region, dorsal view. H. Posterior region, left lateral view. I. Another specimen (MNHN 423531), chaetiger 30, right parapodium, homogomph falciger tip. 
spinigers and 3 heterogomph falcigers with blades $2 \times$ as long as wide, spinulose, tip incurved, tendon visible; subacicular neurochaetae: 5 homogomph spinigers and 3 heterogomph falcigers with blades $2 \times$ as long as wide, spinulose, tip incurved, tendon visible.

Subterminal Chaetigers (Fig. 6F, H). With dorsal cirrus $2-4 \times$ as long as dorsal ligule, about $2 \times$ as long as ventral cirrus. Dorsal and median ligules digitiform, of similar size, $2 \times$ as long as wide, $2 \times$ as long as neuracicular ligule. Neuracicular ligule subconical, slightly longer than wide, almost blunt; ventral ligule digitiform, $2 \times$ as long as wide, $2 \times$ as long as neuracicular ligule. Notochaetae 7 homogomph spinigers (blades mostly lost), falcigers absent. Supracicular neurochaetae: 4 homogomph spinigers and 2 heterogomph falcigers (blades lost); subacicular neurochaetae: 2 heterogomph spinigers and 7 heterogomph falcigers with blades $2 \times$ as long as wide, spinulose, tip incurved, tendon visible.

Posterior Region. Tapered into a blunt cone (Fig. 6H). Pygidium with anus terminal, anal cirri as long as last 7-8 chaetigers (MNHN 495-1).

\section{Remarks}

Fauvel (1916: 81) used the name $N$. falsa for some Mediterranean nereidids and he included as junior synonyms of $N$. falsa two species described from Naples by Claparède (1868): N. parallelogramma and $N$ perivisceralis; he also included $N$. lucipeta Ehlers, 1908 from South Africa. In a subsequent publication, Fauvel (1916: 81) added N. splendida Grube, 1840 as a synonym, another Mediterranean species, as well as a record by Ehlers (1913: 496) for the Cape Peninsula, South Africa. By expanding this synonymy, Fauvel's conclusions generated the " $N$. falsa species group," which he would define later (Fauvel 1923: 337). The list of synonyms includes, after Fauvel, N. parallelogramma Claparède, 1868, $N$. perivisceralis Claparède, 1868, Lycoris pulsatoria Rathke, 1843 and N. lucipeta Ehlers, 1908. This group contains species of Nereis with pharyngeal area V without paragnaths and areas VII-VIII with a single row or 2-3 rows of paragnaths, anterior parapodia with two blunt notopodial ligules, notopodial homogomph falcigers in posterior chaetigers, with blades sinulose, sometimes with a distal ligament or tendon (Fauvel 1923). Two other species, N. callaona and N. victoriana Augener, 1918, were regarded as similar to N. falsa by Salazar-Vallejo \& Jiménez-Cueto (1997: 374), and Reish (1954: 104) regarded $N$. pseudonereis and $N$. robusta Kinberg, 1866 as junior synonyms of $N$. callaona.

This progression of synonymies based on generally similar specimens of different species, without paying attention to some features of the pharynx, was incorrect, especially because $N$. falsa was based on L. pulsatoria? from the Black Sea, which does not match these features. Furthermore, some aspects of the taxonomic history of Hediste diversicolor deserve mention, as it is also complex and not fully resolved. For example, there are no type specimens and there was no indication of the type locality. Furthermore, specimens identified as $H$. diversicolor from the Baltic Sea, which could be the type locality, include at least two different species, and this has complicated resolving what we should regard as this biological species (Oug et al. 2014). Some names are available for the regional forms, in case there is more than one, taking into account that Malmgren (1867: 48-49) proposed Hediste to include $N$. diversicolor, listing $N$. sarsi Rathke, 1843, described from Molde, Norway, and $N$. depressa Frey \& Leuckart, 1847, described from Helgoland, Germany, as junior synonyms. Ehlers (1868: 554) added $N$. brevimanus Johnston, 1840, described from Ireland, to the list of synonyms. Black Sea population haplotypes differ from those present in nearby areas (Vasileiadou et al. 2016); if this difference promotes regarding Black Sea specimens as belonging to a different species, N. falsa de Quatrefages, 1866 would be available for them.

It has been indicated that Nereis splendida cannot be used as a senior synonym for N. falsa (SalazarVallejo et al. 2017), because it was preoccupied by Nereis splendida de Blainville, 1825. Because this is a junior homonym, its name should be replaced (ICZN 1999, arts 52.2, 57.2), and the next available name should be used instead. However, contrary to previous conclusions, there is an alterative for retaining 
$N$. splendida Grube, 1840, and this refers to the fact that the two species involved do not belong in the same genus (ICZN 1999, art. 59.2). Nereis splendida de Blainville, 1825 refers to a nephtyid polychaete, which would be a junior synonym of Nephtys hombergi Savigny in Lamarck, 1818 according to Audouin \& Milne-Edwards (1833: 257) and de Quatrefages (1866a: 434). Consequently, "the junior name is not to be rejected, even if one species-group name was originally proposed in the current genus of the other" (ICZN 1999, art. 59.2). Alós et al. (2004: 513) did not indicate their reasons for retaining N. splendida Grube, 1840, but the above article provides the explanation for it.

Some additional details must be understood. First, the composition of the type material. Augener (1918: 186) noted that what was then regarded as the type material of $N$. splendida Grube, 1840 actually contained three specimens, two of them belonging to Ceratonereis Kinberg, 1865, and the originally described specimen of N. falsa.

Second, the type material is lost. Birger Neuhaus (ZMB, 2019 in email) indicated "We had unspecified type material of Nereis splendida, catalogue number ZMB 'Vermes' 5160; the material was lost at some time. I checked our loan records and found that Augener received this lot on loan to Hamburg around 19.II.1914 from my predecessor Anton Collin, and returned the specimens on 11.VIII.1921. He does not seem to have had the specimens on loan a second time."

The next available name is $N$. splendida Grube, 1840. This name could be used for Mediterranean records of what has been regarded as $N$. falsa. As indicated above, $N$. falsa would be available for the Black Sea populations currently regarded as Hediste diversicolor, once significant differences are found and its independent specific status is confirmed. However, Claparède left no type material because he emphasized that (Claparède 1867: 12 [341 in translation]) "the Annelida can only be well studied at the seaside and by means of living individuals." Because there is no type material, and especially because the species-group name is in conflict, the designation of a neotype is necessary to define the nominal taxon (ICZN 1999, art. 75.1). These are the qualifying conditions:

- a neotype of Nereis splendida Grube, 1840 is proposed to clarify the taxonomic status of the species (ICZN 1999, art. 75.3.1)

- the above description, the key below, and the publication by Gravina et al. (2015, as Nereis falsa) characterize the species and its differences from similar species in the area or from elsewhere (ICZN 1999, art. 75.3.2)

- the description above matches the original description and the labeling ensures the recognition of the neotype (ICZN 1999, art. 75.3.3)

- as indicated above, the type material was lost (ICZN 1999, art. 75.3.4)

- the neotype is a mature male specimen with some modifications for swimming and swarming. Despite the modifications of cephalic appendages and parapodia, the pharynx armature is not modified (Fauvel 1916; Pamungkas \& Glasby 2015), and the neotype matches the original description. Because no other topotype specimen was available, this different life stage is code compliant (ICZN 1999, art. 75.3.5)

- the neotype was collected in Naples harbor, and Grube (1840:2) indicated that most of his specimens, if no locality was given, as is the case for N. splendida, were collected in the Gulf of Naples, and the neotype was collected from the same area (ICZN 1999, art. 75.3.6)

- the neotype has been deposited in the Muséum national d'histoire naturelle, Paris, a recognized scientific institution (ICZN 1999, art. 75.3.7)

Most specimens that have been preserved for about 100 years risk having the blades of compound falcigers detach, and this is why additional specimens must be studied to reveal the specific morphology of the homogomph falcigers in median or posterior chaetigers. It seems that the blades in median 
chaetigers have tips better defined and more acute than those present along more posterior chaetigers. Observations of the inner margin denticulation are also difficult because it can be eroded, and we think this feature is also better defined along median chaetigers.

"Nereis falsa" resembles N. pelagica Linnaeus, 1758, the type species of the genus (Fauvel 1923: 335-336), in pharyngeal ornamentation and parapodial development; their main differences are in the size and dentition of the homogomph falciger blades. In " $N$. falsa" the blades of falcigers are longer ( $3 \times$ as long as wide), the distal tooth is incurved and they have denticulate cutting edges, whereas in $N$. pelagica the blades are shorter (2.0-2.5 $\times$ as long as wide), without a distal tooth and the cutting edges are smooth to barely rugose. On the other hand, Gravina et al. (2015: 162, key) indicated that " $N$. falsa" is more similar to $N$. rava Ehlers, 1864, because both have similar parapodial development in posterior chaetigers, without expanded dorsal ligules, and because the homogomph falciger blades are denticulate. These two species differ because of some fine details in the blades of homogomph falcigers. In $N$. rava, these blades are medially expanded, and there is a thicker distal tooth, without a ligament, whereas in " $N$. falsa" the blades are tapered, and the distal tooth is incurved, with a ligament or tendon. Another relevant difference is that in $N$. rava there is a single transverse row of paragnaths in areas VII-VIII, whereas there are 2-3 rows in " $N$. fals $a$ ". In the latter species, most accounts indicate that there can be 3 or 4-5 paragnaths in area VI in the same population (Fauvel 1923; Gravina et al. 2015), and it would be interesting to evaluate whether these differences are linked with some other morphological features.

It must be emphasized that according to Hartman (1959), N. pelagica includes 18 junior synonyms (and some subspecies) described from the Atlantic; the Northwestern Pacific records (Imajima 1972) differ from the Northeastern Atlantic forms, as illustrated by Chambers \& Garwood (1992: 38), in cephalic appendages, as well as parapodial and chaetal features, including in epitokes. Some of the junior synonyms have also been confused with " $N$. falsa" due to the pigmented glandular parapodial ligules.

As indicated below, $N$. splendida resembles " $N$. falsa" recorded for the Caribbean Sea (Liñero-Arana \& Reyes-Vásquez 1979) in having anterior chaetigers with digitate notopodial ligules, ventral ligules longer than neuracicular ligules in median and posterior chaetigers, and pharyngeal areas VII-VIII with 2-3 transverse rows of paragnaths. Their main differences are in prostomial shape and pharyngeal paragnath numbers in area II. In N. splendida the anterior prostomial lobe is $2 \times$ as long as wide, and area II has about 22 paragnaths, whereas in the Caribbean specimens the anterior prostomial lobe is wider than long, and area II has about 30 paragnaths.

\section{Distribution}

Mediterranean Sea and adjacent localities in the Northeastern Atlantic, in shallow water. The record by Rullier \& Amoureux (1969: 120) cannot be confirmed because their specimens could not be located.

\section{Nereis callaona Grube \& Kröyer in Grube, 1857}

Fig. 7

Nereis (Nereilepas) callaona Grube \& Kröyer in Grube, 1857: 165-166.

Nereis robusta Kinberg, 1866: 168-169.

Nereis pseudonereis Hartman, 1940: 223-224, pl. 36 figs 63-64, pl. 37 figs 65-66.

Nereis callaona - Ehlers 1901b: 108-110, pl. 13 figs 13-20. - Hartman 1940: 227. - Fauvel 1943: 15. - Reish 1954: 104-105, pl. 24 figs 13-14 (synonymy). — Hartmann-Schröder 1960: 19-20, figs 38-39; 1962a: 399-400; 1962b: 107. — Wesenberg-Lund 1962: 297; 75, fig. 28. — Rozbaczylo \& Bolados 1980: 209-212, fig. 2 (synonymy). — Salazar-Vallejo \& Eibye-Jacobsen 2012: 1396 (gave incorrect publication year). 
Nereis robusta - Kinberg 1910: 50, pl. 20 fig. 1. - Hartman 1948: 64-66, pl. 10 figs 10-11.

Nereis falsa-Berkeley \& Berkeley 1964: 129 (non de Quatrefages, 1866).

\section{Diagnosis}

Nereis with posterior eyes completely exposed; tentacular belt $1.5 \times$ as long as first chaetiger; tentacular cirri short, reaching chaetigers 4-5; jaws with 4 teeth; pharyngeal area II with 11 paragnaths in 2 rows, areas VII-VIII with 2-3 transverse rows of paragnaths; anterior chaetigers with notopodial ligules short, globose; ventral ligules in median and posterior chaetigers markedly longer than neuracicular ligules.

\section{Material examined}

\section{Holotype}

PERU • adult; Callao; 18 Sep. 1848; Kröyer leg. (according to Salazar-Vallejo \& Eibye-Jacobsen 2012: 1396; no specimens in Berlin or Wroclaw (Hartwich 1993; Wiktor 1980)); NHMD 109278 (previously ZMUC POL-1495).

\section{Holotype of Nereis pseudonereis}

ECUADOR • Galapagos Islands, "Albemarle Island" [now Isabela Island], Tagus Cove; $00^{\circ} 16^{\prime} 26^{\prime \prime} \mathrm{S}$, 9122'42" W; R/V Velero III, stn 326-34; sand, bryozoans; 27 m depth; 10 Dec. 1934; Allan Hancock Foundation leg.; LACM 824 (not seen).

\section{Description}

BoDy. Holotype (NHMD 109278) atoke, complete, $43 \mathrm{~mm}$ long, $2.5 \mathrm{~mm}$ wide including parapodia, with 75 chaetigers. All parapodia with dark brown glandular masses.

Prostomium. Pyriform, longer than wide; eyes round, of similar size, in trapezoidal arrangement, posterior eyes closer to each other (Fig. 7A). Antennae swollen basally, as long as palps, without gap between them. Palpophores globose, $1.5 \times$ as long as wide, palpostyles rounded.

TENTACULAR BELT. $1.5 \times$ as long as first chaetiger, anterior margin not covering posterior eyes. Tentacular cirri smooth, longest ones reaching chaetiger 4 (Fig. 7A).

Pharynx. Everted. Jaws brown with 4 teeth (Fig. 7A, C). Paragnath formula: I: 2 in tandem; II: 11 in two rows; III: 40 in 4 rows, forming almost oval group; IV: $25-30$ in crescent-shaped groups; V: 0; VI: 4 in diamond; VII-VIII: two rows, anterior row with 29 large cones, almost in zig-zag arrangement, posterior row with 29 small cones in a row (Fig. 7A-C).

Pattern of Parapodial ligules. Anterior chaetigers with ligules blunt, globose, as long as wide, becoming digitate, $2-3 \times$ as long as wide in median and posterior chaetigers; ventral ligule slightly longer than neuracicular ligules in anterior chaetigers, in median and posterior ones markedly longer than them.

ChAETIGers 1-2. With neuraciculae only; with both noto- and neuraciculae thereafter.

ANTERIOR PARAPODIA (Fig. 7D). With dorsal cirrus inserted medially, longer than ventral ones; dorsal and median ligules rounded, subequal; dorsal ligule $1.7 \times$ as long as wide; median ligule as long as wide, $2 \times$ as long as neuracicular ligule; prechaetal lobe rounded, small. Neuracicular ligule rounded, as long as wide; ventral ligule digitiform, $1.6 \times$ as long as wide, $2 \times$ as long as neuracicular ligule, longer than ventral cirrus. Notochaetae 10-11 homogomph spinigers. Supracicular neurochaetae: 7 homogomph spinigers and 4 thick heterogomph falcigers with blades $4 \times$ as long as wide, denticulate along cutting edge, distal tooth incurved, fused to blade (Fig. 7G); subacicular neurochaetae: 3 heterogomph spinigers 
and 10 heterogomph falcigers with blades $6 \times$ as long as wide, distal tooth incurved, fused to blade (Fig. 7H).

MEdian PARAPODIA (Fig. 7E). With dorsal cirrus longer than ventral one, both slightly thin, dorsal cirrus $2 \times$ as long as dorsal ligule; dorsal and median ligules subequal, digitiform, $1.3 \times$ as long as wide, $3 \times$ as long as neuracicular ligule. Neuracicular ligule subconical, $2 \times$ as wide as long; ventral ligule $2.5 \times$ as long as wide, $3 \times$ as long as neuracicular ligule, subulate. Notochaetae: 3 homogomph spinigers and 1 homogomph falciger, slightly denticulate along cutting edge, distal tooth incurved and fused to blade. Supracicular neurochaetae: 4 homogomph spinigers and 3 heterogomph falcigers with blades $4 \times$ as long as wide, distal tooth incurved, fused to blade; subacicular neurochaetae: 1 heterogomph spiniger and 5 heterogomph falcigers with blades $4 \times$ as long as wide, distal tooth incurved, fused to blade (Fig. 7I).

POSTERIOR PARAPODIA (Fig. 7F). With dorsal cirrus inserted medially, longer than ventral one; dorsal ligule basally swollen, distally digitiform, $4 \times$ as long as wide, $1.5 \times$ as long as median one; median ligule digitiform, $3 \times$ as long as wide, $3.2 \times$ as long as neuracicular ligule. Neuracicular ligule subconical; ventral ligule digitiform, $3 \times$ as long as neuracicular ligule. Notochaetae: 1 homogomph spiniger and 2 homogomph falcigers, $6.5 \times$ as long as wide (Fig. $7 \mathrm{~K}$ ), similar to those of median parapodia. Supracicular neurochaetae: 5 homogomph spinigers and 1 heterogomph falciger with blade $3.4 \times$ as long as wide, distal tooth incurved, fused to blade, cutting edge with a few denticles (Fig. 7J); subacicular neurochaetae: 4 heterogomph falcigers with blades $4 \times$ as long as wide, distal tooth incurved and fused to blade.

Posterior Region. Tapered. Pygidium with terminal anus and two anal cirri.
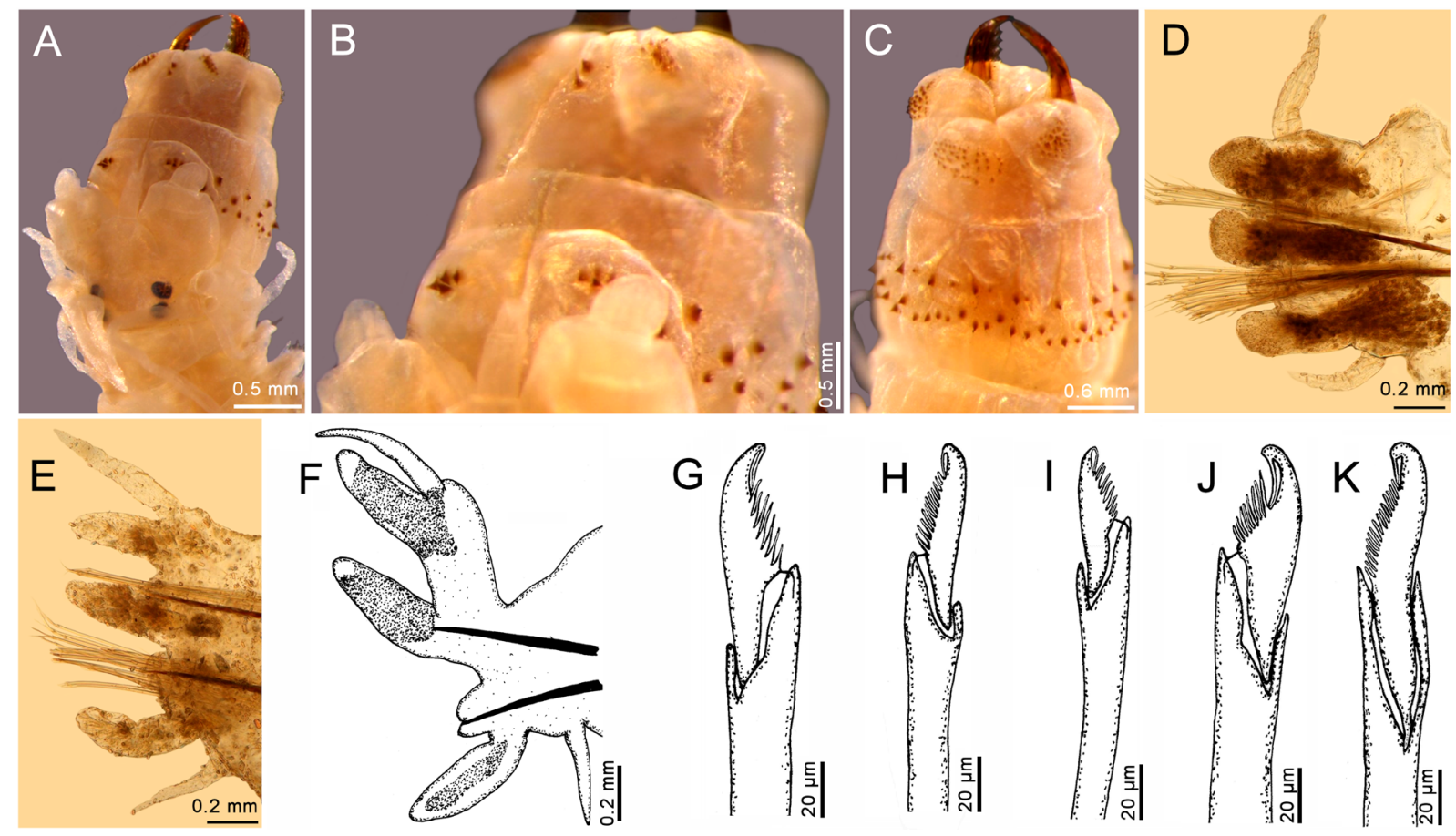

Fig. 7. Nereis callaona Grube \& Kröyer in Grube, 1857, holotype (NHMD 109278). A. Anterior end, oblique dorsal view. B. Same, close-up of pharynx. C. Pharynx, oblique ventral view. D. Chaetiger 10, right parapodium, anterior view. E. Chaetiger 31, right parapodium, anterior view. F. Chaetiger 61 , right parapodium, anterior view. G. Chaetiger 10, neuropodial supracicular heterogomph falciger. H. Chaetiger 10, neuropodial infracicular heterogomph falciger. I. Chaetiger 31, neuropodial subacicular heterogomph falciger. J. Chaetiger 61, neuropodial supracicular heterogomph falciger. K. Same, notopodial homogomph falciger. 


\section{Remarks}

Nereis callaona was described based on specimens from El Callao port, Peru. It differs from other species in the group by the presence of massive, dark glands in parapodial ligules throughout the body. The record by Augener (1918) for West Africa resembles typical specimens because it has the posterior eyes exposed, pharyngeal areas VII-VIII with 2-3 rows of denticles and pigmented glandular areas in posterior parapodia. They differ, however, because the Eastern Pacific species has 11 paragnaths in two rows in pharyngeal area II, whereas the West African form has 28 paragnaths in three rows in the same area. Reish (1954) regarded N. pseudonereis Hartman, 1940, described from the Galapagos and Peru, as a junior synonym of $N$. callaona after a comparison of the type specimens (see above). We follow Reish's conclusion.

Nereis callaona was regarded as identical to N. falsa by Berkeley \& Berkeley (1964), probably following Hartman (1940: 224), who indicated some affinities of her $N$. pseudonereis, a junior synonym of $N$. callaona (as indicated above), with $N$. falsa. However, the status of this latter species has been confused, because it belongs in Hediste Malmgren, 1867 (see above).

Further confusion was introduced by Ehlers (1913) by recording N. splendida Grube, 1840 from Southern Africa. However, N. callaona differs from N. splendida by having dark glandular masses in the parapodial ligules. Augener (1918) recorded N. callaona, from Western Africa, and although specimens of this latter region were not seen, they differ in the number of paragnaths in area II. There are 11 cones in the American specimens and 28 in the African ones. On the other hand, the male epitoke reported as $N$. falsa by Berkeley \& Berkeley (1964) has 26 chaetigers in the pre-natatory region instead of 27, as indicated for " $N$. falsa" by Fauvel (1923: 338). Their account should be referred to N. callaona, as indicated above, and not to any other species.

\section{Distribution}

Galapagos Islands, Ecuador, to northern Chile, in shallow water (0-30 m depth).

Nereis marginata Grube \& Örsted in Grube, 1857

Figs 8-9

Nereis (Nereis) marginata Grube \& Örsted in Grube, 1857: 160-161.

Nereis (Nereis) marginata - Salazar-Vallejo \& Eibye-Jacobsen 2012: 1396.

\section{Diagnosis}

Nereis with posterior eyes partially covered by anterior margin of tentacular belt; tentacular belt $2 \times$ as long as first chaetiger; tentacular cirri short, reaching chaetiger 4; pharyngeal areas VII-VIII with 5 large paragnaths in a single row; posterior chatigers with dorsal ligules $2-3 \times$ as wide as median ones.

\section{Material examined}

\section{Holotype}

UNITED STATES VIRGIN ISLANDS • Saint John (the vial has a label signed by Kröyer inside that says it is Nereis riisei, i.e., a very incorrect label); Kröyer leg.; NHMD 109266 (previously ZMUC POL1483).

\section{Other material}

ANTIGUA AND BARBUDA • 1 spec.; NW Antigua; $17^{\circ} 16^{\prime} \mathrm{N}, 62^{\circ} 02^{\prime} \mathrm{W}$; R/V Pillsbury, Cruise 6907, stn 967; 22 m depth; 20 Jul. 1969; ECOSUR P3119 • 1 spec.; NW Redonda Island; $17^{\circ} 00^{\prime} \mathrm{N}, 62^{\circ} 30^{\prime} \mathrm{W}$; R/V Pillsbury, Cruise 6907, stn 956; 37 m depth; 19 Jul. 1969; ECOSUR P3119. 
COLOMBIA • 1 spec.; N Gulf of Urabá; $8^{\circ} 32^{\prime}$ N, 7702' W; R/V Pillsbury, Cruise 6607, stn 349; 54 m depth; 11 Jul. 1966; ECOSUR P3120.

DOMINICAN REPUBLIC • 2 specs; R/V Pillsbury, Cruise 7006, stn 1254; 20 m depth; 14 Jul. 1970; ECOSUR P3104 1 spec.; Cape Beata; $17^{\circ} 35^{\prime}$ N, 71 ${ }^{\circ} 25^{\prime}$ W; R/V Pillsbury, Cruise 7006, stn 1284; 20 m depth; 19 Jul. 1970; UMML 22.1176 • 1 spec.; Bahia de las Aguilas; R/V Pillsbury, $17^{\circ} 52^{\prime} \mathrm{N}, 71^{\circ} 41^{\prime} \mathrm{W}$; Cruise 7006, stn 1272; 24 m depth; 18 Jul. 1970; ECOSUR P3121 • 1 spec.; S of Cabo Falso; $17^{\circ} 41^{\prime}$ N,

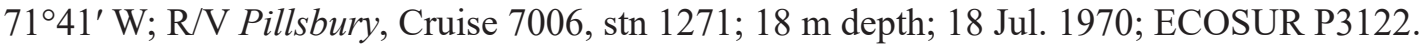

GRENADA • 2 specs; S Grenada; $11^{\circ} 55^{\prime}$ N, $61^{\circ} 43^{\prime} \mathrm{W}$; R/V Pillsbury, Cruise 6907, stn 853; 17 m depth; 3 Jul. 1969; UMML 22.1177.

JAMAICA $\bullet 3$ specs; NE Morant Cays; $17^{\circ} 28^{\prime}$ N, 755' W; R/V Pillsbury, Cruise 7006, stn 1196; 26 m depth; 3 Jul. 1970; UMML 22.1174 • 2 specs; W Pedro Bank; 1709' N, 7857' W; R/V Pillsbury, Cruise 7006, stn 1252; 26 m depth; 14 Jul. 1970; UMML 22.1175.

NICARAGUA • 1 spec.; E Nicaragua; $13^{\circ} 58^{\prime} \mathrm{N}, 8^{\circ} 04^{\prime} \mathrm{W}$; R/V Pillsbury, Cruise 7101, stn 1343; $25 \mathrm{~m}$ depth; 30 Jan. 1971; ECOSUR P3117.

TURKS AND CAICOS • 1 spec.; NE Grand Turk; $21^{\circ} 36^{\prime}$ N, $71^{\circ} 01^{\prime} \mathrm{W}$; R/V Pillsbury, Cruise 7106, stn 1421; 83 m depth; 19 Jul. 1971; ECOSUR P3124.

\section{Description}

\section{Holotype (NHMD 109266)}

BoDy. Atoke specimen, without posterior region, $50 \mathrm{~mm}$ long, $3 \mathrm{~mm}$ wide, 96 chaetigers.

Prostomium. Pyriform, longer than wide, dorsal groove present. Eyes in trapezoidal arrangement, with lenses, anterior eyes rounded, smaller than oval posterior ones. Antennae thin, terminal, with a small gap between them (Fig. 8A-B). Palpophores globose, directed downward, $1.5 \times$ as long as wide, palpostyles rounded.

Tentacular Belt. $2 \times$ as long as first chaetiger, anterior margin slightly covering posterior eyes. Tentacular cirri smooth, longest ones reaching anterior margin of chaetiger 4 (Fig. 8A-B).

Pharynx. Not observed, withdrawn.

PATTERn OF PARAPODial Ligules. Anterior chaetigers with dorsal ligules tapered, blunt, median ligules rounded; median and posterior chaetigers with ligules subconical, becoming wider towards posterior chaetigers. Ligules with contorted glandular tubules.

ChAetigers 1-2. With neuraciculae only, with both noto- and neuraciculae thereafter.

ANTERIOR PARAPODIA (Fig. 8C). With dorsal cirrus basally inserted, incomplete; dorsal ligule subconical, blunt, $1.4 \times$ as wide as long, $1.5 \times$ as long as median ligule; prechaetal lobe absent; median ligule rounded, $1.1 \times$ as long as wide, slightly longer than neuracicular ligule. Neuracicular ligule digitiform, $2 \times$ as long as wide, slightly longer than ventral ligule; ventral ligule digitiform, slightly longer than wide. Notochaetae 9 homogomph spinigers. Supracicular neurochaetae: 6 homogomph spinigers and 2 heterogomph falcigers with blades $6.8 \times$ as long as wide, distal tooth incurved, fused to blade (Fig. $8 \mathrm{G}$ ); subacicular neurochaetae: 6 heterogomph spinigers, 10 heterogomph falcigers with blades $8 \times$ as long as wide, similar in size and shape as supracicular ones and 1 heterogomph falciger with blade $4.2 \times$ as long as wide, distal tooth incurved, fused to blade (Fig. 8H). 
Median PARAPODIA (Fig. 8D). With dorsal cirri thin, as long as dorsal ligule; dorsal ligule subconical, tapering, $1.3 \times$ as wide as long, with massive dark glands. Median ligule subconical, blunt, as long as wide, $4 \times$ as long as neuracicular ligule. Neuracicular ligule subconical, $1.5 \times$ as long as wide; ventral ligule subconical or digitiform, $2 \times$ as wide as long, $2 \times$ as long as neuracicular ligule. Notochaetae: 6 homogomph spinigers and 1 homogomph falciger with blade $7 \times$ as long as wide, distal tooth incurved, fused to blade. Supracicular neurochaetae: 5 homogomph spinigers, 2 heterogomph falcigers with blades $8 \times$ as long as wide, distal tooth incurved, fused to blade (Fig. 8I) and 1 thick heterogomph falciger with blade $2.7 \times$ as long as wide; subacicular neurochaetae: 1 heterogomph spiniger and 6 heterogomph falcigers with blades $4.2 \times$ as long as wide, distal tooth incurved, fused to blade (Fig. $8 \mathrm{~J}$ ).
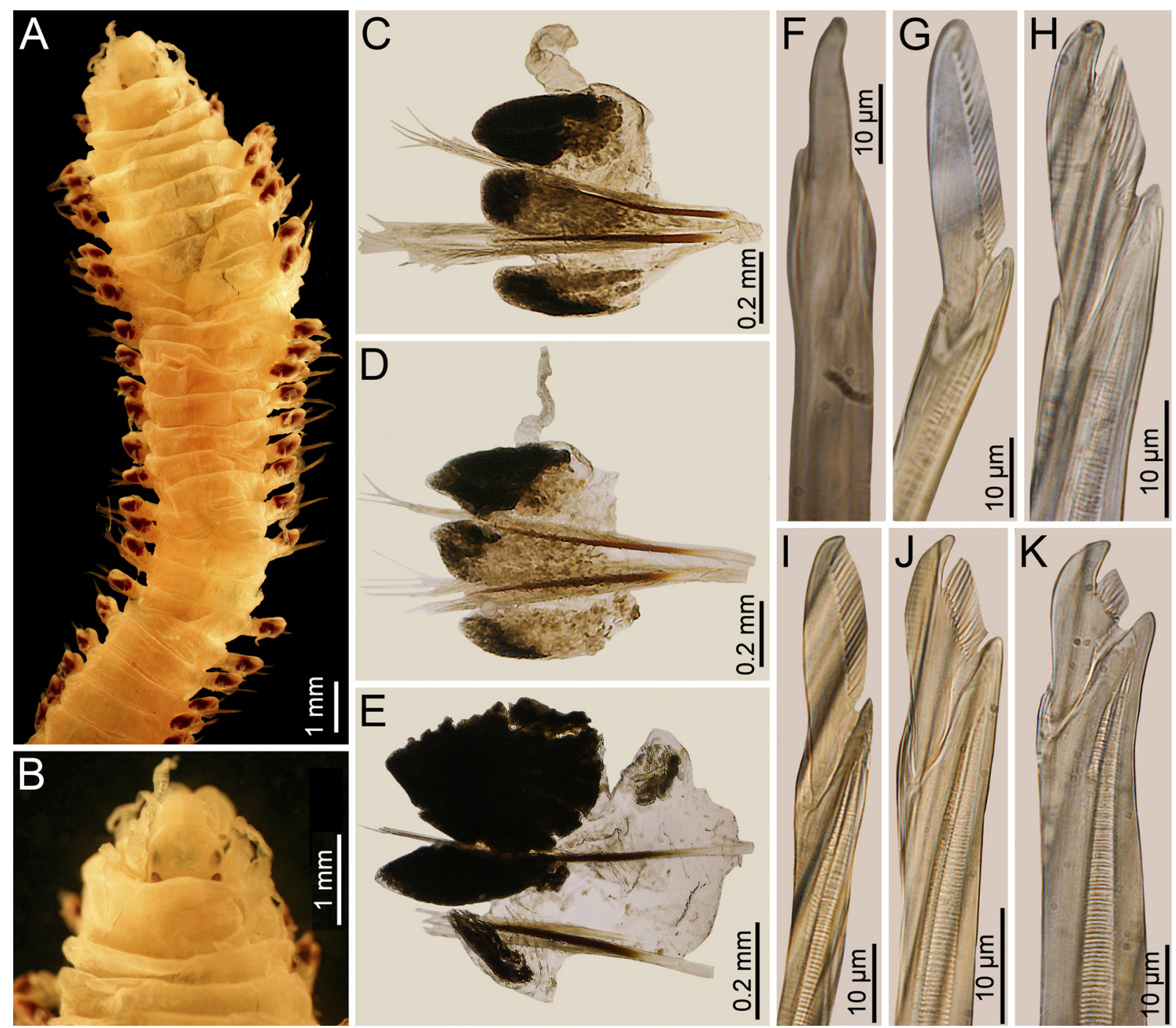

Fig. 8. Nereis marginata Grube \& Örsted in Grube, 1857, reinstated, holotype (NHMD 109266). A. Anterior region, dorsal view. B. Prostomium, dorsal view. C. Chaetiger from anterior region, right parapodium, anterior view. D. Chaetiger from middle region, right parapodium, anterior view. E. Chaetiger from posterior region, right parapodium, anterior view. F. Posterior chaetiger, notopodial homogomph falciger. G. Anterior chaetiger, supracicular heterogomph falciger. H. Same, subacicular heterogomph falciger. I. Middle chaetiger, supracicular heterogomph falciger. J. Same, subacicular heterogomph falciger. K. Posterior chaetiger, supracicular heterogomph falciger. C-E, ventral cirrus missing. 
Posterior PARAPOdia (Fig. 8E). In fair condition, dorsal and ventral cirri missing. Dorsal ligule subconical, tapering, widened, $1.7 \times$ as wide as long, with massive dark glands, as long as median ligule; median ligule subconical to digitiform, $4 \times$ as long as neuracicular ligule, with massive dark glands. Neuracicular ligule subconical, as long as wide; ventral ligule digitiform, $3 \times$ as long as neuracicular ligule, with massive dark glands. Notochaetae: 2 homogomph spinigers and 1 homogomph falciger with blade $7.1 \times$ as long as wide, similar to those of median parapodia (Fig. 8F). Supracicular neurochaetae: 1 homogomph spiniger, 2 heterogomph falcigers with blades $5 \times$ as long as wide and 1 thick heterogomph falciger with blade $2.9 \times$ as long as wide, distal tooth incurved, fused to blade (Fig. 8K); subacicular neurochaetae: 2 heterogomph falcigers with blades $5.8 \times$ as long as wide, distal tooth incurved, fused to blade, similar to those of median parapodia.

Posterior REGION. Missing.

\section{Atokes}

BoDy. Atoke specimen (UMML 22.1174) complete, in good condition, $30 \mathrm{~mm}$ long, $2 \mathrm{~mm}$ wide, 62 chaetigers. Another specimen (ECOSUR P3104) with dark brown pigmentation throughout body; pigmentation present on prostomium and palpophores, tentacular belt fully pigmented (Fig. 8A-B). Dorsal pigmentation pattern as one anterior, transverse band on each segment along anterior body, breaking into several rectangular patches towards posterior chaetigers. Glands present in notopodial and ventral ligules throughout body (Fig. 9A-B, H-K).

Prostomium. Pyriform, longer than wide, dorsal groove present. Eyes rounded, subequal, in trapezoidal arrangement (Fig. 9A, C). Antennae cirriform, as long as prostomium, with a small gap between them (Fig. 9C). Palpophores globose, $1.5 \times$ as long as wide, palpostyles rounded.

TentaCular Belt. $1.5 \times$ as long as first chaetiger, anterior margin slightly covering posterior eyes. Tentacular cirri smooth, longest ones reach chaetiger 4 (Fig. 9A, C).

Pharynx. Dissected; jaws brown, with 10 teeth. Paragnath formula: I: 1; II:18-20 in arc; III: 15 in rectangle; IV: $14-16$ in arc; V: 0; VI: $8-10$ in oval; VII-VIII: 5 in a single band.

Pattern of Parapodial Ligules. Anterior chaetigers with dorsal ligules subconical, blunt, median ligules rounded; median and posterior chaetigers with ligules subconical, becoming wider toward posterior chaetigers; ligules with contorted glandular tubules.

ChaEtigers 1-2 (Fig. 9H). With neuraciculae only, with both noto- and neuraciculae thereafter. Dorsal cirrus basally inserted, $1.2 \times$ as long as dorsal ligules; dorsal and ventral ligules subconical, blunt, subequal, $1.5 \times$ as wide as long, several times longer and wider than neuracicular ligule. Neuracicular ligule subconical. Ventral cirrus as long as ventral ligule.

ANTERIOR PARAPODIA (Fig. 9I). With dorsal cirrus $2 \times$ as long as dorsal ligule; dorsal ligule subconical, blunt, $2 \times$ as wide as long, as long as median one; median ligule rounded, as long as wide, $1.2 \times$ as long as neuracicular one. Neuracicular ligule rounded, as long as wide, as long a ventral ligule; postchaetal lobe subconical, as long as neuracicular one; ventral ligule digitiform to rounded, $2 \times$ as wide as long. Ventral cirrus as long as ventral ligule. Notochaetae 6-7 homogomph spinigers. Supracicular neurochaetae: 7-9 homogomph spinigers and 2-3 heterogomph falcigers with blades $7 \times$ as long as wide, distal tooth incurved, fused to blade; subacicular neurochaetae 3-4 heterogomph spinigers, 3-4 heterogomph falcigers with blades $8 \times$ as long as wide and $1-2$ heterogomph falcigers with blades $4 \times$ as long as wide, distal tooth incurved, fused to blade.

MEDiAn (Fig. 9J) AND POSTERIOR (Fig. 9K) PARAPODIA. With dorsal cirri $1.2-1.5 \times$ as long as dorsal ligule. Dorsal ligule subconical, tapering, widened, $1.2-1.5 \times$ as wide as long, with massive dark glands, slightly longer than median ligule; median ligule subconical, tapering, 3-4× as long as neuracicular 
ligule. Neuracicular ligule subconical, blunt; ventral ligule digitiform, $2 \times$ as long as neuracicular ligule. Ventral cirrus slightly shorter than ventral ligule in median parapodia, becoming slightly longer than ventral ligule toward posterior parapodia. Notochaetae: 2-4 homogomph spinigers and 1 homogomph
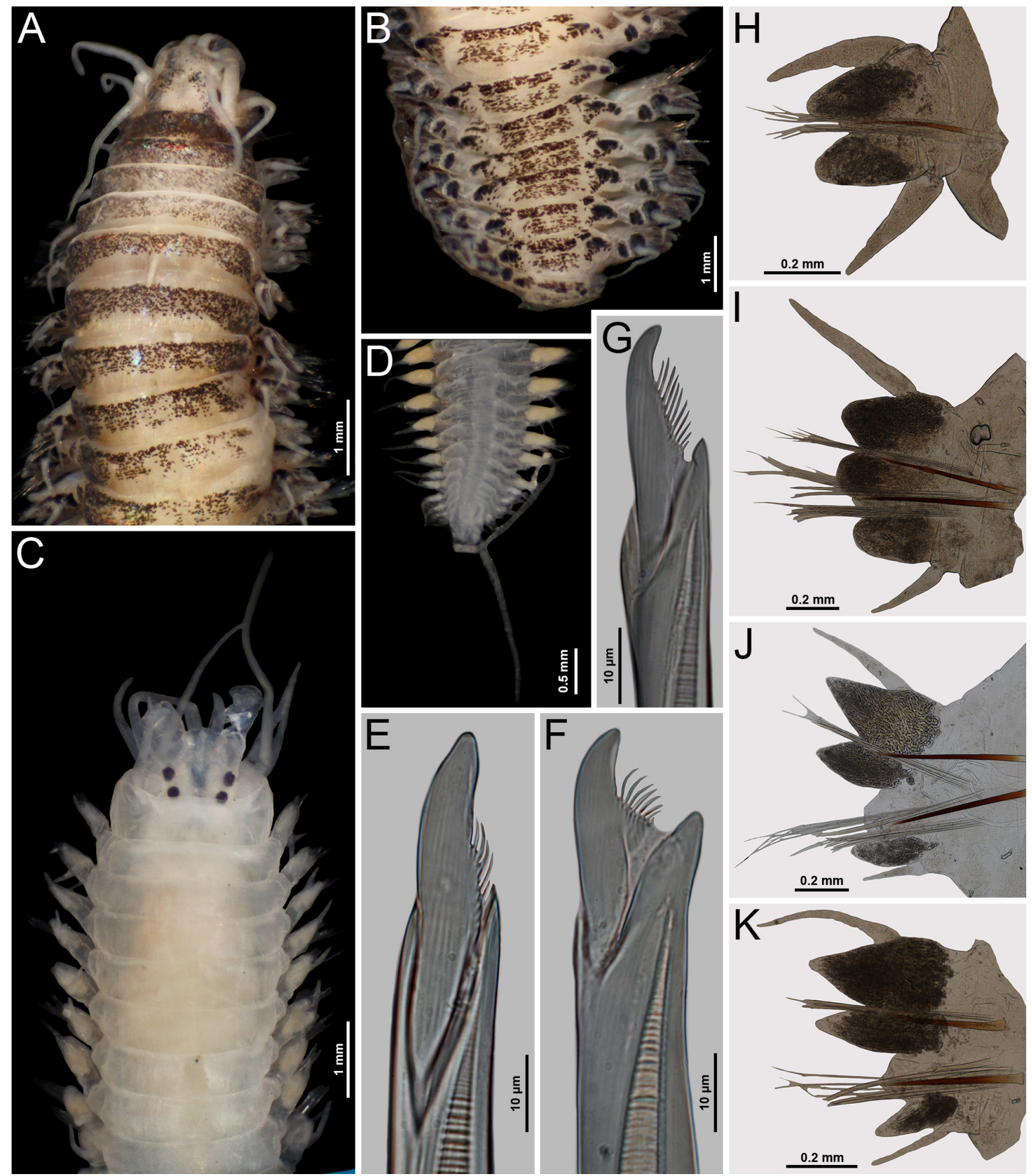

Fig. 9. Nereis marginata Grube \& Örsted in Grube, 1857 reinstated, non-type, atoke specimens. A-B, E-K: ECOSUR P3104; C-D: UMML 22.1174. A. Anterior region, dorsal view. B. Posterior end, dorsal view. C. Anterior region, dorsal view. D. Posterior end, dorsal view. E. Chaetiger 52, notopodial homogomph falciger. F. Same, supracicular heterogomph falciger. G. Same, subacicular heterogomph falciger. H. Chaetiger 1, right parapodium, anterior view. I. Chaetiger 12, right parapodium, anterior view. J. Chaetiger 28, right parapodium, anterior view. K. Chaetiger 52, right parapodium, anterior view. 
falciger with blade $7 \times$ as long as wide (Fig. 9E). Supracicular neurochaetae: 2-6 homogomph spinigers, 1-2 heterogomph falcigers with blades $5 \times$ as long as wide and 1 thick heterogomph falciger (Fig. 9F) with blade $3 \times$ as long as wide, distal tooth incurved, fused to blade; subacicular neurochaetae: 2-3 heterogomph falcigers with blades $5 \times$ as long as wide, distal tooth incurved, fused to blade (Fig. 9G).

Posterior REGION. With pygidium tripartite; anal cirri subulate, as long as last 7 chaetigers (Fig. 9D).

\section{Remarks}

Nereis (Nereis) marginata is a neglected Caribbean species; it was originally described based on a single specimen with about 90 chaetigers from St John, U.S. Virgin Islands (formerly St Jean).

The original description is succinct and has no illustrations; perhaps because of this, Hartman (1959) regarded $N$. marginata as indeterminable. The type material of $N$. (Nereis) marginata (NHMD 109266) was examined. The holotype consists in a single specimen with the pharynx previously removed. The parapodia have black spots on the distal part of the ligules throughout body. Additional specimens from the Caribbean Sea were examined and match the type material.

Nereis marginata resembles N. rava, from the Mediterranean Sea (following Gravina et al. 2015). These two species have posterior eyes partially covered by the tentacular belt's anterior margin and short tentacular cirri reaching chaetigers $2-4$. Their main differences are in pigmentation pattern and in the relative size of the notopodial ligules on posterior chaetigers. In $N$. marginata the dorsum has transverse irregular bands, its dorsal ligules are $2-3 \times$ as wide as median ones and the ventral ligules surpass neuracicular ligules, whereas in $N$. rava the dorsum has two transverse bands, its dorsal and median ligules are of similar width and ventral ligules reach neuracicular ligules in length.

On the other hand, $N$. marginata also resembles $N$. riisei in pharyngeal formula and both parapodial and chaetal morphology, but they can be separated by using several features of the anterior end, parapodia and chaetae. In N. marginata, the posterior eyes are partially covered by the tentacular belt, whereas in $N$. riisei they are completely exposed; in $N$. marginata, the dorsal ligules are wider than long throughout body and become markedly wider toward posterior chaetigers, whereas in $N$. riisei they are of subequal length and width, becoming slightly wider toward posterior chaetigers; in N. marginata, median ligules in anterior chaetigers are much wider than neuroacicular ligules, whereas in $N$. riisei they are of similar width; in N. marginata, the ventral cirri become longer than ventral ligules toward posterior chaetigers, whereas in $N$. riisei they are shorter than the ventral ligules throughout the body; $N$ marginata has neuropodial heterogomph falcigers with blades of different sizes in supra- and infracicular neuropodial fascicles, whereas in N. riisei they are of similar size. These differences are consistent within the material examined, so Nereis marginata is here regarded as a valid species.

\section{Distribution}

Caribbean Sea, in mixed bottoms up to $80 \mathrm{~m}$ depth.

Nereis riisei Grube \& Örsted in Grube, 1857

Figs $10-13$

Nereis (Nereis) riisei Grube \& Örsted in Grube, 1857: 162-163.

Nereis albipes Grube \& Müller in Grube, 1874: 60 (groups), 73 (description) syn. nov.

Nereis glandulata Hoagland, 1919: 575, pl. 30 figs 1-6.

Nereis (Nereis) riisei - Augener 1922: 42; 1925: 6 (redescription). — Monro 1933: 43-44 (synonymy). - Allen 1957: 51-52 (reproduction). — Rullier 1974: 38. - Fauchald 1977b: 31, fig. 8c-e (partim, 
only Caribbean specimens). — Liñero-Arana \& Reyes-Vázquez 1979: 6, pl. 4 figs 1-11. — Taylor 1984: 31.38-31.40, figs 31.35, 31.36a-g. — de León-González et al. 1999: 676. — Salazar-Vallejo \& Eibye-Jacobsen 2012: 1396.

\section{Diagnosis}

Nereis with posterior eyes completely exposed; tentacular belt $2 \times$ as long as first chaetiger; pharyngeal areas VII-VIII with a single row of large denticles; median and posterior parapodia with ventral ligules surpassing neuracicular ligule tips.

\section{Material examined}

Holotype

UNITED STATES VIRGIN ISLANDS • atoke; Saint Croix; Kröyer leg.; NHMD 109270 (previously ZMUC POL-1487).

Syntypes of Nereis albipes Grube \& Müller in Grube, 1874

BRAZIL • 5 syntypes; "Desterro" [now Santa Catarina Island]; Fr. Müller leg.; ZMB Q3441.

\section{Holotype of Nereis glandulata Hoagland, 1919}

PUERTO RICO - holotype (posteriorly incomplete, $8.5 \mathrm{~mm}$ long, $1.2 \mathrm{~mm}$ wide at chaetiger 10, 26 chaetigers; pharyngeal formula: I: 1; II:12-14 cones; III: 9 cones; IV: 17-? cones; V: 0; VI: 5-5 cones; VII-VIII: 7); rocks off Guanica Harbor; 1915; AMNH 1211.

\section{Other material}

ANTIGUA AND BARBUDA - 1 spec.; N Antigua; R/V Pillsbury, Cruise 6806, stn 968; $17^{\circ} 18^{\prime}$ N, 6152' W; 18 m depth; 20 Jul. 1969; UMML 0000 - 1 spec.; SW Barbuda; R/V Pillsbury, Cruise 6802, stn $975 ; 17^{\circ} 29^{\prime} \mathrm{N}, 61^{\circ} 55^{\prime} \mathrm{W} ; 29$ m depth; 21 Jul. 1969; UMML 22.1169.

COLOMBIA • 1 spec.; W San Bernardo Archipelago; 946' N, 76²10' W; R/V Pillsbury, Cruise 6607, stn 372; 91 m depth; 13 Jul. 1966; UMML 22.1170.

FRENCH GUIANA 11 spec.; NE French Guiana; $6^{\circ} 07^{\prime}$ N, $52^{\circ} 19^{\prime} \mathrm{W}$; R/V Pillsbury, Cruise 6806, stn 650; 87 m depth; 8 Jul. 1968; UMML 22.1172.

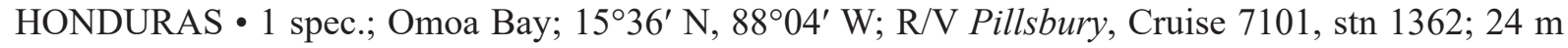
depth; 1 Feb. 1971; UMML 22.1167.

JAMAICA • 2 specs; S Jamaica; $17^{\circ} 47^{\prime}$ N, 7741' W; 28 m depth; R/V Pillsbury, Cruise 7006, stn 1223; 6 Jul. 1970; ECOSUR P3115.

MEXICAN CARIBBEAN (Smithsonian Breeding Expedition) 23 specs; Ascension Bay, Nicchehabin Reef, behind center of reef, E of Allen Point; stn 52-60; 10 Apr. 1960; E.L. Bousfield and H.A. Rehder leg.; USNM 174874 • 19 specs; Ascension Bay, Central Nicchehabin Reef; stn 67-60; 13 Apr. 1960; E.L. Bousfield and H.A. Rehder leg.; USNM $174835 \bullet 46$ specs; behind central part of Nicchehabin Reef; stn 72-60; 14 Apr. 1960; E.L. Bousfield and H.A. Rehder leg.; USNM 174836 • 5 specs; N end of Ascension Bay, shore just E of Halfway Point, turtle grass flats off point to sandy beach and mangrove roots; stn 77-60; 15 Apr. 1960; E.L. Bousfield and H.A. Rehder leg.; USNM 174837 • 9 specs; behind central part of Nicchehabin Reef; stn 82-60; 16 Apr. 1960; W.L. Schmitt, E.L. Bousfield and H.A. Rehder leg.; USNM 174838 - 1 spec.; Ascension Bay, mangrove inlet behind Allen Point Light; stn 83-60; 16 April 1960; USNM 174839 - 1 spec.; Ascencion Bay, 180-270 m off SW of Suliman Point; stn 87-60; 17 Apr. 1960; E.L. Bousfield, F.C. Daiber and H.A. Rehder leg.; USNM $174840 \bullet 1$ spec.; Nicchehabin Reef; stn 91-60; 18 Apr. 1960; USNM 174841 10 specs; Ascension Bay, Suliman Point to 270 m to 
SW shore, reef flats and sand flats; stn 95-60; 19 Apr. 1960; W.L. Schmitt, F.C. Daiber, E.L. Bousfield, J.F. Clarke, H.A. Rehder, Haynes and Harvey leg.; USNM 174842 - 3 specs; S end of Cozumel Island, N of Santa Maria Point, shore and sand; stn 100-60; 21 Apr. 1960; H.A Rehder, E.L. Bousfield and F.C. Daiber leg.; USNM 174843 • 1 spec.; Cozumel Island, San Miguel, along shore $400 \mathrm{~m}$ NE of pier, in front of barracks (military reservation); stn 118-60; 30 Apr. 1960; W.L. Schmitt and H.A. Rehder leg.; USNM 174844.

MEXICO - Veracruz • 3 specs; La Gallega Reef; M.L. Chavez leg.; ICMyL $\bullet 1$ spec.; La Gallega Reef; May 1957; 3 Jun. 1979; B. Galván leg.; ICMyL • 3 specs; La Gallega Reef; 14 Nov. 1992; J.A. de LeónGonzález leg; UANL 8145. - Campeche • 1 spec.; Perez Island; 18 Apr. 1955; F. Bonet leg.; ICMyL • 1 spec.; Bonita Beach, Playa del Carmen; 28 May 1957; M.E. Caso leg.; ICMyL 11 spec.; Bahamita Beach; 1 Aug. 1972; M.E. Caso leg.; ICMyL. - Quintana Roo • 1 atoke; Punta Allen, Bahía Ascensión; sponge on wood pole, intertidal; 11 Jun. 1986; E. Donath leg.; ECOSUR P1114 2 specs; Punta Allen, Bahía Ascensión; 11 Jun. 1986; E. Donath leg.; ECOSUR P1126 • 1 atoke; Xcacel; coral stone; $1 \mathrm{~m}$ depth; 3 Apr. 1992; SI Salazar-Vallejo leg.; ECOSUR P1130 • 3 specs; Playa Aventuras; coral rock; $1 \mathrm{~m}$ depth; 22 Mar. 1992; SISV leg.; ECOSUR P1131 • 2 specs; Banco Chinchorro; 3 Oct. 1983; ECOSUR P1134 - 2 spec.; Xahyayxol; coral rock; 2 m depth; 26 Sep. 1996; L.F. Carrera-Parra and SISV leg.; ECOSUR P1138 - 5 specs; Buenavista, Xahuayxol; coral rock; 2 m depth; 27 Sep. 1996; L.F. CarreraParra and SISV leg.; ECOSUR P1139 • 1 spec.; E Arrowsmith Bank; $21^{\circ} 04^{\prime} \mathrm{N}, 86^{\circ} 19^{\prime} \mathrm{W}$; R/V Gerda, Cruise 6717, stn 898; 352 m depth; 10 Sep. 1967; ECOSUR P3123 • 1 spec.; Arrowsmith Bank; $21^{\circ} 06^{\prime} \mathrm{N}$, 86²8' W; R/V Pillsbury, Cruise 7028, stn 1286; 280 m depth; 23 Aug. 1970; UMML 22.1166.

PANAMA • 2 specs; Manzanillo Bay; $9^{\circ} 21^{\prime}$ N, $7^{\circ} 57^{\prime}$ W; 0 m depth; R/V Pillsbury, Cruise 6607, stn 321; 5 Jul. 1966; UMML 22.1171.

SAINT KITTS AND NEVIS • 2 specs; NW of Saint Christopher; $17^{\circ} 27^{\prime}$ N, $62^{\circ} 54^{\prime}$ W; R/V Pillsbury, Cruise 6907, stn 960; 32 m depth; 19 Jul. 1969; ECOSUR P3116.

UNITED STATES • 1 spec.; E Gulf of Mexico; $25^{\circ} 05^{\prime}$ N, $86^{\circ} 28^{\prime}$ W; R/V Gerda, Cruise 6717, stn 887; 97 m depth; 9 Sep. 1967; ECOSUR P3114.

VENEZUELA 1 atoke (broken in two fragments, used for variation); Isla Margarita, Islote Los Frailes; in seagrasses; 7 Jun. 1961; ECOSUR P2256.

\section{Description}

\section{Holotype of Nereis riisei (NHMD 109270)}

BoDy. Atoke, incomplete posteriorly, $70 \mathrm{~mm}$ long, $3.5 \mathrm{~mm}$ wide including parapodia, 88 chaetigers. Body pale, median parapodia with dark red glands in dorsal, median and ventral ligules, posterior parapodia with glandular areas only in dorsal and median ligules.

Prostomium. Pyriform, longer than wide, dorsal groove present. Eyes in trapezoidal arrangement, anterior ones small, rounded, with lens, posterior ones oval, with lens. Antennae thin, terminal, with a small gap between them (Fig. 10A). Palpophores globose, directed downward, $3 \times$ as long as wide, palpostyles rounded.

TentACUlAR BeLt. $2 \times$ as long as first chaetiger, anterior margin not covering posterior eyes. Tentacular cirri smooth, longest pair reaching anterior margin of chaetiger 2 (Fig. 10A).

PharynX. Previously removed, now lost.

PATtern OF PARAPODial Ligules. Anterior chaetigers with dorsal ligules tapered, blunt, median ligules rounded; median and posterior chaetigers with ligules subconical. Ligules with contorted glandular tubules. 
ChAetigers 1-2. With neuraciculae only, with both noto- and neuraciculae thereafter.

ANTERIOR PARAPODIA (Fig. 10B). With dorsal cirrus $1.5 \times$ as long as ventral one, basally inserted (Fig. 10B); dorsal ligule subconical, blunt, as long as median ligule; median ligule triangular, blunt, $2 \times$ as long as neuracicular ligule; prechaetal lobe absent. Neuracicular ligule subconical, $1.5 \times$ as long as ventral ligule; postchaetal lobe subconical, shorter than neuracicular ligule; ventral ligule subconical, $1.5 \times$ as long as ventral cirrus. Notochaetae 15 homogomph spinigers. Supracicular neurochaetae: 14 homogomph spinigers and 5 heterogomph falcigers with blades $5.6 \times$ as long as wide, slightly denticulate, with apical tooth incurved, fused to blade; subacicular neurochaetae: 26 heterogomph spinigers, blades $35 \times$ as long as wide and 8 other heterogomph spinigers with blades $9 \times$ as long as wide, heterogomph falcigers absent.

Median PARAPODIA (Fig. 10C). With dorsal cirrus thin, $3 \times$ as long as ventral ones; dorsal and median ligules subequal, subconical, $1.5 \times$ as long as neuracicular ligule, dorsal one $2 \times$ as wide as medial
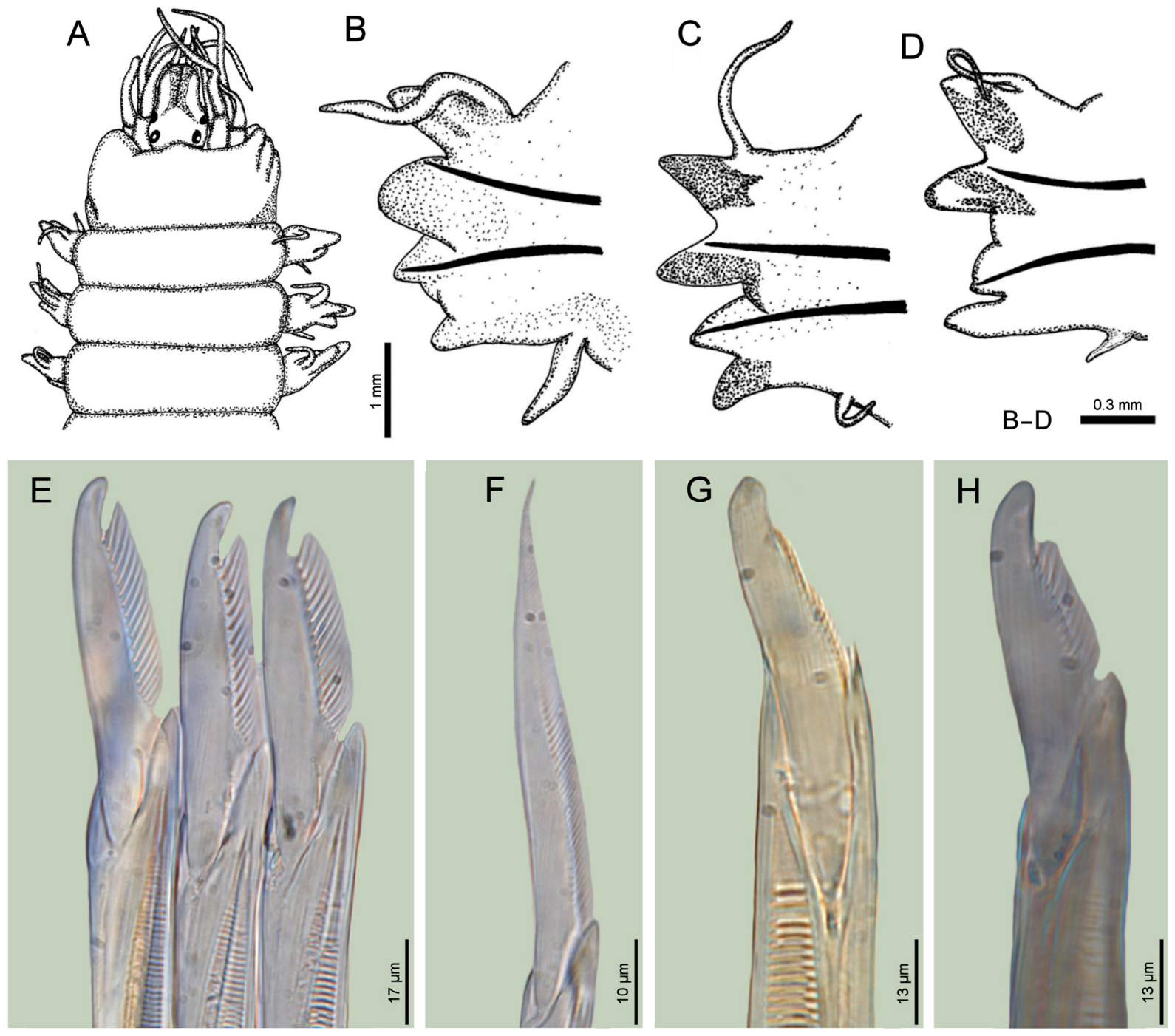

Fig. 10. Nereis riisei Grube \& Örsted in Grube, 1857, holotype (NHMD 109270). A. Anterior end, dorsal view. B. Chaetiger 10, right parapodium, anterior view. C. Chaetiger 40, right parapodium, anterior view. D. Chaetiger 60, right parapodium, anterior view. E. Chaetiger 10, heterogomph falcigers. F. Chaetiger 40, heterogomph spiniger. G. Chaetiger 60, homogomph falciger, tip slightly eroded. H. Chaetiger 60, heterogomph falciger. 
one; prechaetal lobe absent. Neuracicular ligule subconical, as long as ventral ligule; postchaetal lobe subconical, shorter than neuracicular ligule; ventral ligule subconical, $4 \times$ as long as ventral cirrus. Notochaetae: 6 homogomph spinigers and 2 homogomph falcigers with blades $6.5 \times$ as long as wide, teeth minute, distal thin tooth incurved. Supracicular neurochaetae: 14 homogomph spinigers and 2 heterogomph falcigers with blades $6.2 \times$ as long as wide, several long teeth, distal thin tooth incurved; subacicular neurochaetae: 4 heterogomph spinigers and 4 heterogomph falcigers with blades $4 \times$ as long as wide, several long teeth, distal thin tooth incurved.

POSTERIOR PARAPODIA (Fig. 10D). With dorsal cirrus about $2 \times$ as long as ventral one; dorsal and median ligules subconical, subequal, $2 \times$ as long as neuracicular ligule, dorsal one $1.5 \times$ as wide as medial one. Neuracicular ligule subconical; ventral ligule digitiform, $2 \times$ as long as neuracicular ligule, $4 \times$ as long as ventral cirrus. Notochaetae: homogomph spinigers and 2 homogomph falcigers, blades $5.8 \times$ as long as wide, similar in shape to those of median parapodia (Fig. 10G). Supracicular neurochaetae: 5 homogomph spinigers and 2 heterogomph falcigers, blades $5 \times$ as long as wide, both chaetae similar in shape to those of median parapodia (Fig. 10F); subacicular neurochaetae: 3 heterogomph spinigers and 5 heterogomph falcigers, $5.8 \times$ as long as wide, both chaetae resembling those of median parapodia (Fig. 10H).

Posterior Region. Unknown. Pygidium unknown.

\section{Holotype of Nereis glandulata (AMNH 1211)}

The holotype of Nereis glandulata Hoagland, 1919 (Fig. 11A) consists of an anterior fragment $8.5 \mathrm{~mm}$ long, $1.2 \mathrm{~mm}$ wide at chaetiger 10, with 26 chaetigers; a posterior end of a non-nereidid polychaete was found in the same vial. The tentacular belt is projected anteriorly middorsally (Fig. 11B). The pharynx was previously dissected, and is damaged, with the following paragnath formula: I: 1; II:12-14; III: 9; IV: 17; V: 0; VI: 5-5; VII-VIII: ? (5-7 fide Hoagland 1919). Hoagland (1919) described notopodial and supracicular neuropodial heterogomph spinigers, but they were not found in the holotype. First two chaetigers with parapodia only with neuraciculae (Fig. 11C), dorsal and ventral cirri conical, of similar length; ventral ligules blunt conical, with large brownish glands, dorsal ligule more pigmented than ventral one. Anterior chaetigers with noto- and neuraciculae (Fig. 11D); notopodial fascicle with spinigers with blades of varying length; neurochaetae with supracicular and subacicular fascicles with spinigers and heterogomph falcigers (Fig. 11E-F). The size of the eyes and antennae, the length of the tentacular cirri, the paragnath formula, and the shape of both parapodia and chaetae, agree with those of $N$. riisei, so the synonymy proposed by Monro (1933) is maintained.

\section{Atokes}

BoDY. Atoke specimen (ECOSUR P2256) from Venezuela: with body soft, pale (Fig. 12A), subcylindrical, depressed in posterior region; complete, $101 \mathrm{~mm}$ long $(43+58 \mathrm{~mm}), 6 \mathrm{~mm}$ wide, with 187 chaetigers $(66+121)$. Pre-epitokal specimen (UMML 22.1171) from Panama: body pale, muscle being replaced by irregular undifferentiated gonads throughout body (Fig. 13A-B); complete, $65 \mathrm{~mm}$ long, $2.5 \mathrm{~mm}$ wide, with 123 chaetigers.

Prostomium. Slightly longer than wide, dorsal groove present. Eyes black (Fig. 12A-B), larger in preepitoke (Fig. 16A), or reddish, of similar size, anterior eyes oval, directed anteroventrally, about 1/10 of prostomial width, slightly more separated than posterior eyes. Antennae terminal, without gap between them, tips surpassing tips of palpophores, not surpassing palpostyles, half as long as prostomium. Palpophores conical, truncate, $2 \times$ as long as wide; left palpostyle longer than wide, right one as long as wide. 
TENTACULAR BELT. $2 \times$ as long as chaetiger 1 ; anterior margin projected anteriorly middorsally, not covering posterior eyes or nuchal organs. Tentacular cirri regularly corrugated, twisted over anterior end; longest tentacular cirri reach chaetigers 4 or 5 (Figs 12A-B, 13A).

Pharynx. Not exposed, observed by dissection. Jaws brown, with 7-8 teeth. Paragnath formula (ECOSUR P2256): I: 1; II: 16-17 in rows; III: 20; IV: 28-30; V: 0; VI: 8-9; VII-VIII: 3 in a single band. Paragnath formula (UMML 22.1171): I: 4; II: 7-11; III: 9; IV: 10-12 cones; V: 0; VI: 3-3; VII-VIII: 3 in a single band.

PATtern OF PARAPODial Ligules. On first few chaetigers, as well as on medial and posterior ones, with ligules tapered, blunt, about $2 \times$ as long as wide, with massive dark glands, projected beyond ligular bases; anterior chaetigers with ligules massive, shorter, slightly tapered. First chaetigers with ligules granulose or verrucose, in a small area, progressively larger in anterior chaetigers, but missing in medial and posterior chaetigers. Glandular masses leave apical ligular spaces empty in medial and posterior chaetigers.

ChaEtigers 1-2. With neuraciculae only (Figs 12C, 13C), with both noto- and neuraciculae thereafter. Dorsal cirrus longer and slightly wider than ventral one, longer than parapodial ligules. Dorsal ligule about $2 \times$ as long as wide, as long as ventral one, both blunt. Neuracicular ligule slightly longer than wide, projected into a small acicular lobe. Supracicular neurachaetae: 10 homogomph spinigers and 2 heterogomph falcigers with blades spinulose, $6-7 \times$ as long as wide, tips incurved, tendon well defined;
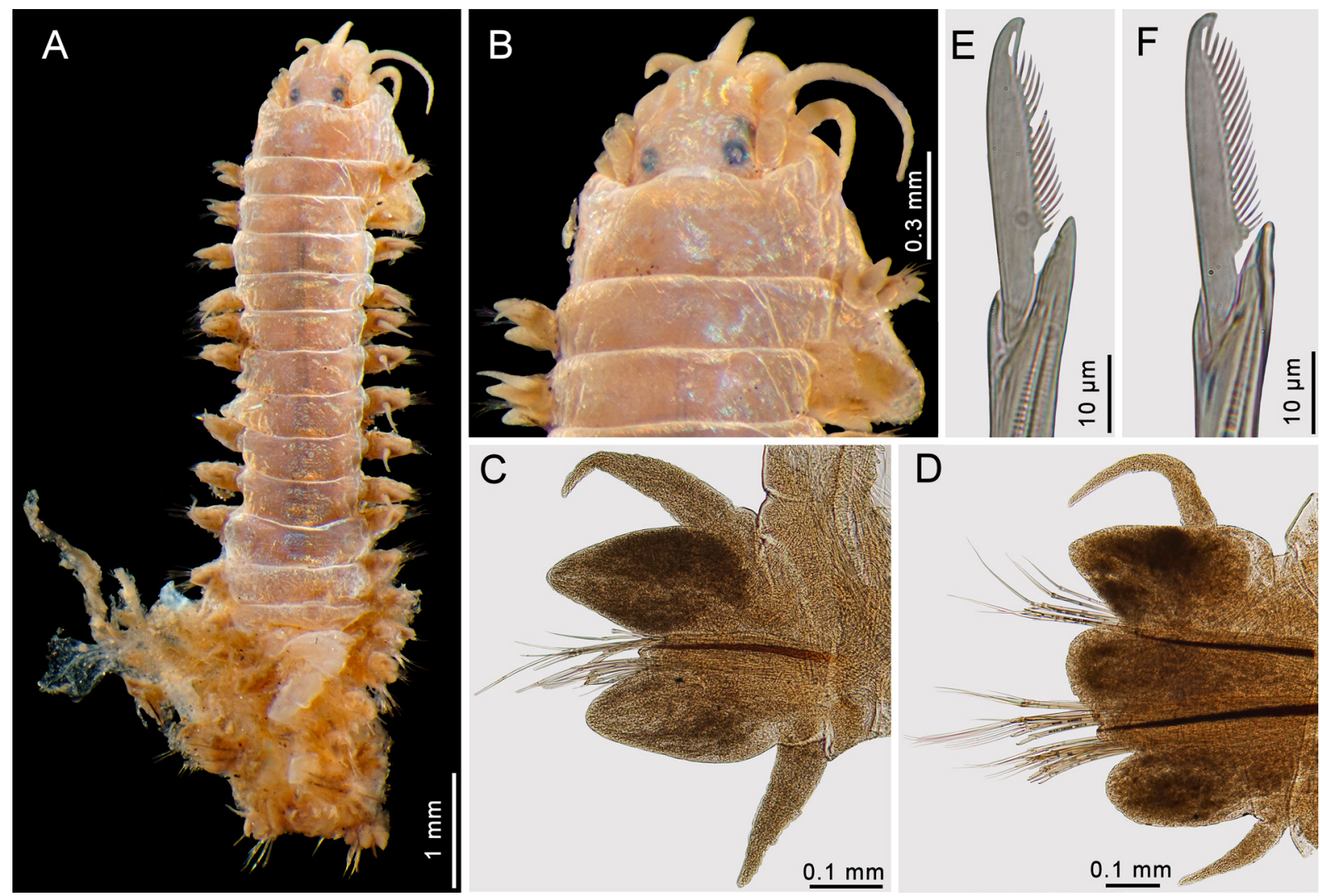

Fig. 11. Nereis riisei Grube \& Örsted in Grube, 1857, holotype of Nereis glandulata Hoagland, 1919 (AMNH 1211). A. Anterior fragment, dorsal view. B. Anterior end, dorsal view. C. Chaetiger 2, right parapodium, anterior view. D. Chaetiger 9, right parapodium, anterior view. E. Same, neuropodial supracicular heterogomph falciger. F. Same, neuropodial subacicular heterogomph falciger. 
subacicular neurochaetae: 8 heterogomph spinigers and 5 heterogomph falcigers with blades spinulose, $8-9 \times$ as long as wide, tips incurved, tendons well defined.

ANTERIOR CHAETIGERs (Figs 12D, 13D). With ligules massive, integument verrucose. Dorsal cirrus tapered, about $2 \times$ as long as ventral one. Dorsal and median ligules subconical, blunt, as long as wide, dorsal one wider. Neuracicular ligule subconical, about $2 \times$ as long as wide, slightly projected into an acicular lobe, as long as postchaetal one; postchaetal lobe digitiform; ventral ligule digitiform, as long as neuracicular one. Notochaetae 9 homogomph spinigers. Supracicular neurochaetae: 10 homogomph spinigers and 4 large heterogomph falcigers with blades spinulose, $3 \times$ as long as wide, tips incurved, tendons well defined; subacicular neurochaetae: 5 heterogomph spinigers and 8 heterogomph falcigers with blades spinulose, $5-6 \times$ as long as wide, tips incurved, tendons well defined.

Posterior CHAETigers (Figs 12E, 13E-F). With dorsal and ventral cirri 5-7× as long as wide, dorsal cirrus $1.5 \times$ as long as dorsal ligule. Dorsal and median ligules digitate to subconical, blunt, slightly longer than wide or $2 \times$ as long as wide; glandular areas not invading central apical regions. Neuracicular ligule subconical, about $2 \times$ as long as wide, with a small acicular lobe, as long as ventral ligule or slightly longer. Notochaetae: 2 homogomph spinigers and 1 homogomph falciger with blade spinulose, $3 \times$ as long as wide, tip incurved, tendon well defined. Supracicular neurochaetae: 12 homogomph spinigers
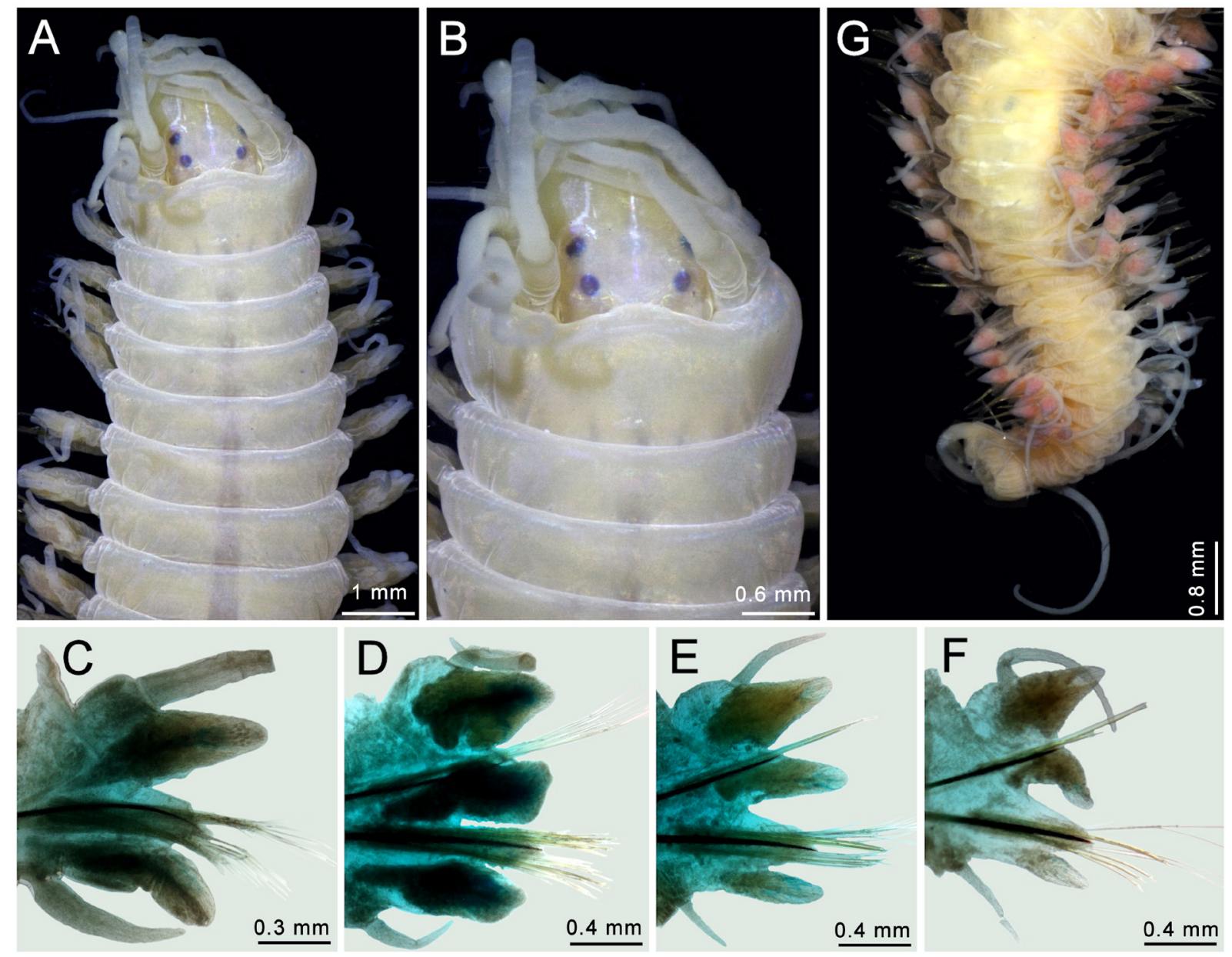

Fig. 12. Nereis riisei Grube \& Örsted in Grube, 1857, non-type specimen (ECOSUR P2256). A. Anterior region, dorsal view. B. Anterior end, dorsal view. C. Chaetiger 2, left parapodium, anterior view. D. Chaetiger 30, left parapodium, anterior view. E. Chaetiger 90, left parapodium, anterior view. F. Chaetiger 168, left parapodium, anterior view. G. Posterior region, dorsal view, after Shirlastain-A staining. 
(Fig. 13I) and 2 large heterogomph falcigers with blades spinulose, $2 \times$ as long as wide, tips incurved, tendons well defined (Fig. 13K); subacicular neurochaetae: 4 homogomph spinigers (Fig. 12J) and 4 heterogomph falcigers with blades spinulose, $3-4 \times$ as long as wide, tips incurved, tendons well defined.

Subterminal Chaetigers. With dorsal cirrus $2 \times$ as long as dorsal ligules (Figs 12F, 13G). Dorsal ligule subconical, tapered, slightly longer than wide, as long as digititiform ventral ligule; central apical regions without glands. Neuracicular ligule subconical, tapered, slightly longer than wide; postchaetal lobe absent; ventral ligule digitate, basally swollen, glands barely visible, $1.5 \times$ as long as neuracicular ligule. Notochaetae: 1 homogomph spiniger and 2 homogomph falcigers with blades spinulose, $3 \times$ as long as wide, tips incurved, tendon well developed. Supracicular neurochaetae: 2 homogomph spinigers
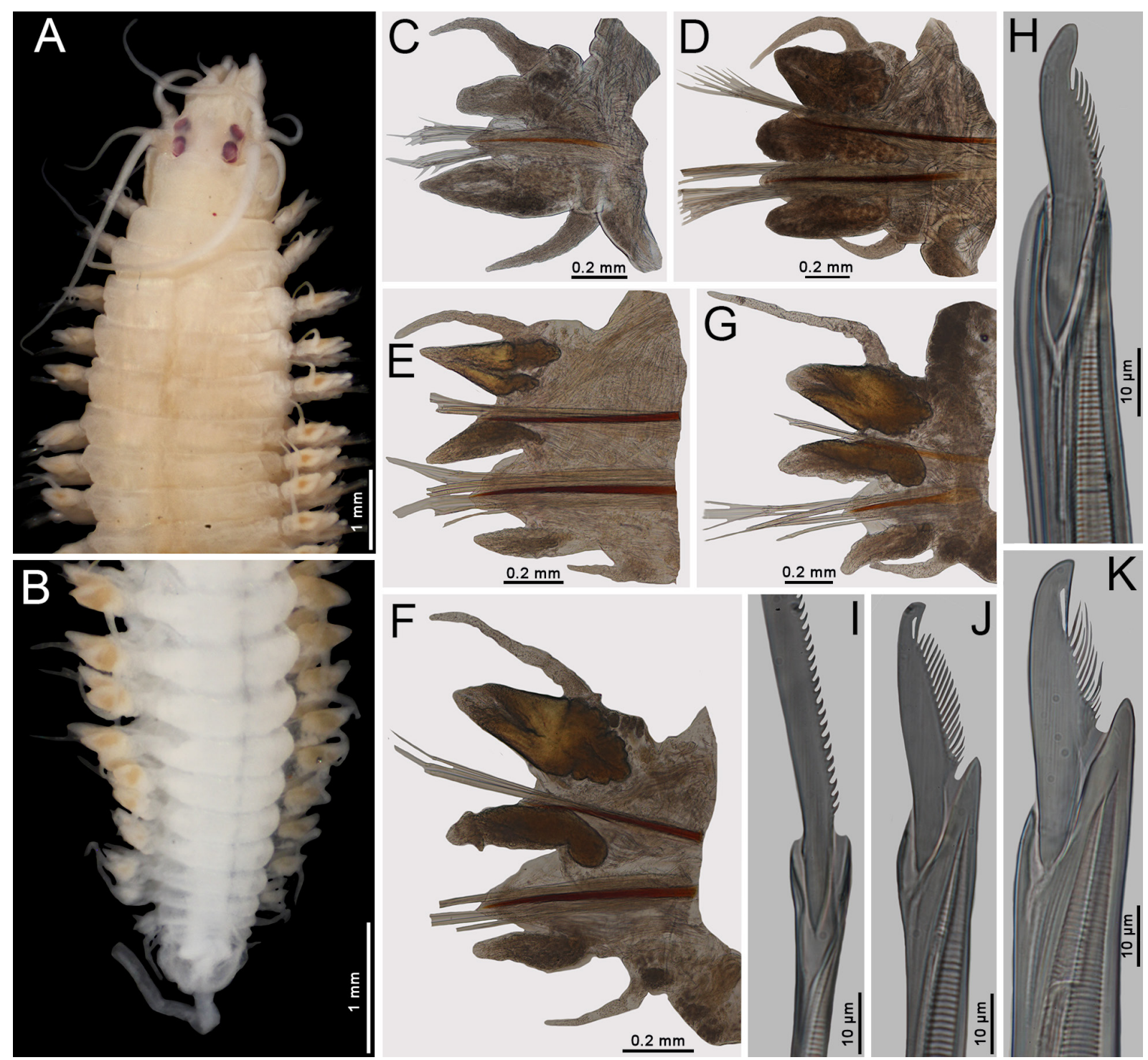

Fig. 13. Nereis riisei Grube \& Örsted in Grube, 1857, non-type, pre-epitokal specimen (UMML 22.1171). A. Anterior region, dorsal view. B. Posterior end, dorsal view. C. Chaetiger 1, right parapodium, anterior view. D. Chaetiger 11, right parapodium, anterior view. E. Chaetiger 49, right parapodium, anterior view. F. Chaetiger 88, right parapodium, anterior view. G. Chaetiger 113, right parapodium, anterior view. H. Chaetiger 88, notopodial homogomph falciger. I. Same, neuropodial supracicular homogomph spiniger. J. Same, neuropodial subacicular heterogomph falciger. K. Same, neuropodial supracicular heterogomph falciger. 
and 1 large heterogomph falciger with blade spinulose, about $2 \times$ as long as wide, tip incurved, tendon well developed; subacicular neurochaetae: 2 homogomph spinigers and 3 heterogomph falcigers with blades spinulose, about $2 \times$ as long as wide, tips incurved, tendons well defined.

Posterior REgION. Tapered into a blunt cone (Figs 12G, 13B). Pygidium truncate, anus terminal, anal cirri as long as last 12 chaetigers.

VARIATION. Some specimens from Quintana Roo, Mexico show some variatons in their paragnath formula and a tendency for it to change with body size. I: 1-4 (increasing with size); II: 12-24 (more or less stable); III: 20-36 (decreasing with size); IV: 33-40 (more or less stable); V: 0 (unchanged); VI: 4-18 (decreasing with size); VII-VIII: 3-7 in a row (decreasing with size).

\section{Remarks}

Salazar-Vallejo \& Eibye-Jacobsen (2012) incorrectly indicated Puntarenas, Costa Rica (Pacific Ocean) as the type locality of Nereis riisei. Rather, St Croix is the correct type locality as indicated both in the description (Grube 1857: 163) and the index for the series (Grube 1858: 119). The label in the holotype material deposited in NHMD indicates that the type locality is St Croix and the collector was Kröyer (Danny Eibye-Jacobsen, pers. comm.).

Although it is a relatively easy species to identify, Nereis riisei has a largely confused taxonomic history and has been widely reported for both coasts of America in temperate to tropical waters. It is likely that the confusion regarding the type locality has given this species its current amphiamerican status. The first amphiamerican report was made by Monro (1933), synonymizing several species with $N$. riisei, and Hartman followed this conclusion in subsequent papers (Hartman 1938, 1940, 1944, 1954). This decision has been widely followed, except for some species such as N. glandulata Hoagland, 1919 (e.g., Treadwell 1924, 1928). We disagree and regard N. ambigua Treadwell, 1937 as a distinct species (see below).

Day (1973) and Gardiner (1976) recorded Nereis (Nereis) riisei from North Carolina, but their specimens differ from Caribbean ones by having tentacular cirri reaching chaetiger 6, ventral ligules as long as neuracicular ligules in posterior chaetigers, and notopodial homogomph falcigers with longer blades. Furthermore, Day (1973) described the dorsal cirri of anterior parapodia as being $3 \times$ as long as dorsal ligules and the dorsal ligules as half as long as median ones, subconical instead of rounded.

On the other hand, $N$. riisei resembles $N$. ambigua Treadwell, 1937 by having the posterior eyes completely exposed and pharyngeal areas VII-VIII with a single row of paragnaths (the latter characterized in Dean 2001). These two species differ because in $N$. riisei the ventral ligules in median and posterior parapodia surpass the neuracicular ligules, and fresh specimens have a blackish tentacular belt, whereas in $N$. ambigua the ventral ligules reach the neuracicular ligule tips in median and posterior parapodia, and fresh specimens have a pale tentacular belt. However, these differences must be taken as preliminary pending the collection of topotype specimens of $N$. ambigua and confirming these diagnostic features.

Nereis (Nereis) puncturata Grube \& Örsted in Grube, 1857 was described based on specimens from two distinct localities. Salazar-Vallejo \& Eibye-Jacobsen (2012) located the type material in two museums: a specimen from St Croix is deposited in the Natural History Museum of Denmark (NHMD), while specimens from Valparaiso are deposited in the Zoological Museum, Berlin (ZMB 4040). Grube did not include type localities in the descriptions. but included them for the index to species (Grube 1858). One syntype of $N$. puncturata (NHMD 109269, previously ZMUC POL-1486) was studied and within it a label by Kröyer was found indicating that this species is similar to N. riisei; the syntype is in poor condition, the body being crystallized, but morphological characters could be observed that place it 
closer to Platynereis dumerilii (Audouin \& Milne Edwards, 1833). The species requires the proposition of lectotypes to separate the Atlantic from the Pacific forms.

The syntypes of Nereis albipes (ZMB Q3441) are similar to N. riisei, and they are herein regarded as snynonyms. This southern Brazilian species has the same pattern of black glandular spots in the parapodial ligules; however, a slight variation is observed in the paragnath formula: I: 1; II: 11- 20 in two rows; III: 11-23 in oval group; IV: 18-28 in a crescent-shaped patch; V: 0; VI: 4-10 in a rounded patch; VII-VIII: 5 in a single band. Incidentally, this species name was indicated, on the same page (Grube 1874: 60), as "N. albipes Gr." and 20 lines below as "albipes Gr. Müll." We are following the latter because Fritz Müller provided some identifications to the specimens sent to Grube.

Other species have been referred to as synonyms of $N$. riisei, but the material needed to corroborate their status were not examined. These species deserve to be studied in further detail to clarify their affinities, but that is beyond our objectives for this contribution. The species are the following ones (in chronological order):

Heteronereis fasciata Schmarda, 1861. Schmarda (1861) described this species based on epitokes from Jamaica, preventing an adequate comparison with atoke specimens of N. riisei. Augener (1925) revised the type material and based upon the paragnaths on pharyngeal areas VII-VIII and the chaetae, he concluded that it was identical to $N$. riisei. Diagnostic features include jaws with five teeth, areas VIIVIII with few paragnaths in one band, neuropodial heterogomph falcigers with short blades and natatory region starting at chaetiger 22-23. Several specimens of this species (with labels V900 and V901), supposed to be the type material observed by Augener, are deposited at the Natural History Museum in Vienna (H. Sattmann, pers. comm.).

Nereis nigripes Ehlers, 1868. Ehlers (1868) described this species based on specimens from Haiti and Florida. Augener (1925) regarded N. nigripes as identical to N. riisei, and Monro (1933) synonymized it with $N$. riisei without further explanation. Hartman (1938), based on Monro's decision, synonymized this species and N. bicruciata Augener, 1906 (see below) with N. riisei. The database of the Museum of Comparative Zoology (Harvard University, Cambridge, MA) indicates they have the specimen from Haiti (ANNa-54). Ehlers (1868) detailed the following paragnath formula: I: irregular patch; II: arc patch; III: transverse patch; IV: arc patch; V: 0; VI: 8-13; VII-VIII: 5. Based on the original description, $N$. nigripes differs from $N$. riisei by having the antennae as long as the prostomium, tentacular cirri reaching chaetiger 9 and dorsal ligules longer than median ones in posterior chaetigers.

Nereis (Lycoris) trifasciata Grube, 1878. Grube (1878) described this species from Bohol, Philippines. He provided the following paragnath formula: I: 0; II: 11 in two rows; III: 8 in two rows; IV: 15 in two rows; V: 0 or 1; VI: 5-6; VII-VIII: a single band. The original description is succinct and prevents any further comparison between $N$. trifasciata and N. riisei. Monro (1933) regarded this species as a synonym of $N$. riisei without further explanation, but this conclusion must be evaluated based upon topotype specimens because of the different type localities for these species. The species was transferred to Neanthes Kinberg, 1865 by Villalobos-Guerrero \& Idris (2021).

Nereis lata Hansen, 1882. Hansen (1882) described this species based on one specimen from Rio de Janeiro, Brazil. Augener (1934) concluded that this species must be regarded as a synonym of $N$. riisei because of the presence of ligules with dark glands in middle and posterior chaetigers and the presence in pharyngeal areas VII-VIII of 4 paragnaths in a single band. The original description and Augener's redescription were very short, preventing further comparisons with $N$. riisei. Records of Nereis sp. by Nonato \& Luna (1970) and of $N$. riisei by Santos \& Lana (2003) might belong to N. lata if they are shown to be different from $N$. riisei. 
Nereis scolopendroides Hansen, 1882. This species was also described based on specimens from Rio de Janeiro (Hansen 1882). According to Augener (1934), the type material contains two species, one of them very similar to $N$. lata and therefore, in his opinion, probably conspecific with $N$. riisei. Augener (1934) detailed the following paragnaths in the oral pharyngeal ring: V: 0; VI: 11-15; VII-VIII: 4 in a single band. Based on the original description, $N$. scolopendroides differs from $N$. riisei by having shorter antennae, dorsal and median ligules shorter than neuracicular ligules and heterogomph falcigers with shorter blades.

Nereis unifasciata Willey, 1905. Willey (1905) described this species from Sri Lanka (formerly Ceylon) and provided the following paragnath formula: I-IV: unknown; V: 0; VI: small patch; VII-VIII: a single band. Fauvel (1919) thought that this species differed from $N$. trifasciata only in its pigmentation. Monro (1933) regarded N. unifasciata as a synonym of $N$. riisei without further explanation. Based on the original description, $N$. unifasciata differs from $N$. riisei by having tentacular cirri reaching chaetiger 7 and lacking notopodial homogomph falcigers. This explains why Day (1967: 318) regarded it as belonging in Neanthes. Pamungkas \& Glasby (2015) provided an account of this species.

Nereis bicruciata Augener, 1906 species inquirenda. Augener (1906) described this species based on an incomplete specimen from St Croix, Virgin Islands, dredged from sediments at a depth of $210 \mathrm{~m}$. Hartman (1938) examined the type specimen and determined that $N$. bicruciata and N. nigripes Ehlers, 1868 were synonyms of $N$. riisei, although she identified some differences in jaw dentition and paragnath numbers. The type material was supposedly deposited in the Museum of Comparative Zoology, Harvard University (MCZ ANNc-2277) but has been lost since 1983, requiring the proposal of a neotype. Augener (1906) detailed the following paragnath formula: 1: 1; II: several rows; III: 7; IV: triangular patch; V: 0; VI: 4-5; VII-VIII: 3 in a single band. Based on the original description, N. bicruciata differs from $N$. riisei by having tentacular cirri reaching chaetigers $10-11$ and fewer paragnaths in pharyngeal area III.

Nereis decora Treadwell, 1932. Hartman (1938: 14; 1956: 255) synonymized this species from Ilha de São Sebastião, Brazil, with N. riisei, but made no comments about this decision. Treadwell (1932) detailed the following paragnath formula: I: 1; II: about 15 in two rows; III: oblong patch; IV: oval patch smaller than in III; V: 0; VI: 6-8; VII-VIII: 4-5 in a single band. Based on the original description, $N$. decora differs from $N$. riisei mainly by having antennae as long as the prostomium and tentacular cirri reaching chaetiger 7 , while the parapodia are very similar in both species.

Neanthes varia Treadwell, 1941 (replacement name for Nereis (Neanthes) paucidentata Treadwell, 1939). Hartman (1956) synonymized this species with $N$. riisei, notwithstanding the fact that she detailed clear differences between them, such as the presence in $N$. varia of paragnaths in area $\mathrm{V}$, a single paragnath in areas VI and two rows of paragnaths in areas VII-VIII. Moreover, in the middle parapodia of $N$. varia, the dorsal cirri are half as long as the dorsal ligules, and the dorsal ligules are $2 \times$ as long as the median ligules; in $N$. riisei, the dorsal cirri are longer than the dorsal ligules, and the dorsal and median ligules are subequal. Finally, notopodial homogomph falcigers were not noticed for N. varia. All these mentioned features are enough to separate it from $N$. riisei.

\section{Distribution}

Western Atlantic from North Carolina (USA) to Florianópolis (Desterro), Brazil.

Nereis lunulata Ehlers, 1901 stat. nov.

Figs 14-15

Nereis pelagica var. lunulata Ehlers, 1901a: 259 (nomen nudum). 
Nereis pelagica var. lunulata - Ehlers 1901b: 103-104, pl. 12 figs 12-17. — Wesenberg-Lund 1962: 77 (records by Ehlers).

Nereis pelagica lunulata - Hartmann-Schröder 1962: 407 (key). — Hartman 1964: 101, pl. 31 fig. 1 (image from Ehlers 1901b).

Nereis falsa - Fauvel 1941: 279. — Wesenberg-Lund 1962: 77 (records by Fauvel; both non de Quatrefages, 1866).

\section{Diagnosis}

Nereis with posterior eyes completely exposed; tentacular belt $1.5 \times$ as long as first chaetiger; tentacular cirri short, reaching chaetigers 4-5; jaws with 6-7 teeth; pharyngeal area II with 16 paragnaths in oblique rows, areas VII-VIII with 46 paragnaths in 3 transverse rows; anterior chaetigers with notopodial ligules digitate, longer than wide; ventral ligules in median and posterior chaetigers reaching tip of neuracicular ligules.

\section{Material examined}

Syntype

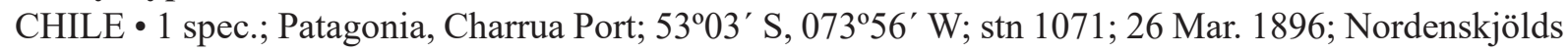
Expedition till Eldslandet och Patagonien 1895-96 leg.; rocky shore, low tide; SMNH Type 513.

\section{Other material}

CHILE - 2 specs (both complete, regenerating posterior end); Punta Arenas, "No. 25, T 59"; 5310' S, $70^{\circ} 56^{\prime}$ W; M. Lebrun leg.; MNHN 83-T52.

\section{Description}

\section{Syntype}

BoDy. Complete, $26 \mathrm{~mm}$ long, $1.5 \mathrm{~mm}$ wide including parapodia, with 70 chaetigers. Dorsum pale brown, anterior chaetigers with two semicircular lateral spots per segment, remaining segments pale. Prostomium with brown pigmentation laterally, close to palps.

Prostomium. Longer than wide, subpyriform, dorsal groove present. Eyes black, in trapezoidal arrangement, anterior eyes slightly longer than posterior ones. Antennae half as long as prostomium, not reaching tips of palpostyles, with a small gap between them. Palpophores globose, $2 \times$ as long as wide, palpostyles rounded (Fig. 14A).

TENTACULAR BELT. $1.5 \times$ as long as first chaetiger, anterior margin not covering posterior eyes. Tentacular cirri smooth, longest pair reaching anterior margin of chaetiger 5 (Fig. 14A).

Pharynx. Not everted, observed by dissection. Jaws brown with 6-7 teeth. Paragnath formula: I: 2 in tandem; II: 16 in 3 oblique rows; III: 36 in oval group; IV: 20 in a crescent-shaped group; V: 0; VI: 4-4 in diamond; VII-VIII: 46 in three bands, basal band with larger paragnaths.

PATTERN OF PARAPODIAL LIGULES. Anterior and median chaetigers with ligules massive, blunt, round, slightly longer than wide, posterior chaetigers with ligules conical, blunt, as long as wide, or slightly longer than wide in posterior chaetigers; ventral ligule reaching tip of neuracicular ligules.

Chaetigers 1-2. With neuraciculae only, with both noto- and neuraciculae thereafter.

ANTERIOR PARAPODIA (Fig. 14B). With dorsal cirrus inserted medially, longer than ventral ones, dorsal cirrus about $3 \times$ as long as dorsal ligule. Dorsal and median ligules subequal; dorsal one subconical, blunt, median ligule rounded. Neuracicular and ventral ligules subequal; neuracicular one subconical, ventral one digitiform, longer than ventral cirrus. Notochaetae 6 homogomph spinigers. Supracicular neurochaetae: 6 homogomph spinigers and 2 heterogomph falcigers, blades $6 \times$ as long as wide; 
subacicular neurochaetae: 2 heterogomph spinigers and 5 heterogomph falcigers, blades $6 \times$ as long as wide.

MEDIAN PARAPODIA (Fig. 14C). With dorsal cirrus inserted medially, longer than ventral one, dorsal cirrus $2.8 \times$ as long as dorsal ligule. Dorsal and median ligules subequal, subconical, $1.5 \times$ as long as

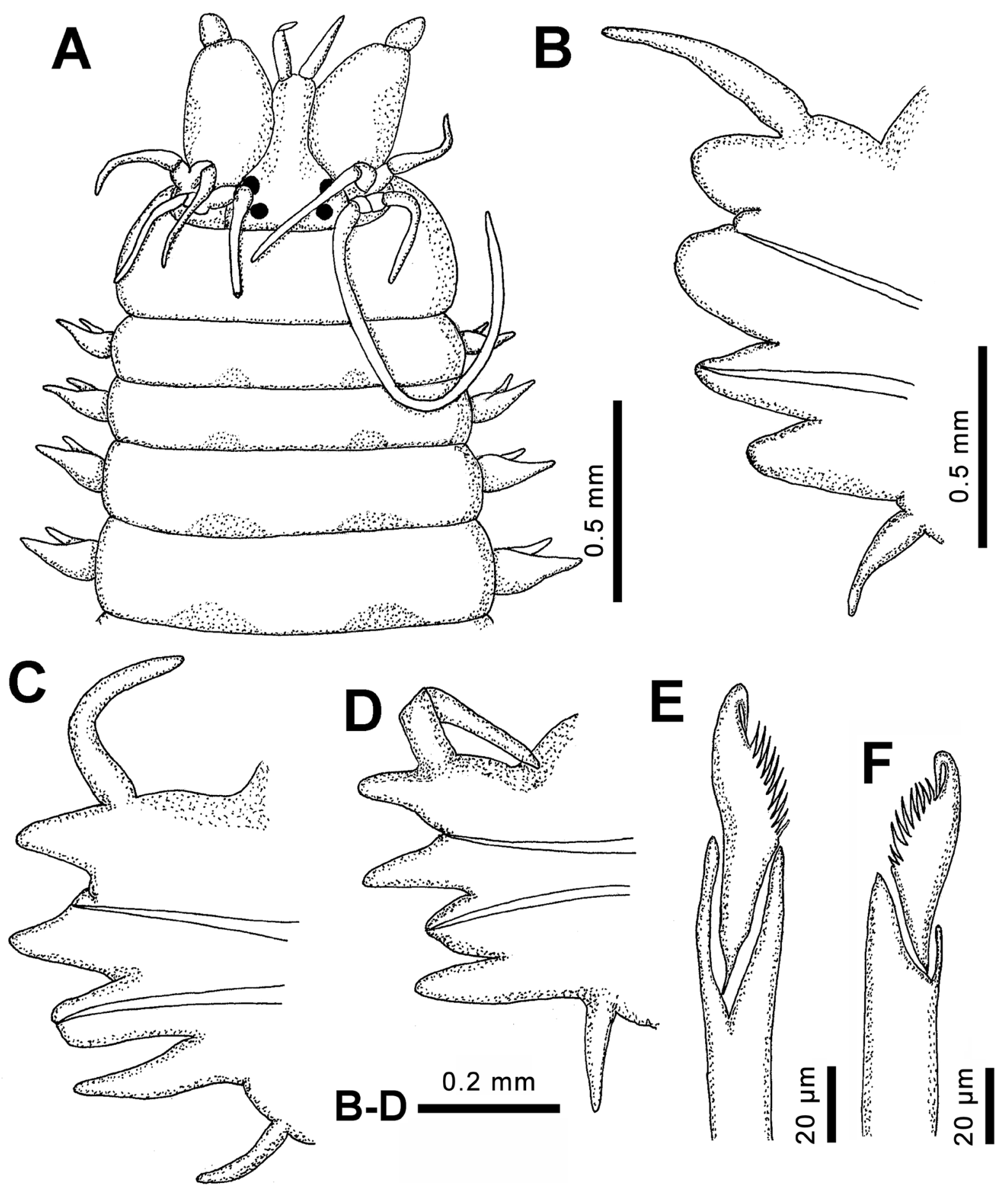

Fig. 14. Nereis lunulata Ehlers, 1901 stat. nov., syntype (SMNH Type 513). A. Anterior region, dorsal view. B. Chaetiger 11, right parapodium, anterior view. C. Chaetiger 30, right parapodium, anterior view. D. Chaetiger 52, right parapodium, posterior view. E. Chaetiger 30, notopodial homogomph falciger. F. Same, neuropodial heterogomph falciger of infracicular fascicle. 
neuracicular ligule. Neuracicular ligule digitiform, slightly longer than ventral ligule; ventral ligule digitiform, longer than ventral cirrus. Notochaetae: 2 homogomph spinigers and 1 homogomph falciger with blade $5.6 \times$ as long as wide, distal tooth incurved and fused to blade, heavily serrated (Fig. 14E). Supracicular neurochaetae: 5 heterogomph spinigers and 1 heterogomph falciger, blades $2 \times$ as long as wide, inner edge spinulose, distal tooth incurved, fused to blade (Fig. 5F); subacicular neurochaetae: 2 heterogomph falcigers with blades barely $2 \times$ as long as wide, distal tooth incurved, fused to blade.

Posterior PARAPODIA (Fig. 14D). With dorsal cirrus inserted medially, $2.5 \times$ as long as ventral one, about $3 \times$ as long as dorsal ligule. Dorsal ligule subconical, slightly longer than median ligule; median ligule subconical, $2 \times$ as long as neuracicular ligule. Neuracicular ligule subconical; ventral ligule digitiform, clearly longer than neuracicular ligule, $2 \times$ as long as ventral cirrus. Notochaetae: 3 homogomph spinigers and 1 homogomph falciger, similar to those of middle parapodia. Supracicular neurochaetae: 5 heterogomph spinigers and 1 heterogomph falciger, similar to those of middle parapodia; subacicular neurochaetae: 1 heterogomph spinigers and 3 heterogomph falcigers, similar to those of median chaetigers (Fig. 14E).

Posterior REgION. Tapered. Pygidium with anus terminal; anal cirri as long as last 5 chaetigers.

\section{Non-type specimens}

BoDy. Specimens complete (MNHN 83-T52), damaged, slightly macerated (soft, fluffy), integument separated on cephalic appendages (Fig. 15A), most chaetae broken or softened. Body 24-26 mm long, 1.8-2.0 mm wide, with 65-80 chaetigers. Body pale, almost colorless, subcylindrical along anterior and medial body thirds, slightly depressed along posterior third.

Prostomium. $2 \times$ as long as wide, dorsal groove present. Eyes blackish, of similar size, anterior ones oval, directed anteroventrally, diameter $1 / 6-1 / 7$ of prostomial width, slightly more separated than posterior eyes (Fig. 6B). Antennae half as long as prostomium, without gap between them, tips reaching palpostyle tips. Palpophores $2 \times$ as long as wide; palpostyles longer than wide (left) or rounded (right).

TENTACUlAR BeLt. $2 \times$ as long as first chaetiger; anterior margin projected anteriorly (less pronounced in smaller specimen), with an unpigmented irregular area along its right side. Tentacular cirri smooth, integument detached along almost all their length, longest ones reaching chaetigers 3-4.

Pharynx. Not everted, observed by dissection of largest specimen. Jaws with 7 denticles. Paragnath formula: I: 1; II: 17-18; III: about 36 in oval group; IV: 26-28 in oval groups; V: 0; VI: 4 in diamond; VII-VIII: $2-3$ rows in of small and large paragnaths in two bands.

PATTERN OF PARAPODIAL LIGUles. Anterior and median chaetigers with ligules blunt, slightly longer than wide, becoming blunt triangular, slightly longer than wide in posterior chaetigers. Ventral ligules as long as neuracicular ligules, tapered.

ChaEtigers 1-2. With neuraciculae only (Fig. 15D); with both noto- and neuraciculae thereafter. Dorsal cirrus slightly longer and about as wide as ventral cirrus, $1.5 \times$ as long as dorsal and ventral ligules. Dorsal ligule wider, as long as ventral one, $2 \times$ as long as neuracicular ligule. Neuracicular ligule subconical, blunt. Supracicular neurochaetae: 4 homogomph spinigers and 3 heterogomph falcigers, blades spinulose, $6 \times$ as long as wide, tips incurved; subacicular neurochaetae: 12 heterogomph chaetae (only 2 spiniger and 1 twisted falciger blade remaining).

MEDiAn PARAPODIA (Fig. 15E). With dorsal cirrus $1.5 \times$ as long as dorsal ligule, slightly longer and wider than ventral cirri, both with sessile ciliates. Dorsal ligules $1.5 \times$ as wide as long, blunt; median ligule rounded, slightly longer than neuracicular ligule, glandular areas unpigmented, extended along ligular bases. Neuracicular ligule digitiform, $2 \times$ as long as wide, slightly longer than ventral ligule; ventral 
ligule digitiform, $3 \times$ as long as wide, longer than ventral cirrus. Notochaetae 8 homogomph spinigers, without falcigers. Supracicular neurochaetae: 5 homogomph spinigers and 3 heterogomph falcigers with blades spinulose, $2-3 \times$ as long as wide, distal tooth incurved, fused to blade; subacicular neurochaetae: 3 heterogomph spinigers and 7 heterogomph falcigers with blades spinulose, $2-3 \times$ as long as wide, distal tooth incurved, fused to blade.

Posterior REGION (Fig. 15F). With dorsal and ventral cirri $6-8 \times$ as long as wide, dorsal cirrus $1.2 \times$ as long as dorsal ligule, often with several sessile ciliates transforming their appearance into medially swollen, ventral cirrus shorter than ventral ligule, some with sessile ciliates (Fig. 15F, inset). Dorsal and median ligules subconical to digitate, about as long as wide, $1.5 \times$ as long as neuracicular ligule, glandular areas unpigmented, extended along ligular bases; dorsal one slightly wider than long, median one slightly longer than wide. Neuracicular ligule subconical, blunt, as long as wide, as long as ventral ligule; ventral ligule digitiform, slightly longer than wide. Notochaetae 6 homogomph spinigers, falcigers absent. Supracicular neurochaetae: 2 homogomph spinigers and 2 heterogomph falcigers,
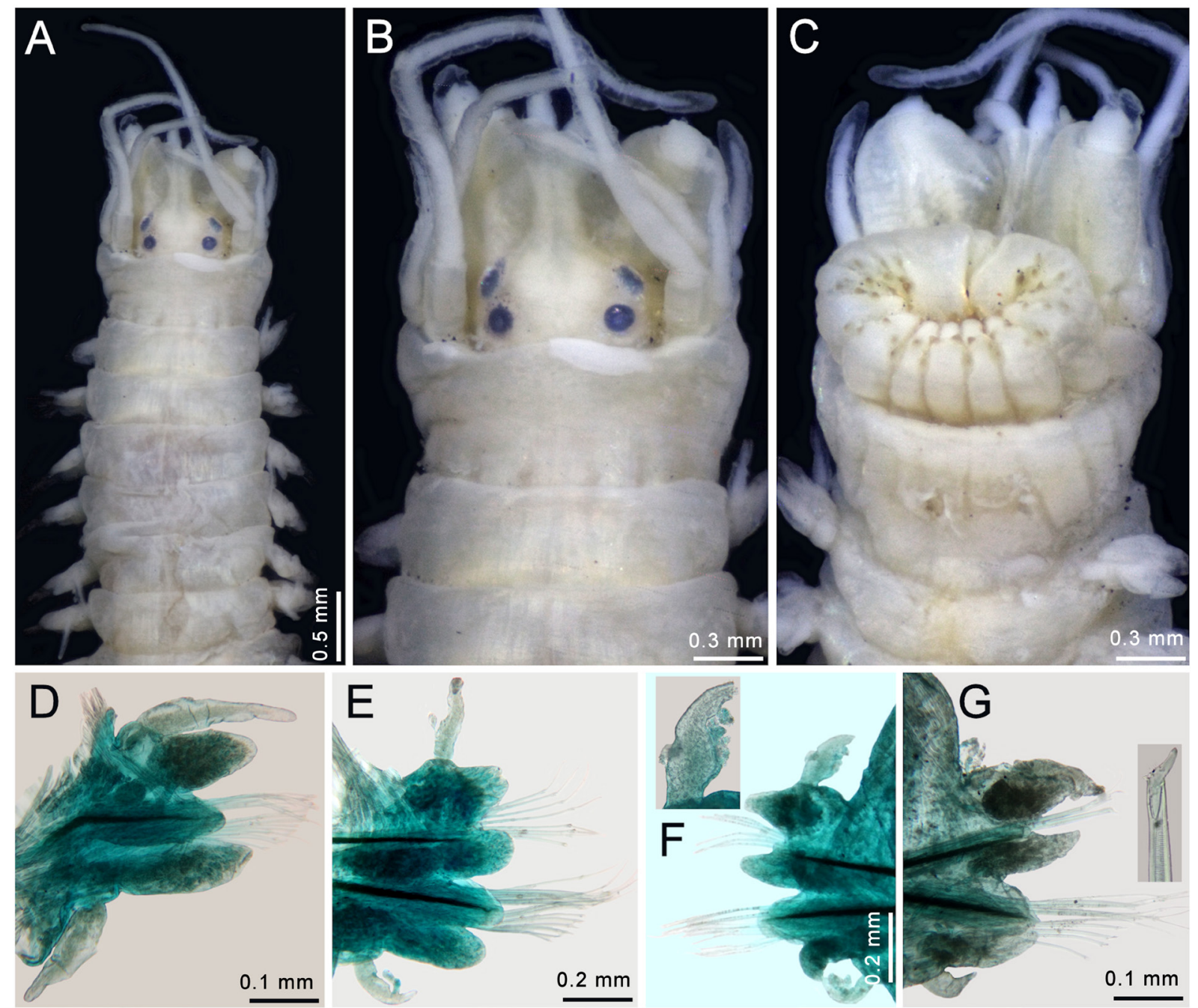

Fig. 15. Nereis lunulata Ehlers, 1901 stat. nov., non-type specimen (MNHN 83-T52). A. Anterior region, dorsal view. B. Anterior end, dorsal view. C. Anterior end, ventral view. D. Chaetiger 2, left parapodim, anterior view. E. Chaetiger 14, left parapodium, anterior view. F. Chaetiger 30, left parapodium, posterior view (inset: close-up of dorsal cirrus). G. Chaetiger 56, left parapodium, anterior view (inset: homogomph falciger). 
blades missing; subacicular neurochaetae: 2 heterogomph spinigers and 8 heterogomph falcigers with blades spinulose, $3 \times$ as long as wide, distal tooth incurved, fused to blade.

SubTERMinAl CHAETigers (Fig. 15G). With dorsal cirrus slightly longer than dorsal ligule, about $2 \times$ as long as ventral cirrus. Dorsal ligule subconical, tapered, slightly longer than wide, $1.5 \times$ as long as median ligule; median ligule subconical, $1.5 \times$ as long as wide, $2 \times$ as long as neuracicular ligule. Neuracicular ligule subconical, about as wide as long, as long as ventral ligule; ventral ligule digitiform, slightly longer than wide, $3 \times$ as long as ventral cirrus. Notochaetae: 3 homogomph spinigers and 1 homogomph falciger with blade distorted, bent dorsally, spinulose, distal tooth incurved, tendon visible (Fig. 15G, inset). Supracicular neurochaetae: 4 homogomph spinigers and 6 heterogomph falcigers with blades spinulose, $1-2 \times$ as long as wide, distal tooth barely incurved, tendon visible. Subacicular neurochaetae: 2 homogomph spinigers and 4 heterogomph falcigers with blades spinose, $2 \times$ as long as wide, distal tooth incurved, tendon not seen.

Posterior Region. Tapered into a blunt cone. Pygidium regenerating, almost completed in smallest specimen, anus terminal, anal cirri as long as last 5-6 chaetigers.

\section{Remarks}

Nereis pelagica lunulata Ehlers, 1901 differs from the stem species, N. pelagica Linnaeus, 1758 as defined by Chambers \& Garwood (1992: 16, figs 17-18), because its ventral ligules are tapered in posterior chaetigers, instead of being blunt, lobate, and because its notopodial homogomph falcigers are spinulose, with a barely defined tendon, as opposed to dentate or smooth in N. pelagica. Consequently, it is herein elevated in rank from subspecies to species.

As indicated in the key below, because of the presence of 2-3 transverse rows of paragnaths in pharyngeal areas VII-VIII, and by having digitate notopodial ligules in anterior chaetigers, $N$. lunulata stat. nov. resembles N. splendida Grube, 1840, from the Mediterranean Sea, and "N. falsa" sensu Liñero-Arana \& Reyes-Vásquez (1979), from the southeastern Caribbean. These three species differ by the relative size of ventral ligules and by the number of paragnaths in pharyngeal area II. In N. lunulata stat. nov., ventral ligules are as long as neuracicular ligules, and area II has 16 paragnaths, whereas $N$. splendida and " $N$. falsa" have ventral ligules longer than neuracicular ligules, and there are 22 paragnaths in area II in the former, and about 30 in the latter.

It is worth noting that the presence of some unidentified, solitary peritrich ciliates on the parapodial cirri modifies their appearance, making them look wider, and the surface also becomes more irregular, i.e., it is not as smooth as in other similar species.

\section{Distribution}

Souhern Chile, from Punta Arenas to Tierra del Fuego, in shallow water.

Nereis lucipeta Ehlers, 1908 reinstated

Fig. 16

Nereis lucipeta Ehlers, 1908: 69-71, pl. 8 figs 7-13.

Nereis splendida - Ehlers 1913: 496 (non Grube, 1840).

Nereis falsa - Fauvel 1919: 398 (non de Quatrefages, 1866).

Nereis lucipeta - Hartman 1959: 262 (synonymy).

Nereis (Nereis) falsa - Day 1967: 317, fig. 14.7k-o (non de Quatrefages, 1866). 


\section{Diagnosis}

Nereis with posterior eyes completely exposed; tentacular belt $2 \times$ as long as first chaetiger; tentacular cirri short, reaching chaetiger 3; jaws with 7 denticles; pharyngeal area II with 18-20 paragnaths in crescent-shaped group, areas VII-VIII with 30-46 paragnaths in 2-3 transverse rows; anterior chaetigers with notopodial ligules short, globose; ventral ligules in median and posterior chaetigers markedly longer than neuracicular ligules.

\section{Material examined}

\section{Syntypes}

ANGOLA • many syntypes (fide Hartwich 1993: 114); Big-Fish Bay; ZMB Verm. $4440 \bullet 2$ syntypes; same collection data as for preceding; ZMF $1660 \bullet 2$ syntypes; University of Marburg (fide Fiege \& Wehe 2004). Not seen.

\section{Other material}

MADAGASCAR • 4 specs; “Tuléar” [Toliara]; stn 52; 1906; Mission F. Geay leg.; MNHN 83-52.

\section{Description (MNHN 83-52)}

BoDy. Atoke specimens; two complete, and two anterior fragments; complete specimens 18-29 mm long, 0.9-1.4 mm wide, with 64-72 chaetigers; anterior fragments 6-18 mm long, 1.2-2.0 mm wide, with 18-30 chaetigers (largest one broken in two pieces). Body pale, subcylindrical, depressed along posterior region.

Prostomium. Slightly longer than wide, dorsal groove present (Fig. 16A-D). Eyes blackish, of similar size, anterior eyes oval, directed anteroventrally, diameter about $1 / 6-1 / 7$ of prostomial width, slightly more separated than posterior eyes (Fig. 16A-D). Antennae half as long as prostomium, without gap between them, tips surpassing palpophore tips, sometimes reaching palpostyle tips (Fig. 4C). Palpophores subconical, $2 \times$ as long as wide; palpostyles projected, blunt, slightly longer than wide (Fig. 16A-D).

TeNTACUlAR BelT. $2 \times$ as long as first chaetiger, anterior margin projected anteriorly middorsally, not covering posterior eyes or nuchal organs. Tentacular cirri smooth, barely contracted distally; smallest complete specimen with longest tentacular cirri reaching chaetiger 3 (Fig. 16A), in largest complete specimen reaching chaetiger 3 .

PhARYNX. Not everted, observed by previous dissection of largest specimen. Jaws brown, with 7 denticles. Paragnath formula: I: 2 in tandem; II: 18-20 in crescent-shaped group; III: 30 in oval group; IV: 28-30 in oval groups; V: 0; VI: 4 in diamond; VII-VIII: 30-46 paragnaths in 2-3 rows (size dependent).

Pattern of parapodial ligules. Anterior chaetigers with ligules blunt, slightly longer than wide, becoming blunt subconical to digitiform in median and posterior chaetigers; ventral ligules thinner, $3-4 \times$ as long as wide.

Chaetigers 1-2. With neuraciculae only (Fig. 16E); with both noto- and neuraciculae thereafter. Dorsal cirrus slightly longer and wider than ventral one, $2 \times$ as long as parapodial ligules. Dorsal ligule longer than wide, blunt, as long as tapered median one. Neuracicular ligule subconical, blunt, as long as wide. Supracicular neurochaetae: barely exposed, 5 homogomph spinigers and 3 heterogomph falcigers with blades spinulose, $5-6 \times$ as long as wide, distal tooth incurved, tendons not visible; subacicular neurochaetae: 5 heterogomph spinigers and 6 heterogomph falcigers with blades spinulose, $6-7 \times$ as long as wide, distal tooth incurved, tendons not visible.

MEDian PaRAPODIA (Fig. 16F). With dorsal cirrus $2 \times$ as long as dorsal ligule, slightly longer than ventral cirrus. Dorsal ligule as long as wide, subconical, blunt; median ligule rounded; both ligules subequal, $2.5 \times$ as long as neuracicular ligule, with glandular areas unpigmented, extended along ligular 
bases. Neuracicular ligule subconical, blunt, wider than long; ventral ligule digitiform, slightly longer than wide, $2 \times$ as long as neuracicular ligule. Notochaetae 9 heterogomph spinigers. Supracicular neurochaetae: 4 homogomph spinigers and 3 heterogomph falcigers with blades spinulose, $3 \times$ as long as wide, distal tooth incurved, tendons barely visible; subacicular neurochaetae: 3 heterogomph spinigers and 7 heterogomph falcigers with blades spinulose, $3-5 \times$ as long as wide, distal tooth incurved, tendons barely visible.

Posterior PARAPODIa (Fig. 16G). With dorsal and ventral cirri 5-6× as long as wide, dorsal cirrus about $2 \times$ as long as dorsal ligule, ventral cirrus shorter than ventral ligule. Dorsal and median ligules subequal, blunt, subconical to digitiform, $2 \times$ as long as wide, glandular areas unpigmented, darker along ligular bases. Neuracicular ligule subconical, $2 \times$ as wide as long; ventral ligule digitiform, $2 \times$ as long as wide, $2 \times$ as long as neuracicular ligule. Notochaetae: 4 homogomph spinigers and 1-2 homogomph falcigers with blades spinulose, $4 \times$ as long as wide, tip incurved, tendon visible. Supracicular neurochaetae: 5 homogomph spinigers and 2 heterogomph falcigers with blades spinulose, $2 \times$ as long as wide, distal tooth incurved, fused to blade; subacicular neurochaetae: 2 heterogomph spinigers and 3 heterogomph falcigers with blades spinulose, $2 \times$ as long as wide, distal tooth incurved, fused to blade.

SubTeRminal ChaEtigers (Fig. 16H). With dorsal cirrus $2.3 \times$ as long as dorsal ligule, almost $2 \times$ as long as ventral cirrus. Dorsal notopodial ligule digitiform, $2.5 \times$ as long as wide, slightly longer than median one; median ligule digitiform, $2 \times$ as long as wide, $2 \times$ as long as neuracicular ligule. Neuracicular ligule truncate, slightly wider than long; ventral ligule digitiform, $2 \times$ as long as neuracicular ligule. Notochaetae: 3 homogomph spinigers and 1 homogomph falciger, blade spinulose, about $3 \times$ as long as
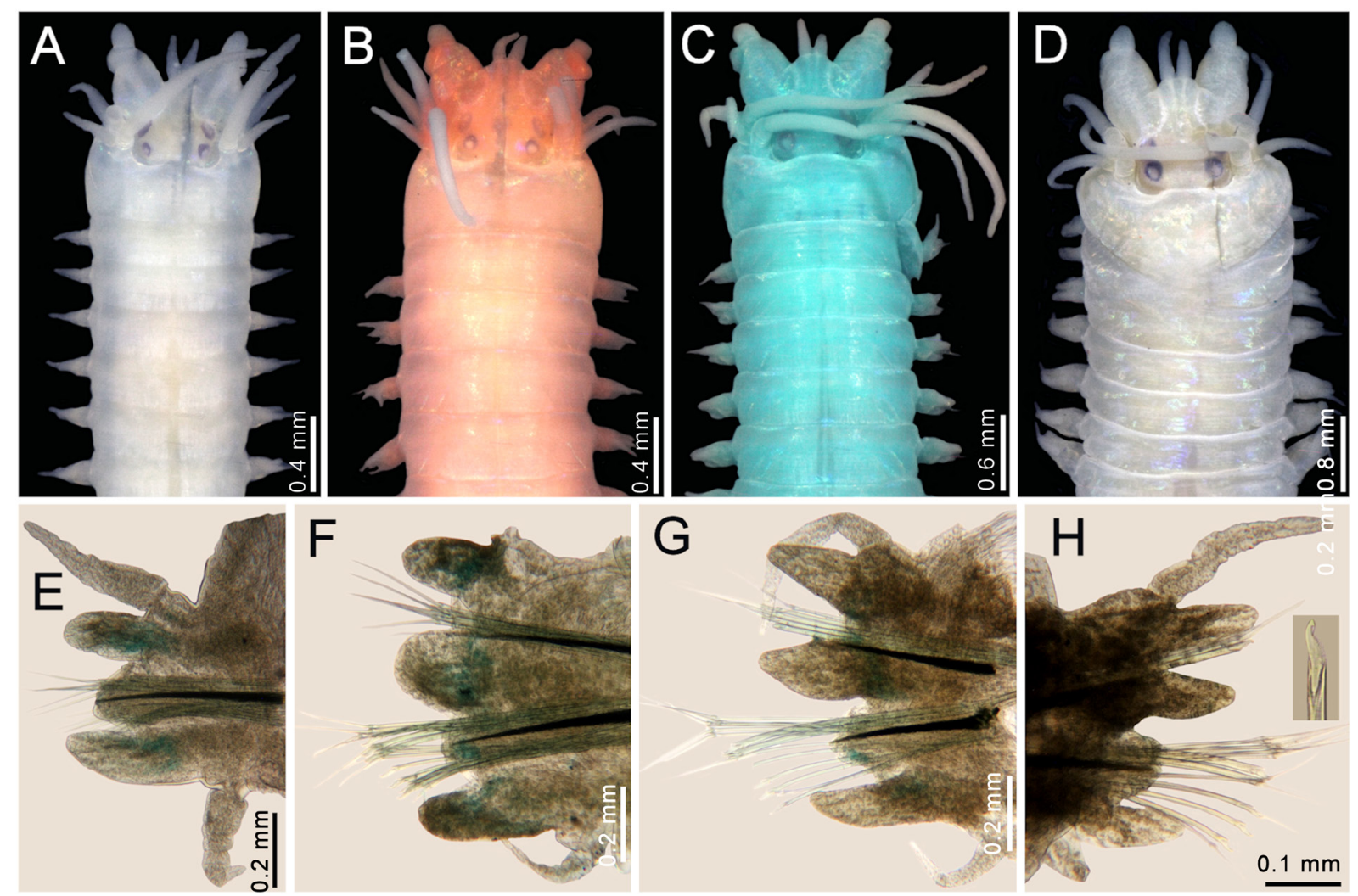

Fig. 16. Nereis lucipeta Ehlers, 1908, reinstated, non-type specimens (MNHN 83-52), anterior region in dorsal view. A. $0.9 \mathrm{~mm}$ wide. B. $1.2 \mathrm{~mm}$ wide, after Shirlastain-A staining. C. $1.4 \mathrm{~mm}$ wide, after methyl green. D. $2.0 \mathrm{~mm}$ wide. E. Largest fragment, chaetiger 2, right parapodium, anterior view. F. Same, chaetiger 15, right parapodium, anterior view. G. Same, chaetiger 28, right parapodium. H. Complete specimen, chaetiger 65, left parapodium, anterior view (inset: homogomph falciger). 
wide, distal tooth incurved and fused to blade. Supracicular neurochaetae: 5 homogomph spinigers and 2 heterogomph falcigers with blades spinulose, almost $2 \times$ as long as wide, distal tooth incurved, fused to blade; subacicular neurochaetae: 4 heterogomph spinigers and 3 heterogomph falcigers with blades spinulose, $3 \times$ as long as wide, distal tooth incurved, fused to blade.

Posterior Region. Tapered into a blunt cone. Pygidium with anus terminal, anal cirri as long as last $6-8$ chaetigers.

\section{Remarks}

Nereis lucipeta Ehlers, 1908 was described based on prenatatory male epitokes dredged in Big-Fish Bay, Angola (Valdivia, stn 76, 16 $6^{\circ} 33^{\prime} \mathrm{S}, 1^{\circ} 46^{\prime} \mathrm{E} ; 14 \mathrm{~m}$ ). Ehlers (1913: 496) recorded atoke specimens but regarded this species as a junior synonym of $N$. splendida Grube, 1840. This latter record was regarded as a synonym of " $N$. falsa" by Fauvel (1919), after finding it in Madagascar. This same conclusion was followed by Hartman (1959) and Day (1967). However, N. lucipeta must be reinstated.

The main difference between the male epitokes of $N$. lucipeta and those of $N$. splendida is in the number of chaetigers in the non-natatory region, as indicated in the key below. In $N$. lucipeta the anterior region includes 20 chaetigers, whereas in $N$. splendida, it has 27 . An additional difference is in the shape of the prostomium and the size of the palpophores. In $N$. lucipeta the anterior prostomial region is longer than the posterior, ocular one, and the palpophores are markedly swollen, projected laterally beyond the level of the lateral eyes, whereas in N. splendida the anterior prostomial region is as long as, or shorter than, the posterior ocular one, and the palpophores are not so markedly swollen.

The atokes of what could be regarded as $N$. lucipeta were briefly characterized by Day (1962: 639), under the name of $N$. falsa, based on some specimens from Natal, and later he keyed out the atokes and provided an extended diagnosis (Day 1967: 317). These records are herein regarded as $N$. lucipeta because of the similarities in parapodial and pharyngeal features, although the anterior end of an atoke has not been illustrated before.

As indicated in the key below, by having short tentacular cirri $N$. lucipeta resembles $N$. callaona and N. callaona sensu Augener 1918 from Western Africa. However, typical N. callaona can be separated from the two other species because its jaws only have 4 denticles, whereas the two other species have 6-7 denticles. The main difference between $N$. lucipeta and $N$. callaona from Western Africa are in the pharyngeal areas II and III, because $N$. lucipeta has 18-20 paragnaths in II and about 30 paragnaths in III, whereas $N$. callaona sensu Augener has 28 paragnaths in II and about 50 in III.

\section{Distribution}

From Angola to Madagascar, in shallow water.

Nereis callaona sensu Augener, 1918

Nereis callaona Augener, 1918: 184-186 (non Grube \& Kröyer in Grube, 1857).

Nereis falsa - Fauvel 1936: 35; 1950: 353. - Fauvel \& Rullier 1957: 73-74. — Amoureux 1973: 53 (non de Quatrefages, 1866).

\section{Diagnosis}

Nereis with dorsal brownish pigmentation as trapezoidal transverse bands; parapodial glands dark. Jaws with 6 denticles; paragnaths formula: I: 2 in tandem; II: about 28 in three rows; III: about 50; IV: about 34; V: 0; VI: 3-5; VII-VIII: 2 irregular bands with about 60 paragnaths (largest paragnaths in I, VI, VII-VIII). 


\section{Material examined}

None.

\section{Remarks}

Dark pigmented glands in parapodial ligules have been reported several times for West African specimens recorded as N. callaona. Augener (1918: 184) and later Fauvel (1936: 35) noted 2-3 transverse rows of paragnaths in pharyngeal areas VII-VIII. Fauvel recorded this species with a single specimen from Agadir $\left(30^{\circ} 25^{\prime} 00^{\prime \prime} \mathrm{N}, 09^{\circ} 35^{\prime} 00^{\prime \prime} \mathrm{W}\right)$, on ascidians. He gave the paragnath formula as: I: 0,2 ; II: two arches; III: rectangular group; IV: arched groups; V: 0; VI: 3-5 large paragnaths in a cross on each side; VII-VIII: 2-3 irregular series with subequal paragnaths. The presence of a dorsal homogomph falciger was indicated with a blade denticulated, and with a ligament from the top. The pigmentation was given as greenish with transverse brownish bands along the anterior region. However, West African specimens differ from typical N. callaona from western South America in several features. In West African specimens, jaws have 6 denticles, but only 4 are present in western South American specimens. In African specimens, the pharyngeal area II has about 28 paragnaths in three rows, whereas American specimens have about 11 in two rows.

Augener (1918: 186) indicated some resemblance of his specimens to N. lucipeta Ehlers, 1908, and to $N$. splendida; we have not seen these specimens and their affinities must be clarified in the future.

\section{Distribution}

Togo to Angola, from the intertidal to shallow depths (10 m).

Nereis ambigua Treadwell, 1937 reinstated

Nereis ambiguus Treadwell, 1937: 149-150, pl. 2 figs 19-24.

Nereis riisei - Monro 1933: 43-44 (living pigmentation). - Hartman 1940: 221-222, pl. 33 fig. 37; 1956: 279 (synonymy). — Reish 1968: 77. — Fauchald 1977b: 31, fig. 8c-e (partim, only Pacific Panama specimens). — de León-González \& Solís-Weiss 2000: 560-561. — Dean 2001: 57-58, figs 44-48 (non Grube \& Örsted in Grube, 1857).

\section{Diagnosis}

Nereis with posterior eyes completely exposed; tentacular belt $2 \times$ as long as first chaetiger; pharyngeal areas VII-VIII with a single row of large denticles; median and posterior parapodia with ventral ligules reaching tip of neuracicular ligules.

\section{Material examined}

\section{Syntypes}

MEXICO • 1 juv.; Revillagigedo Islands, Clarion Island, Sulphur Bay, Clarion Island; $18^{\circ} 20^{\prime} 40^{\prime \prime} \mathrm{N}$, 11444'20" W; Templeton Crocker Expedition, stn 163 D1; depth 36 m; 11 May 1936; AMNH 36595 • 1 heteroneris; same collection data as for preceding; AMNH 36883 (not seen).

\section{Other material}

MEXICO - Gulf of California - 3 specs; Baja California, Bahía de Los Angeles, fiscal harbour; $28^{\circ} 56^{\prime} 49.8^{\prime \prime} \mathrm{N}, 113^{\circ} 33^{\prime} 25.8^{\prime \prime} \mathrm{W}, 18$ Apr. 2010; J.A. de León leg.; UANL 8146 • 3 specs; Baja California

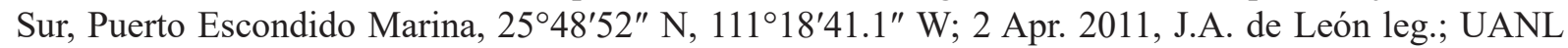
8147 • 3 spec.; same locality as for preceding; 2 Sep. 2011, J.A. de León leg.; UANL 8148 • 6 specs; same locality as for preceding; 5 Nov. 2013, J.A. de León leg.; UANL $8149 \bullet 3$ specs; Baja California Sur, Santa Rosalia Marina; $7^{\circ} 20^{\prime} 13.4^{\prime \prime}$ N, $112^{\circ} 15^{\prime} 47.6^{\prime \prime}$ W; 12 Nov. 2013, J.A. de León leg.; UANL 8150 • 2 specs; 24 Jun. 2017; J.A. de León leg.; UANL 8151. 
Description (abridged from several sources)

BoDy. Dark brownish pigmentation on dorsal surfaces of prostomium and tentacular belt, often continued as two transverse bars per segment along anterior chaetigers.

Prostomium. Pyriform, longer than wide; eyes round, of similar size, in a rectangular arrangement. Antennae slightly surpassing palp tips. Palpophores globose, as long as wide, palpostyles rounded.

TENTACULAR BELT. $2 \times$ as long as first chaetiger, anterior margin middorsally projected anteriorly, not covering posterior eyes. Tentacular cirri smooth, longest one reaching chaetiger 5-9.

Pharynx. Jaws brownish with 9-10 teeth. Paragnaths formula: I: 2 in tandem; II: 33-34 in an arch; III: 36 in an oval; IV: 33, 35 of different sizes; V: 0; VI: 8, 11 in a cluster; VII-VIII: single row with 4-5 small cones.

PATtern of parapodial Ligules. Anterior chaetigers with ligules blunt, slightly longer than wide, of similar length and width, becoming tapered, blunt, slightly longer than wide in median and posterior chaetigers; ventral ligule progressively smaller, thinner, $2 \times$ as long as wide.

Chaetigers 1-2. With neuraciculae only. Ligules without glandular masses.

MEDIAN PARAPODIA. With dorsal cirrus longer than ventral one, both thin; dorsal cirrus almost $2 \times$ as long as dorsal ligule; dorsal ligule slightly longer and wider than median ligule, both with dark inner compact glandular masses. Neuracicular ligule blunt, subconical, about as long as wide. Ventral ligule digitate, $2 \times$ as long as wide. Ventral cirrus not reaching tip of ventral ligule. Notochaetae: homogomph spinigers and falcigers from chaetiger 39 , blades $3 \times$ as long as wide, margin denticulate, distal tooth incurved. Neurochaetae: homogomph spinigers and heterogomph falcigers in supracicular and subacicular fascicles; falcigers with blades slightly more than $2 \times$ as long as wide, with margin denticulate, distal tooth incurved.

Posterior REgION. Tapered. Pygidium with anus terminal with two anal cirri, as long as last 11 chaetigers.

\section{Variation}

Gulf of California specimens $(n=14)$ showed some variation in their paragnath formula which is not size-dependent. Pharyngeal area I: $0-3$ cones $(50 \%$ of specimens with $2 ; 25 \%$ with only one; $15 \%$ without cones; $10 \%$ with 3 teeth and when the third cone is present, it is minute). Area II: right side 7-23 cones, left side 10-26 cones. Area III: oval patch with 13-30 cones in three lines, proximal line with larger cones ( $20 \%$ of specimens with 21 cones). Area IV: right side 12-30 cones, left side 12-34 cones. Area V: none. Area VI: right side 3-10 cones, left side 3-9 cones ( $25 \%$ of specimens with 5-5 cones, respectively). Area VII-VIII: $2-7$ in a row (60\% of specimens with 5 cones). Longest tentacular cirri reach chaetiger $2-6$ (in almost $25 \%$ of specimens reaching chaetiger 4 ).

\section{Remarks}

The specific epithet must be modified because the original one was masculine ('ambiguus', 'uncertain'), but the gender of Nereis is feminine. Therefore, the epithet must be used in the feminine form (ambigua).

There are some problems regarding the type material of $N$. ambigua. Treadwell (1937: 149) selected and described as "type" a juvenile collected in the Revillagigedo Islands. It was $25 \mathrm{~mm}$ long, $1 \mathrm{~mm}$ wide, without the posterior region, and he recorded another, smaller specimen. Surprisingly, he indicated "the type retained only one anal cirrus" (Treadwell 1937: 150), and this might correspond to the heteronereis he referred to in the last line of his description. Treadwell (1937) described the largest specimen, $25 \mathrm{~mm}$ 
long and $1 \mathrm{~mm}$ wide, and its pharynx was not exposed, preventing him to clearly count the numbers of paragnaths.

Hartman (1940) synonymized this species with $N$. riisei on the basis of parapodial ligules and homogomph falciger shape only, but no further comments were made. Later, Hartman (1956) studied one of the type specimens, but she failed to indicate which one it was or whether there was only a single specimen remaining in the jar, the largest one being destroyed after dissection. She dissected the pharynx and found a paragnath distribution different from the one originally indicated by Treadwell (1937). Treadwell indicated that areas I and II were smooth, whereas Hartman found 3 paragnaths in I and a patch of larger paragnaths in II; furthermore, larger differences relate to areas VI and VII-VIII, because Treadwell indicated 3-4 cones in VI, 7-8 cones in VII and a circular patch with about 20 paragnaths in VIII, but Hartman noted 12 cones in VI and a single continuous band with about 10 alternating larger and smaller cones in VII-VIII. On the other hand, Hartman (1940: 222) found a different pattern in her Eastern Pacific specimens, with 4-5 cones in VI and a single band with 4-5 in VII-VIII. A similar pattern, matching Hartman's account, was recorded by Dean (2001) for his Costa Rican specimens. Hartman (1956) also detailed 9 teeth on the jaws, dark aciculae and homogomph falcigers (presumably notopodial ones) appearing from chaetiger 26.

Because of this series of differences, which were more or less corroborated in the Gulf of California material, and because Treadwell (1937) indicated he had two specimens, the chances are that those two specimens belong to different species. An alternative is that Treadwell confused the pharyngeal areas in the non-everted pharynx, as he indicated, and that would explain the specific epithet. The specimens that Hartman (1940) and Dean (2001) studied were more similar to N. riisei than the specimen Hartman (1956) studied. Regretfully, subsequent collecting trips to the Revillagigedo Islands (Hartman 1939; Rioja 1960) did not provide topotype specimens of $N$. ambigua.

Consequently, the key below indicates that $N$. ambigua resembles $N$. riisei because both have posterior eyes completely exposed and a single row of paragnaths in areas VII-VIII, after the careful characterization by Dean (2001). Based on the original description, N. ambigua differs from N. riisei mainly by having larger eyes, tentacular cirri reaching chaetiger 9 and dorsal cirri in posterior chaetigers shorter than dorsal ligules. These two species further differ because in $N$. ambigua the ventral ligule in median and posterior parapodia reach the tips of the neuracicular ligules, and in fresh specimens the tentacular belt is pale. On the contrary, in $N$. riisei the ventral ligules in median and posterior parapodia surpass the neuracicular ligules, and fresh specimens have a blackish tentacular belt. Nevertheless, these differences must be taken as preliminary pending the finding of topotype specimens and confirming their diagnostic features.

\section{Distribution}

Originally described from the Revillagigedo Islands, the potential distribution of Nereis ambigua might extend along the Eastern Pacific, from the Gulf of California to the Galápagos Islands and Ecuador, in shallow water.

Nereis occidentalis Hartman, 1945

Fig. 17

Nereis pelagica occidentalis Hartman, 1945: 20, pl. 4 figs 1-6.

Nereis pelagica occidentalis - Hartman 1951:46.

Nereis (Nereis) occidentalis - Pettibone 1956: 291 (new status; partim).

Nereis falsa - Day 1973: 41. — Gardiner 1975: 152, fig. 15s-u. 


\section{Diagnosis}

Nereis with posterior eyes completely exposed; tentacular belt $1.5 \times$ as long as first chaetiger; tentacular cirri long, reaching chaetiger 8; jaws with 7-9 teeth; pharyngeal area II with 14-15 paragnaths in 2 rows, areas VII-VIII with 46 paragnaths in 3-4 transverse rows, basal row with larger paragnaths; median chaetigers with notopodial ligules conical, blunt; ventral ligules in median and posterior chaetigers markedly longer than neuracicular ligules.

\section{Material examined}

\section{Holotype}

UNITED STATES • atoke; Sheepshead Shoal, Beaufort, North Carolina; 3442'22" N, 76 36 $11^{\prime \prime}$ "W; 7 Jun. 1940; O. Hartman leg.; in colonies of Petaloproctus socialis Andrews, 1891; LACM 836.

\section{Paratypes}

UNITED STATES • 95 atokes; same collection data as for holotype; LACM 837.

\section{Description}

Body. Holotype (LACM 836) atokous, complete, $42 \mathrm{~mm}$ long, $2 \mathrm{~mm}$ wide at chaetiger 10 excluding parapodia, with 93 chaetigers. Body pale, dorsum with a light brown striate pattern along anterior chaetigers (Fig. 12A). Paratype (LACM 837) atokous complete, $40 \mathrm{~mm}$ long, $2 \mathrm{~mm}$ wide excluding parapodia, with 68 chaetigers.

Prostomium. Pyriform, longer than wide; eyes blackish, rounded, of similar size, in trapezoidal arrangement, about $1 / 7$ prostomial width (Fig. 17A). Antennae half as long as prostomium, without gap between them, swollen basally, slightly shorter than palps. Palpophores $1.5 \times$ as long as wide, palpostyles subcylindrical (Fig. 17A).

TENTACUlAR Belt. $1.5 \times$ as long as first chaetiger; anterior margin not covering posterior eyes (Fig. 17A). Tentacular cirri smooth, longest ones reaching chaetiger 8.

Pharynx. Everted. Jaws brown with 7-9 accesory teeth. Paragnath formula: I: 3 in tandem; II: 14-15 in 3 oblique lines; III: 25 in ellipse; IV: 23-25 in a crescent-shaped group; V: 0; VI: 5-3 in diamond; VII-VIII: 46 cones in 3-4 transverse rows, basal row with larger paragnaths.

Pattern of PARAPODial Ligules. Anterior chaetigers with ligules tapered, blunt; median and posterior chaetigers with ligules subconical, slightly blunter in median ones, progressively sharper. Ligules with contorted glandular tubules.

Chaetigers 1-2. With neuraciculae only (Fig. 17E); with both noto- and neuraciculae thereafter. Dorsal cirrus as long as ventral one, $2 \times$ as long as dorsal ligule. Dorsal and ventral ligules subequal, digitiform, $3 \times$ as long as neuracicular ligule. Neuracicular ligule subconical; postchaetal lobe digitiform, shorter than neuracicular ligule. Supracicular neurochaetae: 10-12 homogomph spinigers and 3-4 heterogomph falcigers; subacicular neurochaetae: $8-9$ heterogomoph spinigers, falcigers not observed.

ANTERIOR PARAPODIA (Fig. 17F). Dorsal cirrus longer than ventral cirrus; dorsal cirrus twice as long as dorsal ligule, ventral cirrus as long as ventral ligule. Dorsal and median ligules subequal; dorsal one subconical, blunt, $1.2 \times$ as wide as long; median one rounded, $1.2 \times$ as long as neuracicular ligule. Neuracicular ligule subconical, as long as wide, $1.2 \times$ as long as ventral ligule; postchaetal lobe rounded, shorter than neuracicular ligule; ventral ligule digitiform, $1.2 \times$ as wide as long. Notochaetae $16-20$ homogomph spinigers. Supracicular neurochaetae: 15-18 homogomph spinigers and 4-6 heterogomph falcigers; subracicular neurochaetae: one heterogomph spiniger and 6-9 heterogomph falcigers with blades short (Fig. 17F). 
Median PARAPODIa (Fig. 17G). With dorsal cirrus more than $2 \times$ as long as ventral one, $2 \times$ as long as dorsal ligule. Dorsal and median ligules subequal, subconical; dorsal ligule $1.3 \times$ as wide as long; median ligule $1.2 \times$ as long as wide, $3 \times$ as long as neuracicular ligule; notacicular papilla present. Neuracicular ligule rounded to subconical; rounded postchaetal lobe, shorter than neuracicular ligule; ventral ligule
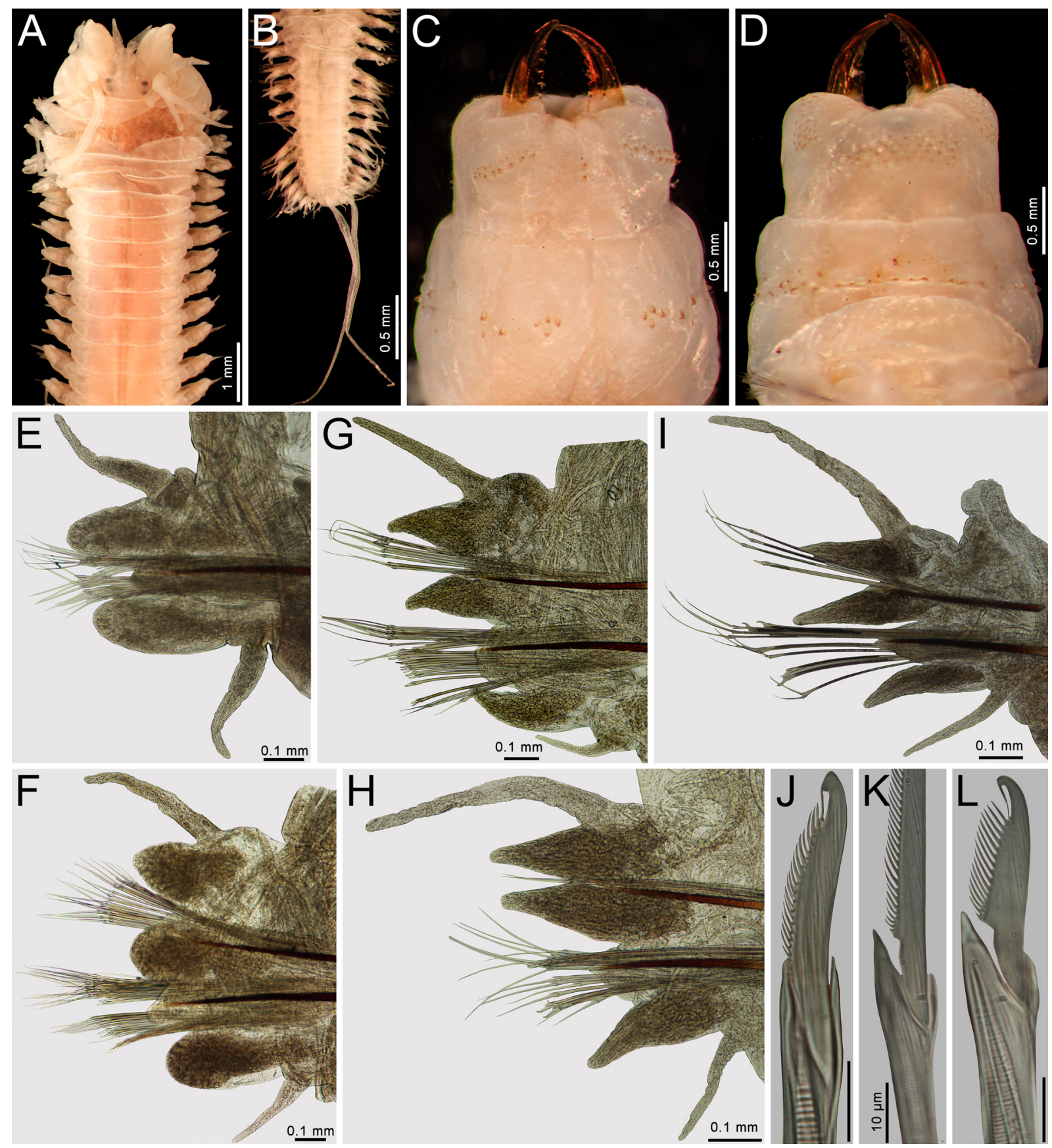

Fig. 17. Nereis occidentalis Hartman, 1945. A-B, I: holotype (LACM 836); C-H, J-L: paratype (LACM 837). A. Anterior region, dorsal view. B. Posterior region, dorsal view. C. Pharynx, dorsal view. D. Same, ventral view. E. Chaetiger 2, right parapodium, posterior view. F. Chaetiger 11, right parapodium, posterior view. G. Chaetiger 34, right parapodium, posterior view. H. Chaetiger 62, right parapodium, posterior view. I. Chaetiger 87, right parapodium, posterior view. J. Same, notopodial homogomph falciger. K. Same, neuropodial subacicular heterogomph spiniger. L. Same, neuropodial subacicular heterogomph falciger. 
subconical, $1.2 \times$ as long as wide, $1.2 \times$ as long as neuracicular ligule, $2 \times$ as long as ventral cirrus. Notochaetae 6-8 homogomph spinigers. Supracicular neurochaetae: 11 homogomph spinigers and 2-3 thick heterogomph falcigers, blades denticulate, distal tooth incurved, fused to blade; subacicular neurochaetae: 3-4 heterogomph spinigers, thin, short, and 9-12 thick heterogomph falcigers, denticulate along cutting edge, distal tooth incurved, fused to blade.

Posterior PARAPODIA (Fig. 17H-I). With dorsal cirrus inserted medially, $1.5 \times$ as long as dorsal ligule. Dorsal and median ligules subequal, subconical, tapered; dorsal ligule $1.3 \times$ as long as wide; median ligule $2 \times$ as long as wide, $3.5 \times$ as long as neuracicular ligule; notoacicular papilla absent. Neuracicular ligule subconical, as long as wide; ventral ligule subconical, tapered, $1.5 \times$ as long as wide, $2 \times$ as long as neuracicular ligule, subequal to ventral cirrus. Notochaetae: $2-4$ homogomph spinigers and 1 homogomph falciger (Fig. 17J), blades with 12-14 narrow teeth, stout distal tooth, incurved, fused to blade. Supracicular neurochaetae: 6-8 homogomph spinigers and 1-2 heterogomph falcigers similar to those of median parapodia; subacicular neurochaetae: 4-6 heterogomph spinigers and 2 heterogomph falcigers, similar to those of median parapodia (Fig. 17K-L).

Posterior Region. Tapered. Pygidium damaged, anus terminal; anal cirri as long as last 17 chaetigers (Fig. 17B).

\section{Remarks}

Hartman (1945) regarded this species as a subspecies of Nereis pelagica Linnaeus, 1758, but Pettibone (1956) thought they were different and regarded it as a distinct species, although further comments about this conclusion were not given. Because there is no available redescription of $N$. pelagica, here the description and illustrations in Chambers \& Garwood (1992: 38-40) are followed.

Nereis occidentalis Hartman, 1945 differs from N. pelagica in the following features: N. occidentalis has larger paragnaths basally in pharyngeal areas VII-VIII, whereas $N$. pelagica has larger paragnaths distally; in $N$. occidentalis, the ventral ligules are longer than the neuracicular ligules in middle and posterior chaetigers, whereas in N. pelagica they are subequal; in N. occidentalis, parapodial ligules are subconical with pointed tips, whereas in $N$. pelagica they are digitiform with blunt tips; in N. occidentalis, the notopodial homogomph falcigers have several narrow teeth and a distal, stout tooth with a tendon, whereas in $N$. pelagica these falcigers are not denticulate.

As discussed elsewhere (Conde-Vela \& Salazar-Vallejo 2015), Pettibone (1956) raised this species to species level and described it with specimens from Laguna Madre, Texas, Gulf of Mexico. Some features of those specimens resemble those of $N$. occidentalis, such as the length of the tentacular cirri, the arrangement of paragnaths on the pharynx (although she did not indicate most paragnath numbers) and the shape of blades of both notopodial and neuropodial falcigers. However, there are some relevant parapodial differences between specimens from Texas and typical $N$. occidentalis: in the anterior chatigers of $N$. occidentalis, median ligules are rounded and neuracicular ligules are as long as ventral ligules, whereas in specimens from Texas the median ligules are digitiform and neuracicular ligules are shorter than ventral ligules; in the middle chaetigers of $N$. occidentalis, medial ligules are $3 \times$ as long as neuracicular ligules, whereas in specimens from Texas, median ligules are $2 \times$ as long as neuracicular ligules; in the posterior chaetigers of $N$. occidentalis, ventral ligules are $2 \times$ as long as neuracicular ligules, whereas in specimens from Texas, ventral ligules are shorter than neuracicular ligules. These variations might be intraspecific variations, but clarifying this will depend of a future study. Taylor (1984: 31.39, fig. 31.38) identified specimens from the Gulf of Mexico Florida coasts as Nereis falsa, and he included a plate combining figures made of North Carolinean specimens by Hartman (1945) and Gardiner (1975); Taylor's specimens are similar to ones from Texas, requiring a further examination of them to clarify the affinities between these local populations. 
Dueñas-Ramírez (1980) reported N. occidentalis from the Colombian Caribbean and included a brief description and illustration; his specimens differ from N. occidentalis in having larger overlapping eyes, in contrast to the smaller and separated eyes and dorsal ligules with relatively narrow bases in the Carolinian specimens of $N$. occidentalis.

\section{Distribution}

North Carolina, United States.

Nereis falsa sensu Liñero-Arana \& Reyes-Vázquez 1979

Nereis falsa - Liñero-Arana \& Reyez-Vázquez 1979: 6, pl. 3 figs 1-13 (non de Quatrefages, 1866).

\section{Diagnosis}

Nereis with with posterior eyes completely exposed; longest tentacular cirri reaching chaetiger 8-10. Jaws with 7-9 denticles; paragnath formula: I: 1-3 in tandem; II: 22-34 in two rows; III: 28-35; IV: 34-40; V: 0; VI: 4; VII-VIII: 45-53 in 2 bands. Posterior parapodia with ventral ligules longer than neuracicular ligules and ventral cirri.

\section{Material examined}

None.

\section{Remarks}

Because no specimens were available, we cannot clarify the status for this record. There is a discrepancy between the description and the illustration regarding the tentacular cirri; in the illustration they reach about chaetiger 5 , but the description indicated that they were twice as long. Based on the available data and by following the key below, the Venezuelan specimens resemble $N$. splendida Grube, 1840, by having anterior notopodial ligules digitate, median and posterior chaetigers with ventral ligules longer than neuracicular ligules and pharyngeal areas VII-VIII with 2-3 transverse rows of paragnaths. Their main differences are in the prostomial shape and the pharyngeal paragnath numbers in area II. In the specimens reported by Liñero-Arana \& Reyes-Vázquez (1979) the anterior prostomial lobe is wider than long, and there are about 30 paragnaths in area II, whereas in $N$. splendida the anterior prostomial lobe is $2 \times$ as long as wide, and there are about 22 paragnaths in area II.

\section{Distribution}

Venezuela, Gulf of Cariaco, in intertidal rocky shores.

Nereis mezianei sp. nov. urn:1sid:zoobank.org:act:9E0D6CE0-F754-4E19-9ACE-6C77485ADBF9

Figs 2, 18-20

Nereis falsa - Fauvel \& Rullier 1959: 162 (non de Quatrefages, 1866).

\section{Diagnosis}

Nereis with posterior eyes partially covered by anterior margin of tentacular belt; tentacular belt $1.5 \times$ as long as first chaetiger; tentacular cirri long, reaching chaetigers 7-8; pharyngeal areas VII-VIII with 5 large paragnaths in a single row; posterior chatigers with dorsal and median ligules of similar width. 


\section{Etymology}

This species is named after Dr Tarik Meziane, curator of polychaetes at the Muséum national d'histoire naturelle, Paris, in recognition of his curatorial activities and especially as a means of gratitude for his long-standing support of our research activities.

\section{Material examined}

\section{Holotype}

SENEGAL - atokous + (without posterior region); Sénégambie, $50 \mathrm{~km} \mathrm{~W}$ of Abene; $12^{\circ} 55^{\prime} 30^{\prime \prime} \mathrm{N}$, $17^{\circ} 33^{\prime} 00^{\prime \prime} \mathrm{W}$; R/V Calypso, stn 4; depth 65-75 m; 16 May 1956; MNHN 372-4.

\section{Paratypes}

SENEGAL • 2 우 (without posterior region); same collection data as for holotype; MNHN 372-4b.

\section{Other material}

EQUATORIAL GUINEA • 1 spec. (complete, broken in two pieces, anterior end distorted by label, anterior fragment previously dissected, $13.5 \mathrm{~mm}$ long, $1.5 \mathrm{~mm}$ wide, 42 chaetigers; posterior fragment $5 \mathrm{~mm}$ long, $1.5 \mathrm{~mm}$ wide, 20 chaetigers, most chaetae broken; jaws with 5 accesory denticles; paragnath formula: I: 0; II: 4-5; III: destroyed; IV: 4-5; V: 0; VI: 3-6; VII-VIII: single row with 5 paragnaths); Annobon; 01 $24^{\prime} 04^{\prime \prime} \mathrm{S}, 05^{\circ} 36^{\prime} 45^{\prime \prime} \mathrm{E}$; R/V Calypso, stn 50; depth 7-10 m; 13 Jun. 1956; MNHN 372-50.

GUINEA - 1 spec. (anterior end distorted by pressure of the label; $12 \mathrm{~mm}$ long, $0.7 \mathrm{~mm}$ wide at chaetiger 10 without parapodia, with 52 chaetigers, anal cirri lost; tentacular cirri slightly damaged, reaching chaetiger 5; antennae thick, as long as palps; eyes blackish, round, of similar size, posterior eyes partially covered by anterior margin of tentacular belt; used for glandular patterns in parapodial ligules); $140 \mathrm{~km} \mathrm{~W}$ of Kaloum; $09^{\circ} 16^{\prime} \mathrm{N}, 14^{\circ} 50^{\prime} \mathrm{W}$; R/V G. Trica, stn 45; depth $45 \mathrm{~m}$; 11 Mar. 1953; J. Forest leg.; MNHN 372-45.

GUINEA-BISSAU 1 spec. (without posterior region, $13 \mathrm{~mm}$ long, $1 \mathrm{~mm}$ wide, 61 chaetigers; anterior eyes oblique, directed anterolaterally; anteroventrally dissected, paragnaths not seen); $100 \mathrm{Km} \mathrm{SSW}$ of Uite, Ilha de Orangozinho; $10^{\circ} 19^{\prime} 00^{\prime \prime} \mathrm{N}, 16^{\circ} 33^{\prime} 40^{\prime \prime} \mathrm{W}$; R/V Calypso, stn 6; depth 73-60 m; 16 May 1956; MNHN 372-6.

SÃO TOMÉ AND PRÍNCIPE • $1 \mathrm{spec}$. (complete juvenile, $8 \mathrm{~mm}$ long, $0.8 \mathrm{~mm}$ wide, 57 chaetigers), 1 ㅇ (anterior end distorted by label); Ilha de São Tomé; R/V Calypso, stn T28; 23 Jun. 1956; low tide; MNHN 372-T28 • 1 spec. (complete); S of Baía das Agulhas, "Ilha Principe" [Príncipe]; 01³7'00" N, 07²4'00" E; R/V Calypso, stn 92; depth 4-8 m; 26 Jun. 1956; MNHN 372-92.

Description (holotype, except where indicated)

BoDy. Mature female, without posterior end (Fig. 18A). Body subcylindrical up to chaetiger 15, depressed thereafter to end of fragment; $23 \mathrm{~mm}$ long, $1.5 \mathrm{~mm}$ wide (without parapodia), with 63 chaetigers. Dorsum brownish, darker along first 10 chaetigers, progressively paler; dorsal pigmentation as a solid transverse bar, paler approaching parapodia. Venter homogeneously brownish, progressively paler medially and posteriorly. Parapodial ligules with brownish glands from chaetiger 5.

Prostomium. Slightly longer than wide; eyes blackish, of similar size, anterior eyes oval, longer than wide, about $1 / 6$ of prostomial width, slightly more distant from each other than posterior eyes (Fig. 18B). Antennae terminal, without gap between them, tips reaching palpophore ends. Palpophores $2 \times$ as long as wide; palpostyles rounded, small. 
TENTACULAR BelT. $1.5 \times$ as long as first chaetiger; anterior margin partially covering posterior eyes. Tentacular cirri corrugate to articulate, tips broken, posterior dorsal cirri lost, remaining ones reaching chaetiger 2 .

PhARYNX. Barely exposed, showing paragnaths and tips of jaws, but not dissected to avoid further damage. Another specimen (MNHN 372-50) with jaws with 5 accesory denticles. Paragnath formula: I: 0; II: 4-5; III: destroyed; IV: 4-5; V: 0; VI: 3-6; VII-VIII: single row with 5 paragnaths.

PATTERN OF PARAPODIAL LIGULES. Anterior, median and posterior chaetigers with ligules tapered, slightly blunter in anterior chaetigers, progressively sharper, $3-4 \times$ as long as wide. Ventral ligules progressively smaller. Ligules with contorted glandular tubules (Fig. 2).

CHAETIGers 1-2. With neuraciculae only; with both noto- and neuraciculae thereafter.

ANTERIOR PARAPODIA (Figs 2A-C, 18C). With dorsal cirrus thicker, slightly longer than dorsal ligule and ventral cirrus. Dorsal and median ligules subequal, dorsal ligule wider than ventral one. Neuracicular ligule digitiform, blunt, $2 \times$ as long as wide, slightly longer than ventral ligule. Notochaetae 6 homogomph spinigers. Supracicular neurochaetae: 5 homogomph spinigers and 3 heterogomph falcigers with blades spinulose, $6-7 \times$ as long as wide, distal tooth incurved, fused to blade; subacicular neurochaetae: 5 homogomph spinigers and 4 heterogomph falcigers with blades lost (in MNHN 372-T28 with blades $5-6 \times$ as long as wide, spinulose, distal tooth incurved).
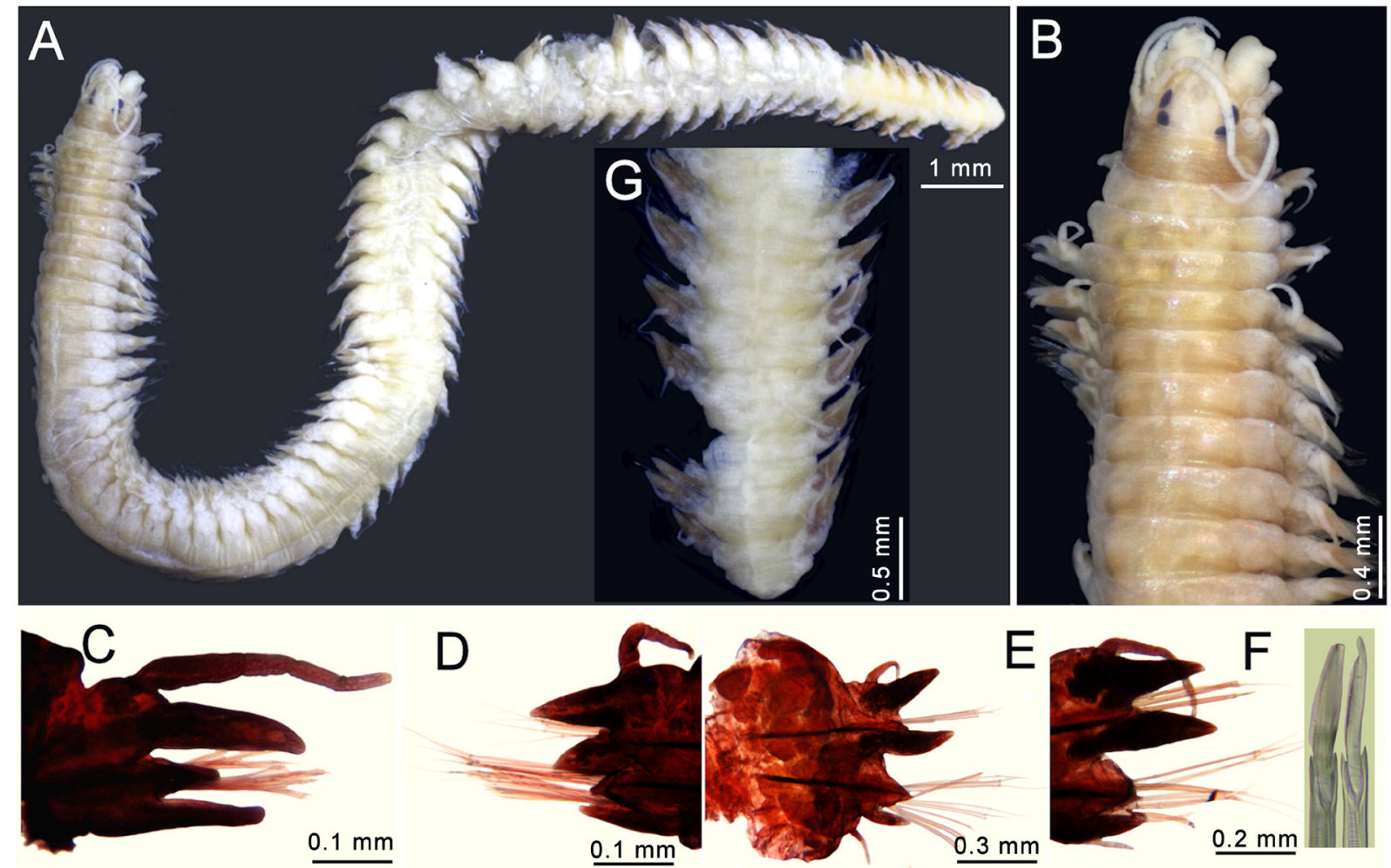

Fig. 18. Nereis mezianei sp. nov., holotype (MNHN 372-4). A. Dorsal view. B. Anterior region, dorsal view. C. Chaetiger 2, left parapodium, anterior view (ventral cirrus lost). D. Chaetiger 16, left parapodium, posterior view (ventral cirrus lost). E. Chaetiger 31, right parapodium, posterior view (notopodial homogomph and supracicular heterogomph falcigers broken). F. Chaetiger 55, right parapodium, posterior view (insets: homogomph falcigers tips). G. Posterior region, dorsal view. 
MEdian PARAPODIA (Fig. 18D). With dorsal cirrus shorter than dorsal ligule, slightly longer than ventral one in MNHN 372-T28. Both dorsal and median ligules subconical, tapered, $2 \times$ as long as wide, dorsal ligule slightly longer than median one, glandular areas distinct, expanded inside ligular bases. Neuracicular ligule subconical, as long as wide, shorter than ventral ligule; ventral ligule subconical, blunt, $3 \times$ as long as wide, as long as ventral cirrus. Notochaetae 5 homogomph spinigers. Supracicular neurochaetae: 8 homogomph spinigers and 1 heterogomph falciger with blade spinulose, $5 \times$ as long as wide, distal tooth incurved, fused to blade; subacicular neurochaetae: 4 heterogomph spinigers, and 7 heterogomph falcigers with blades spinulose, $3 \times$ as long as wide, distal tooth incurved, fused to blade.
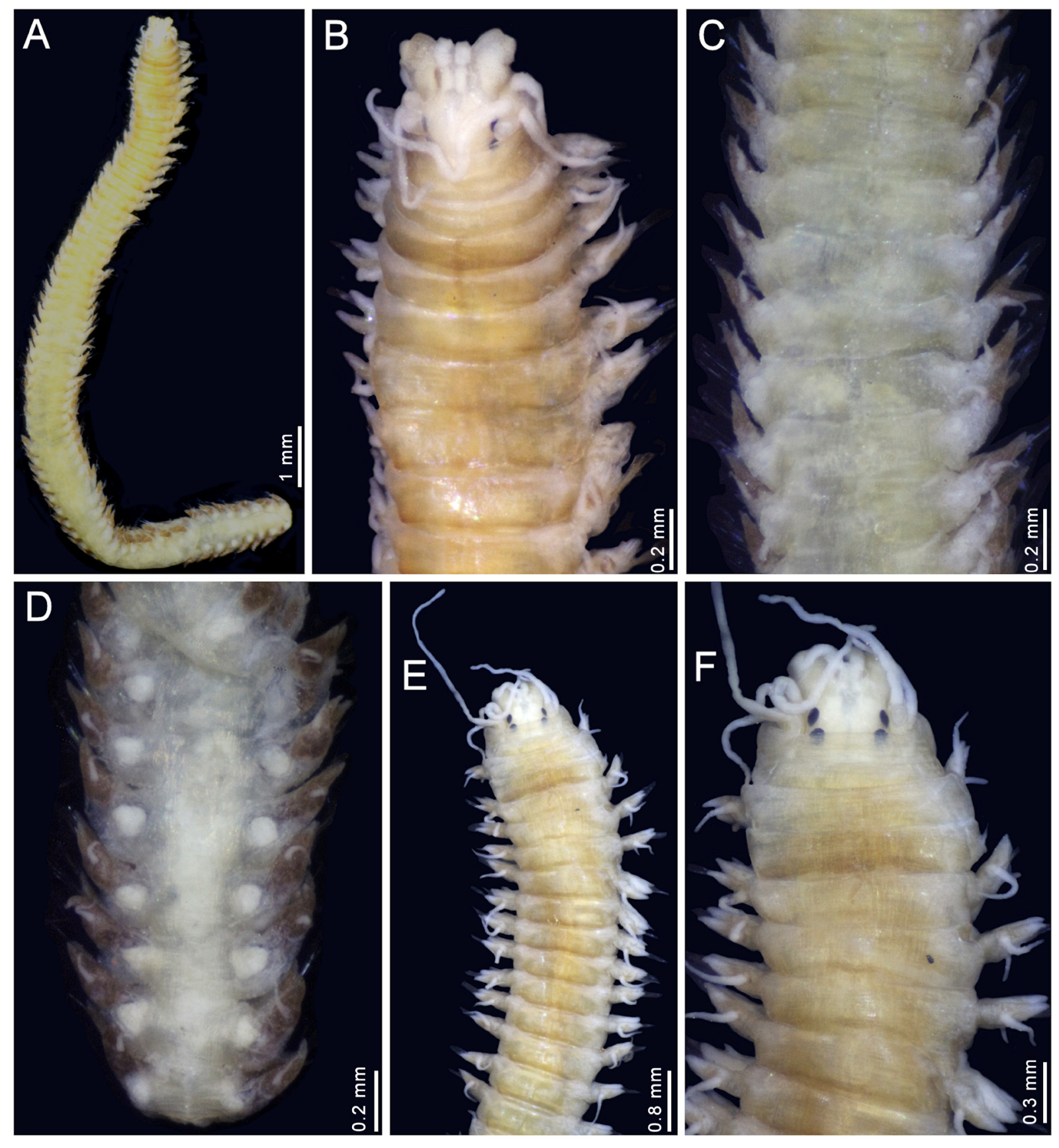

Fig. 19. Nereis mezianei sp. nov., paratypes (MNHN 372-4b). A. Smallest paratype, dorsal view. B. Same, anterior end, dorsal view. C. Same, median segments, dorsal view. D. Same, posterior region, dorsal view. E. Largest paratype, anterior region, dorsal view. F. Same, anterior end, dorsal view. 
Posterior PARAPODIA (Fig. 18E). With dorsal cirrus $1.3 \times$ as long as dorsal ligule. Dorsal and median ligules subequal, subconical, tapered, $1.5-2.5 \times$ as long as wide, $2 \times$ as long as neuracicular ligule, glandular areas distinct, expanded inside ligular bases. Neuracicular ligule subconical, as long as wide, subequal to ventral ligules; ventral ligule digitiform, slightly longer than wide, longer than ventral cirrus. Notochaetae: 4 homogomph spinigers and 1 homogomph falciger. Supracicular neurochaetae: 5 homogomph spinigers and 1 heterogomph falciger (broken); subacicular neurochaetae: 3 heterogomph spinigers and 5 heterogomph falcigers with blades spinulose, $2 \times$ as long as wide, distal tooth incurved and fused to blade.

SUBTERMINAL PARAPODIA (Fig. 18F). With dorsal cirrus markedly longer than notopodial ligules. Both dorsal and median ligules subconical, $2 \times$ as long as wide, median ligule slightly longer than dorsal one. Neuracicular ligules subconical, as long as wide, tapered; ventral ligules digitiform, slightly longer than wide, slightly longer than neuracicular ligules, longer than ventral cirri. Notochaetae 1 homogomph spiniger, and 2 homogomph falcigers, blades spinulose, $3-4 \times$ as long as wide, tip blunt, tendon well developed. Supracicular neurochaetae 4 homogomph spinigers and 1 larger heterogomph falciger, blade spinulose, $3 \times$ as long as wide, tip blunt, tendon well developed. Infracicular neurochaetae 3 heterogomph spinigers, and 3 heterogomph falcigers, blades spinulose, $3 \times$ as long as wide, tip blunt, tendon well developed.

Posterior REGION. Missing. In MNHN 372-T28, posterior end tapered into a blunt pygidium, anus terminal, anal cirri as long as last 5-6 chaetigers.

Oocytes. Yellowish, visible from about chaetiger 30; each about $150 \mu \mathrm{m}$ in diameter (distorted, inside parapodium in Fig. 18E).
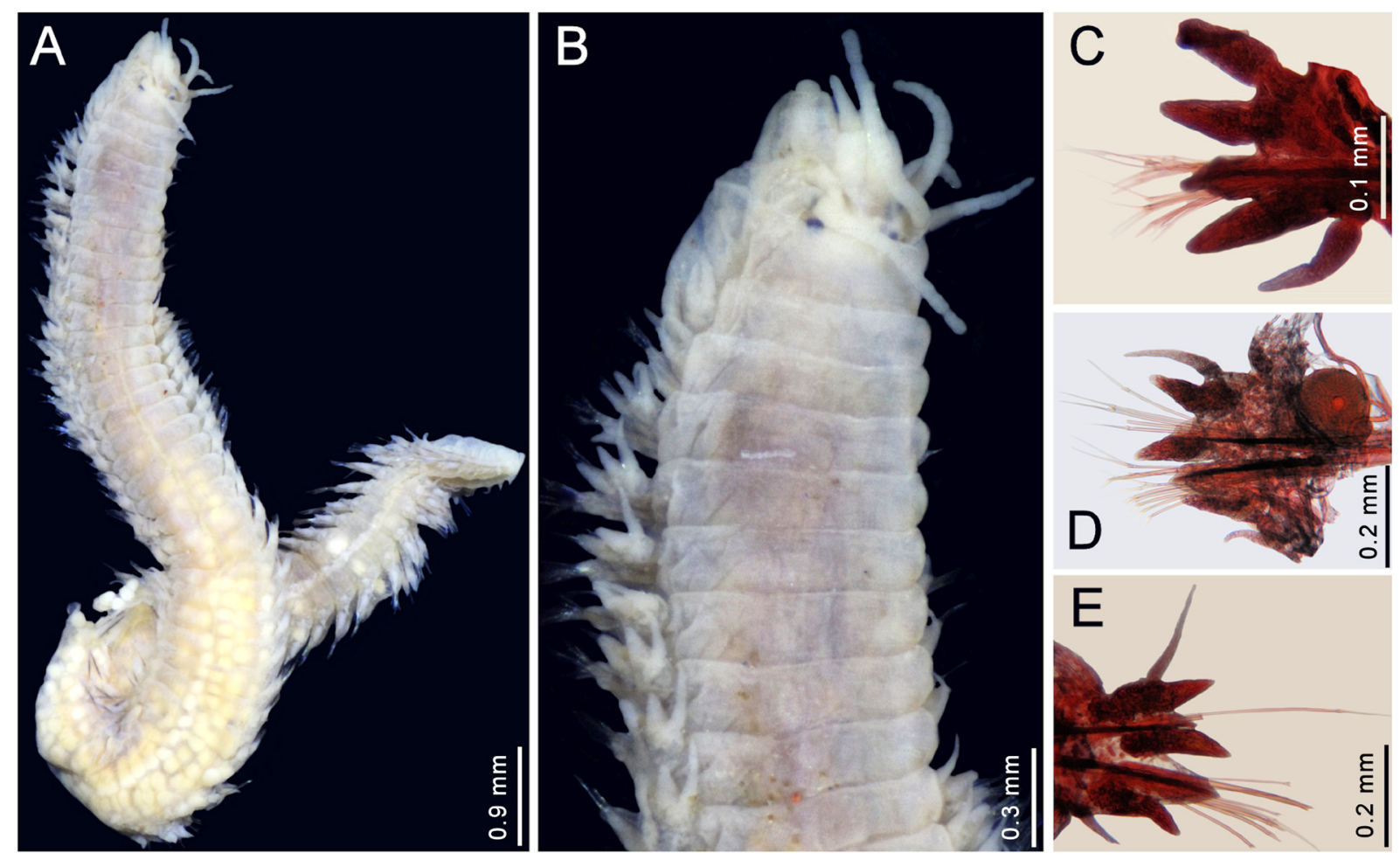

Fig. 20. Nereis mezianei sp. nov., mature female (MNHN 372-T28). A. Dorsal view. B. Anterior region, dorsal view. Parapodia stained with Shirslastain-A. C. Chaetiger 2, right parapodium, anterior view (dorsal cirrus bent). D. Chaetiger 35, left parapodium, posterior view. E. Chaetiger 52, right parapodium, posterior view. 


\section{Variation}

The paratypes are anterior fragments, regarded as mature females due to the presence of oocytes in their coelom (Fig. 19), as damaged as in the holotype. Body with dorsum brownish, especially along anterior third of body (Fig. 19A-B, E), and parapodial ligules with brownish glandular regions from chaetigers $3-4$, often darker in posterior chaetigers. They are 12-23 mm long, 1-2 mm wide, with 61-62 chaetigers; all parapodial ligules with dark brown glands, many chaetae broken. The left posterior dorsal tentacular cirri in the largest paratype are broken, reaching chaetiger 6 (Fig. 19E). The right one is longer, but it was broken during manipulation, such that tentacular cirri might reach chaetiger 8 . The tentacular belt partially covers the posterior eyes (Fig. 19B, F), and the eyes are of similar size, with the posterior eyes slightly closer to each other than the anterior ones. Both paratypes with oocytes from about chaetiger 30 (Fig. 19C), although they can appear from chaetiger 18 (MNHN 372-T28), and continue throughout most segments, even in the smallest paratype (Fig. 19D); each oocyte about $150 \mu \mathrm{m}$ in diameter.

Another mature female (MNHN 372-T28), defined as such by the presence of oocytes in its coelom, is $12 \mathrm{~mm}$ long, $1.2 \mathrm{~mm}$ wide, with 72 chaetigers, and has an almost complete histolysis such that most of the coelomic space is filled with oocytes (Fig. 20A), first visible from chaetiger 8-9, but more abundant from chaetiger 18, each about $150 \mu \mathrm{m}$ in diameter. Tentacular cirri articulate, broken. Antennae slightly longer than palps. the parapodia do not show any trace of epitokal transformation.

Chaetigers 1-2 with neuraciculae only (Fig. 20C). With dorsal cirri slightly longer than ventral ones, and dorsal and ventral ligules of similar shape and size. Neurochaetal ligule conical, blunt, as long as wide. Supracicular neurochaetae: 5 homogomph spinigers and 2 heterogomph falcigers, blades spinulose, 5-6× as long as wide, tips incurved, tendons barely visible; subacicular neurochaetae: 4 heterogomph spinigers and 4 smaller heterogomph falcigers, blades spinulose, $4-6 \times$ as long as wide, tips incurved, tendons indistinct.

Median chaetigers (Fig. 20D) with dorsal cirri slightly longer than notopodial ligules and ventral cirri. Neuracicular ligules conical, tapered, wider than long. Ventral ligule slightly shorter than neurochaetal lobe. Notochaetae 5 homogomph spinigers. Supracicular neurochaetae: with 3 homogomph spinigers and one larger heterogomph falciger, blade spinulose, about $3 \times$ as long as wide, tips incurved, tendon well defined; subacicular neurochaetae: with 2 heterogomph spinigers and 5 smaller heterogomph falcigers, blades spinulose, almost $3 \times$ as long as wide, tips incurved, tendons well developed. Oocytes $150 \mu \mathrm{m}$ in diameter.

Subterminal chaetigers with dorsal cirri about $2 \times$ as long as parapodial ligules and ventral cirri (Fig. 20E). Notopodial ligules acute, about $2 \times$ as long as wide, tapered. Neurochaetal ligule conical, tapered, about $2 \times$ as long as wide. Notochaetae: 1 homogomph spiniger and 1 homogomph falciger (broken). Supracicular neurochaetae: 2 homogomph spinigers and 1 larger heterogomph falciger (blade lost); subacicular neurochaetae: 3 heterogomph spinigers and 3 smaller heterogomph falcigers, blades spinulose, about $2 \times$ as long as wide, tips incurved, tendons well defined. Ventral ligule digitate, shorter than neuracicular ligule.

\section{Remarks}

Nereis mezianei sp. nov. has been recorded as "N. falsa" de Quatrefages, 1866 from the Gulf of Guinea, herein regarded as resembling $N$. splendida instead. However, these two species differ in relevant pharyngeal and parapodial features, and the main difference is that $N$. mezianei sp. nov. has a single row of paragnaths in areas VII-VIII, whereas N. splendida has 2-3 rows. Furthermore, because the posterior eyes are partially covered by the anterior margin of the tentacular belt, $N$. mezianei $\mathrm{sp}$. nov. groups with N. marginata Grube \& Örsted in Grube, 1857 from the Caribbean Sea, and with N. rava Ehlers, 1868 from the Mediterranean Sea. However, N. mezianei sp. nov. can be separated from these two other species because its tentacular cirri are longer. 
Nevertheless, $N$. mezianei sp. nov. approaches $N$. rava by having dorsal and median ligules in the posterior parapodia of similar width. Although the depth of the sampling site was not given in the original description of $N$. rava, the type locality (Gulf of Quarnero) has a maximaum depth of $128 \mathrm{~m}$. There are at least three different morphs regarded as belonging to $N$. rava in the Mediterranean region, and it has been reported from sediments in depths of 130-1685 m (Fauvel 1914: 169). Herein, we follow Gravina et al. (2015) regarding the specific features of N. rava. Nereis mezianei sp. nov. and N. rava have corrugate or articulate tentacular cirri. They especially differ in pigmentation pattern, in the relative size of tentacular cirri and in some parapodial features. In N. mezianei sp. nov., anterior segments have a solid brownish pigmentation, their longest tentacular cirri reach chaetigers $7-8$, and the ventral ligule is longer than the neuracicular ligule, whereas in N. rava, anterior segments have two transverse brownish bands, their longest tentacular cirri reach chaetigers $2-3$, and the neuracicular ligule is as long as the ventral ligule. Another important difference relies on mature females. In N. mezianei sp. nov., there is no metamorphosis or parapodial modification in mature females, whereas female heteronereis are known for N. rava (Núñez 2004: 374-375).

Nereis mezianei sp. nov. also resembles $N$. caparti Fauvel, 1953 described from off Namibia, because they have the longest tentacular cirri reaching chaetiger 7-8, parapodial ligules tapered and pharynx areas VII-VIII with a single row of paragnaths. They differ, however, because in N. mezianei sp. nov. the posterior eyes are partially covered by the anterior margin of first segment, notopodial ligules are of similar length and width, and compound notofalcigers have spinulose blades, whereas in N. caparti, posterior eyes are fully exposed, dorsal ligules are progressively longer than median ones, and the blades of the notofalcigers are smooth.

\section{Distribution}

Senegal to Equatorial Guinea, Western Africa, in shallow subtidal sediments in depths up to $75 \mathrm{~m}$.

\section{Key to atokes of the Nereis splendida Grube, 1840 species group}

(formerly " $N$. falsa" de Quatrefages, 1866 species group)

1. Prostomium with posterior eyes partially covered by anterior margin of tentacular belt; dorsum usually brownish; pharyngeal areas VII-VIII with a single row of paragnaths

- Prostomium with posterior eyes completely exposed …….........................................................

2. Longest tentacular cirri reaching chaetigers 7-8; dorsum with a solid brownish pigmentation along anterior chaetigers, fading in median and posterior ones

N. mezianei sp. nov. (Gulf of Guinea)

- Longest tentacular cirri reaching chaetigers $2-4$

3. Dorsum with two diffuse transverse brownish bands, anterior ones wider, better defined; dorsal and median ligules of similar width in posterior chaetigers

.N. rava Ehlers, 1868 sensu Gravina et al. 2005 (Mediterranean Sea)

- Dorsum with irregular transverse bands; dorsal ligules $2-3 \times$ as wide as median ones in posterior chaetigers N. marginata Grube \& Örsted in Grube, 1857 (Caribbean Sea)

4. Pharyngeal areas VII-VIII with 2-3 transverse rows of paragnaths ..........................................

- Pharyngeal areas VII-VIII with a single row of large paragnaths .............................................11

5. Anterior chaetigers with notopodial ligules short, globose, usually as long as wide, round, slightly longer than neuracicular ligules

- Anterior chaetigers with notopodial ligules digitate, usually longer than wide ..................... 
6. Tentacular cirri long, longest one reaching chaetiger 8; pharyngeal area II with 14-15 paragnaths .................................................. occidentalis Hartman, 1945 (North Carolina, USA)

- Tentacular cirri short, longest one reaching chaetiger 3-5 .............................................

7. Jaws with 4 teeth; pharyngeal area II with 11 paragnaths in 2 rows; ventral ligules in median and posterior chaetigers markedly longer than neurochaetal lobes

N. callaona Grube \& Kröyer in Grube, 1857 (Southeastern Pacific)

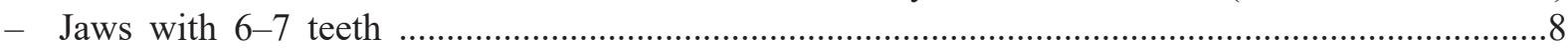

8. Pharyngeal area II with 28 paragnaths, area III with about 50 paragnaths

N. callaona sensu Augener, 1918 (Western Africa) (size relationships of parapodial ligules to neuracicular ligules unknown)

- Pharyngeal area II with 18-20 paragnaths, area III with 30 paragnaths; ventral ligule markedly longer than neuracicular ligule ................ lucipeta Ehlers, 1908 reinstated (Southern Africa)

9. Median and posterior chaetigers with ventral ligules as long as neuracicular ligules; pharyngeal area II with 16 paragnaths, area III with 36 paragnaths

N. lunulata Ehlers, 1901 stat. nov. (Patagonia)

- Median and posterior chaetigers with ventral ligules slightly to markedly longer than neuracicular ligules

10. Anterior prostomial lobe $2 \times$ as long as wide; pharyngeal area II with about 22 paragnaths ...... ..N. splendida Grube, 1840 (Mediterranean Sea)

- Anterior prostomial lobe wider than long; pharyngeal area II with about 30 paragnaths N. falsa sensu Liñero-Arana \& Reyes-Vásquez 1979 (Caribbean Sea)

11. Tentacular belt pale; median and posterior parapodia with ventral ligules surpassing neuracicular ligules N. riisei Grube \& Örsted in Grube, 1857 (Grand Caribbean)

- Tentacular belt blackish; median and posterior parapodia with ventral ligules reaching tip of neuracicular ligules N. ambigua Treadwell, 1937 (Eastern Pacific)

\section{Remarks}

Nereis perivisceralis Claparède, 1868 is not included in the key because it has notopodial homogomph falcigers with blades with 1-2 large basal denticles, instead of a series of spines (Gravina et al. 2015: 152, fig. 4).

On the other hand, Nereis rava Ehlers, 1868 apparently has three different body patterns in the Mediterranean, especially regarding the anterior end features. The original illustration by Ehlers (1868: pl. 21 fig. 10) was repeated by Fauvel (1923: 340, fig. 131e), and it shows the anterior margin of the tentacular belt as crenulated, not covering the posterior eyes, the anterior eyes are not round, but oval with their longest axis horizontal, and the tentacular cirri are long, reaching about chaetiger 6 . Núñez (2004: fig. 138a) illustrated an alternative anterior end pattern: the anterior margin of the tentacular belt is smooth, not covering the posterior eyes, the anterior eyes are round, and the tentacular cirri are short, reaching about chaetiger 2-3, although they were described as reaching chaetiger 8 (Núñez 2004: 373). The third pattern was illustrated by Gravina et al. (2015: 158, fig. 8e): they show the anterior margin of the tentacular belt as smooth, partially covering the posterior eyes, the anterior eyes are round, and the tentacular cirri are very short, barely reaching chaetiger 2 . These differences might be explained by the use of different fixatives, ethanol by Ehlers, formaline by the others, but in the key above we follow the characterization of Gravina et al. (2015) for this Mediterranean species. 


\section{Key to male epitokes of the Nereis splendida Grube, 1840 species group}

(formerly " $N$. falsa" de Quatrefages, 1866 species group)

1. Non-natatory region with 27 chaetigers; palpophores not expanded laterally beyond prostomial lateral margins, narrower than prostomium ........ s. splendida Grube, 1840 (Mediterranean Sea)

- Non-natatory region with 20 chaetigers; palpophores expanded laterally beyond prostomial lateral margins, about as wide as $2 / 3$ of prostomial width N. lucipeta Ehlers, 1908 (South Africa)

\section{Discussion}

The widespread confusion regarding what Nereis falsa de Quatrefages, 1866 is can be partially solved if it is regarded as belonging in Hediste Malmgren, 1867, and probably as a junior synonym of $H$. diversicolor (Müller, 1776). However, with the indication of a distinct species in the Black Sea, the name $N$. falsa would be available for it once it is accepted as a valid species. This conclusion was reached early, but influential scientists like McIntosh and Fauvel overlooked it. As a means to encourage the solution of this problem, some notes on the taxonomy of Hediste and a key to identify species of Hediste are also included.

The alternative delineation by Fauvel $(1914,1923)$ of $N$. falsa was widely used, and eventually it was further expanded to include other species as junior synonyms. However, this species-group name must be changed. The next available name, $N$. splendida Grube, 1840, is an alternative for what has been regarded as $N$. falsa de Quatrefages, 1866 from the Mediterranean and adjacent eastern Atlantic region. A neotype has been proposed, and atoke and epitoke species have been fully described and illustrated.

Most of the species previously regarded as junior synonyms of " $N$. falsa" deserve to be reinstated, and one, Nereis lunulata Ehlers, 1901 stat. nov., is elevated to species rank. Furthermore, the expansion of "N. falsa" resulted in the inclusion of other morphological patterns, including some species having a single row of paragnaths on pharyngeal areas VII-VIII. These species would not strictly belong to the group, but were included in this contribution and in the key to species, to emphasize their resemblances and differences.

The grouping of species under $N$. falsa, now Nereis splendida, is restricted to encompass a homogeneous set of species including $N$. splendida, $N$. callaona, $N$. lucipeta, $N$. lunulata stat. nov. and $N$. occidentalis. They share the presence of anterior parapodia with blunt ligules, becoming blunt conical to digitate in median and posterior parapodia, as well as having dorsal cirri or notopodia of similar proportions along the body or a similar paragnath pattern on the pharynx. The pharynx has conical paragnaths in both maxillary rings, but none in area V, and areas VII-VIII have $2-3$ rows of paragnaths. The notopodial homogomph falcigers have blades spinulose, tips incurved, and well defined tendons.

\section{Acknowledgments}

Linda Ward from the Smithsonian Institution, Washington DC, Andy Mackie from National Museum Wales, Cardiff, Geoff Read from NIWA, Wellington, New Zealand, and João Gil from the Blanes Centre for Advanced Studies, Spain, kindly provided PDFs of difficult to find publications. Tarik Meziane (MNHN) helped a lot by providing lab space. The late Nancy Voss (UMML) helped a lot by allowing us to study part of the collections in her charge. JALG made a research visit to Naturalis Biodiversity Center, Leiden, thanks to a CONACYT grant (no. 61609) and the warm hospitality of Harry A. ten Hove and Joke Blekker. Elin Sigvaldadóttir (Swedish Museum of Natural History, Stockholm), Birger Neuhaus (ZMB), Danny Eibye-Jacobsen (NHMD), Linda Ward and Viviane Solís Weiss (ICMyL) kindly provided specimens from the collections in their care. SISV received funding from CONACYT, ECOSUR and MNHN. VMCV thanks Leslie Harris and David Ocker for their warm hospitality, and specially to Leslie 
Harris for the amenities given during the visit at the LACM. VMCV received funding from CONACYT and ECOSUR. Maestros Drs Masanori Sato and Torkild Bakken, and Rudy C.A.M. Jocqué carefully read a previous draft and recommended many positive means to improve this contribution. This final presentation was accomplished by the careful reading and editing by Danny Eibye-Jacobsen.

\section{References}

Allen M.J. 1957. The breeding of polychaetous annelids near Parguera, Puerto Rico. Biological Bulletin 113: 49-57.

Alós C., Laborda J., Núñez J., Parapar J., Besteiro C., Moreira J., San Martín G. \& Alonso-Zarazaga M.A. 2004. Apéndice 1. Nomenclatura: lista de sinónimos y combinaciones. Fauna Ibérica 25: 495-521.

Amoureux L. 1973. Quelques annélides polychètes de 1'Afrique occidentale et équatoriale. Cahiers ORSTOM, Série Oceánographie 11: 41-65.

Audouin J.V. \& Milne-Edwards H. 1833. Classification des annélides, et description de celles qui habitent les côtes de la France. Quatrième famille: Néréidiens. Annales des Sciences naturelles, Paris 29: 195-269. Available from https://www.biodiversitylibrary.org/item/29342\#page/199/mode/1up [accessed 16 Sep. 2021].

Audzijonyte A., Ovcarenko I., Bastrop R. \& Väinölä R. 2008. Two cryptic species of the Hediste diversicolor group (Polychaeta, Nereididae) in the Baltic Sea, with mitochondrial signatures of different population histories. Marine Biology 155: 599-612. https://doi.org/10.1007/s00227-008-1055-3

Augener H. 1906. Reports on the results of dredging, under the supervision of Alexander Agassiz, in the Gulf of Mexico and the Caribbean Sea, and on the east coast of the United States, 1877 to 1880, by the U.S. Coast Survey Steamer Blake, Lieut. Commander C.D. Sigsbee, U.S.N., and Commander J.R. Bartlett, U.S.N. Commanding, 42. Westindische Polychaeten. Bulletin of the Museum of Comparative Zoology 43 (4): 91-196. Available from https://www.biodiversitylibrary.org/page/30295058 [accessed 16 Sep. 2021].

Augener H. 1913. Polychaeta I. Errantia. In: Michaelsen W. \& Hartmeyer R. (eds) Die Fauna SüdwestAustraliens. Ergebnisse der Hamburger südwest-australischen Forschungsreise 19054 (5): 65-304. Gustav Fischer, Jena, Germany. Available from https://www.biodiversitylibrary.org/page/7160888 [accessed 16 Sep. 2021].

Augener H. 1918. Polychaeta. Beiträge zur Kenntnis des Meeresfauna West-Afrikas. Z.L. Friederichsen \& Co., Hamburg.

Augener H. 1922. Ueber Litorale Polychaeten von Westindien. Sitzungsbericht der Gesellschaft naturforschender Freunde, Berlin 1922: 38-63. Available from https://www.biodiversitylibrary.org/item/148305\#page/46/mode/1up [accessed 16 Sep. 2021].

Augener H. 1925. Über westindische und einige andere Polychaeten-Typen von Grube (Öersted), Krøyer, Mörch und Schmarda. Publikationer fra Universitetets Zoologiske Museum, København 39: 1-47.

Augener H. 1934. Polychaeten aus den Zoologischen Museen von Leiden und Amsterdam 4 (Schluss). 2. Polychaeten-Typen von Arm. Hansen 1881, aus dem Naturhistorischen Reichsmuseum Leiden. Zoologische Mededeelingen, Leiden 17 (8): 123-160.

Bakken T. 2004. A Revision of Nereidinae (Polychaeta, Nereididae). PhD thesis. Norwegian University of Science and Technology, Trondheim.

Available from https://ntnuopen.ntnu.no/ntnu-xmlui/handle/11250/272013 [accessed 16 Sep. 2021].

Bakken T. \& Wilson R.S. 2005. Phylogeny of nereidids (Polychaeta, Nereididae) with paragnaths. Zoologica Scripta 34: 507-547. https://doi.org/10.1111/j.1463-6409.2005.00200.x 
Bakken T., Glasby C.J. \& Wilson R.S. 2009. A review of paragnath morphology in Nereididae (Polychaeta). Zoosymposia 2: 305-316. https://doi.org/10.11646/zoosymposia.2.1.21

Beebe W. 1937. The Templeton Crocker Expedition, 2. Introduction, itinerary, list of stations, nets and dredges. Zoologica 22: 33-46. https://doi.org/10.5962/p.203672

Berkeley E. \& Berkeley C. 1964. Notes on some pelagic and some swarming Polychaeta taken off the coast of Peru. Canadian Journal of Zoology 42: 121-134. https://doi.org/10.1139/z64-012

Bobretzky N. 1870. Materiali dlya fauni Chernogo Morya: Annelidi (Annelida Polychaeta). Zapiski Kievskogo Obshchestva Estestvoispytateleii 1: 188-274.

Bobretzky N. 1882. Dopolneniya ki fauni annelidi Chernogo Morya. Zapiski Kievskogo Obshchestva Estestvoispytateleii 6: 183-212.

Chambers S. \& Garwood P. 1992. Polychaetes from Scottish Waters: A Guide to Identification 3. Family Nereidae. National Museums of Scotland, Edinburgh.

Chester C., Agosti D., Sautter G., Catapano T., Martens K., Gérard I. \& Bénichou L. 2019. EJT editorial standard for the semantic enhancement of specimen data in taxonomy literature. European Journal of Taxonomy 586: 1-22. https://doi.org/10.5852/ejt.2019.586

Claparède E. 1867. De la structure des annélides: Note comprenant un examen critique des travaux les plus récents sur cette classe de vers. Archives des Sciences physiques et naturelles, nouvelle période 30: 5-44. Available from https://www.biodiversitylibrary.org/item/92897\#page/9/mode/1 up [accessed 16 Sep. 2021]. [Translated into English: On the structure of the Annelida, including a critical examination of the most recent works on this class of worms. Annals and Magazine of Natural History 3 20: 337361. Available from https://www.biodiversitylibrary.org/item/53344\#page/351/mode/1up [accessed 16 Sep. 2021].]

Claparède E. 1868. Les annélides chétopodes du Golfe de Naples. Mémoires de la Société de Physique et d'Histoire naturelle de Genève 19: 313-584. Available from http://www.biodiversitylibrary.org/item/50163\#page/375/mode/1up [accessed 16 Sep. 2021].

Conde-Vela V.M. 2018. New species of Pseudonereis Kinberg, 1865 (Polychaeta: Nereididae) from the Atlantic Ocean, and a review of paragnath morphology and methodology. Zootaxa 4471 (2): 245-278. https://doi.org/10.11646/zootaxa.4471.2.2

Conde-Vela V.M. \& Salazar-Vallejo S.I. 2015. Redescriptions of Nereis oligohalina (Rioja, 1946) and N. garwoodi González-Escalante \& Salazar-Vallejo, 2003 and description of $N$. confusa sp. n. (Annelida, Nereididae). ZooKeys 518: 15-49. https://doi.org/10.3897/zookeys.518.9564

Cossu P., Maltagliati F., Lai T., Casu M., Curini-Galletti \& Castelli A. 2012. Genetic structure of Hediste diversicolor (Polychaeta, Nereididae) from the northwestern Mediterranean as revealed by DNA intersimple sequence repeat (ISSR) markers. Marine Ecology Progress Series 452: 171-178.

https://doi.org/10.3354/meps09611

Coutinho M.C.L. \& Santos C.S.G. 2014. Morphological anomalies in polychaetes: Perinereis species (Polychaeta: Annelida) examples from the Brazilian coast. Memoirs of Museum Victoria 71: 45-51. https://doi.org/10.24199/j.mmv.2014.71.05

Day J.H. 1962. Polychaeta from several localities in the western Indian Ocean. Proceedings of the Zoological Society of London 139 (4): 627-656. https://doi.org/10.1111/j.1469-7998.1962.tb01597.x

Day J.H. 1967. A monograph on the Polychaeta of Southern Africa. British Museum (Natural History) Publication 656, 2 volumes. https://doi.org/10.5962/bhl.title.8596

Day J.H. 1973. New Polychaeta from Beaufort, with a key to all species recorded from North Carolina. NOAA Technical Reports NMFS Circular 375: 1-140. https://doi.org/10.5962/bhl.title.62852 
De León-González J.A. \& Solís-Weiss V. 2000. A review of the polychaete family Nereididae from Western Mexico. Bulletin of Marine Science 67: 549-569.

De León-González J.A., Solís-Weiss V. \& Ochoa-Rivera V. 1999. Nereids (Polychaeta) from the Caribbean Sea and adjacent coralline islands from the southeastern Gulf of Mexico. Proceedings of the Biological Society of Washington 112 (4): 667-681.

Dean H.K. 2001. Some Nereididae (Annelida: Polychaeta) from the Pacific coast of Costa Rica. Revista de Biología Tropical 49 (Suppl. 2): 37-67.

Dueñas-Ramírez PR. 1980. Inventario preliminar de los poliquetos (Annelida) de aguas someras de la Bahía de Cartagena y áreas adyacentes. Boletín Museo del Mar 10: 82-138.

Ehlers E. 1868. Die Borstenwürmer (Annelida Chaetopoda) nach systematischen und anatomischen Untersuchungen dargestellt 2: 269-748. Wilhelm Engelmann, Leipzig. Available from https://www.biodiversitylibrary.org/page/1985162\#page/321/mode/1up [accessed 16 Sep. 2021].

Ehlers E. 1901a. Die Anneliden der Sammlung Plate. Abhandlungen zur Kenntnis der Zoologie Chiles nach den Sammlungen von Dr. L. Plate. Zoologische Jahrbücher 5 (Suppl.): 251-271. Available from https:/www.biodiversitylibrary.org/item/49920\#page/263/mode/1up [accessed 16 Sep. 2021].

Ehlers E. 1901b. Die Polychaeten des magellanischen und chilenischen Strandes: ein faunistischer Versuch. Weidmannsche Verlagsbuchhandlung, Berlin.

Ehlers E. 1908. Die bodensässigen Anneliden aus den Sammlungen der deutschen Tiefsee-Expedition. Wissenschaftliche Ergebnisse der deutschen Tiefsee-Expedition auf dem Dampfer 'Valdivia' 18981899 16: 1-168. Available from https://www.biodiversitylibrary.org/page/2129178\#page/3/mode/1up [accessed 16 Sep. 2021].

Ehlers E. 1913. Die Polychaeten-Sammlungen der Deutschen Südpolar-Expedition 1901-1903. Deutsche Südpolar-Expedition 1901-1903 im Auftrage des Reichsamtes des Innern, herausgegeben von Erich von Drygalski, Leiter der Expedition 13 (Zoologie 5): 397-598.

Available from https://www.biodiversitylibrary.org/page/2139283 [accessed 16 Sep. 2021].

Fauchald K. 1977a. The polychaete worms. Definitions and keys to the orders, families and genera. Natural History Museum of Los Angeles County, Science Series 28: 1-188.

Fauchald K. 1977b. Polychaetes from intertidal areas in Panama, with a review of previous shallow-water records. Smithsonian Contributions to Zoology 221: 1-81. https://doi.org/10.5479/si.00810282.221

Fauvel P. 1913. Quatrième note préliminaire sur les polychètes provenant des campagnées de l'Hirondelle et de la Princesse-Alice, ou deposées dans le Musée océanographique de Monaco. Bulletin de l'Institut océanographique 270: 1-80. Available from

https://www.biodiversitylibrary.org/item/173088\#page/259/mode/1up [accessed 16 Sep. 2021].

Fauvel P. 1914. Annélides polychètes non pélagiques provenant des Campagnes de l'Hirondelle et de la Princesse-Alice (1885-1910). Résultats des Campagnes scientifiques accomplies sur son Yacht par Albert $1^{e r}$, Prince souverain de Monaco 46: 1-432. Available from

https://www.biodiversitylibrary.org/page/2117722\#page/9/mode/1up [accessed 16 Sep. 2021].

Fauvel P. 1916. Annélides polychètes pélagiques provenant des Campagnes de l'Hirondelle et de la Princesse-Alice (1885-1910). Résultats des Campagnes scientifiques accomplies sur son Yacht par Albert $1^{\text {er, }}$ Prince souverain de Monaco 48: 1-152. https://doi.org/10.5962/bhl.title.48837

Fauvel P. 1919. Annélides polychètes de Madagascar, de Djibouti, et du Golfe Persique. Archives de Zoologie expérimentale et générale 58: 315-473. https://doi.org/10.5962/bhl.part.8154

Fauvel P. 1923. Polychètes errantes. Faune de France 5: 1-488.

Fauvel P. 1936. Contribution à la faune des annélides polychètes du Maroc. Mémoires de la Société des Sciences naturelles du Maroc 43: 1-143. 
Fauvel P. 1941. Annélides polychètes de la Mission du Cap Horn (1882-1883). Bulletin du Muséum national d'Histoire naturelle, série 213 (4): 272-298.

Fauvel P. 1943. Annélides polychètes de Californie receuillies par L. Diguet. Mémoires du Muséum national d'Histoire naturelle 18 (1): 1-32.

Fauvel P. 1950. Contribution a la faune des annélides polychètes du Sénégal. Bulletin de l'Institut français d'Afrique noire, série A 12 (2): 335-394.

Fauvel P. \& Rullier F. 1957. Nouvelle contribution à la faune des annélides polychètes du Sénégal (première partie). Bulletin de l'Institut français d'Afrique noire, série A 19 (1-2): 24-96.

Fauvel P. \& Rullier F. 1959. Contribution à la faune des annélides polychètes du Sénégal et de Mauritanie (première partie). Bulletin de l'Institut français d'Afrique noire, série A 21 (2): 477-533.

Fiege D. \& Wehe T. 2004. Type catalogue of the Annelida: Polychaeta in the collections of the Senckenberg-Museum in Frankfurt am Main, Germany. Senckenbergiana Biologica 84: 27-43.

Gardiner S.L. 1976 (1975). Errant polychaete annelids from North Carolina. Journal of the Elisha Mitchell Scientific Society 91 (3): 77-220.

González-Escalante L.E. \& Salazar-Vallejo S.I. 2003. A new estuarine species, Nereis garwoodi (Polychaeta: Nereididae), from Bahia Chetumal, Mexican Caribbean coast. Revista de Biología Tropical 51: $155-164$.

Gravier C. 1901. Sur la classification des Néréidiens de Quatrefages (Lycoridiens Grube). Bulletin du Muséum national d'Histoire naturelle 7: 350-357.

Gravier C. 1934. Remarques sur la morphologie du parapode des néréidiens. Annals des Sciences naturelles, Zoologie, série 10 17: 347-367.

Gravina M.F., Lezzi M., Bonifazi A. \& Giangrande A. 2015. The genus Nereis L., 1758 (Polychaeta, Nereididae); state of the art for identification of Mediterranean species. Atti della Società toscana di Scienze naturali, Memorie, serie B 122: 147-164.

Grube A.E. 1840. Actinien, Echinodermen und Würmer des Adriatischen- und Mittelmeers, nach eigenen Sammlungen beschrieben. J.H. Bon, Königsberg [Kaliningrad]. https://doi.org/10.5962/bhl.title.10133

Grube A.E. 1850. Die Familien der Anneliden. Archiv für Naturgeschichte 16: 249-364. Available from https://www.biodiversitylibrary.org/item/51061\#page/257/mode/1up [accessed 16 Sep. 2021].

Grube A.E. 1857. Annulata örstediana. Enumeratio Annulatorum, quae in itinere per Indiam occidentalem et Americam centralem annis 1845-1848 suscepto legit cl. A.S. Örsted, adjectis speciebus nonnullis a cl. H. Kröyero in itinere ad Americam meridionalem collectis, (Fortsættelse [continued]). 2. Familia Euniceae - F. Syllidea. Videnskabelige Meddelelser fra Dansk Naturhistorisk Forening for 1857: 158186. Available from https://www.biodiversitylibrary.org/item/110674\#page/159/mode/1up [accessed 16 Sep. 2021].

Grube A.E. 1858. Annulata örstediana. Enumeratio Annulatorum, quae in itinere per Indiam occidentalem et Americam centralem annis 1845-1848 suscepto legit cl. A.S. Örsted, adjectis speciebus nonnullis a cl. H. Kröyero in itinere ad Americam meridionalem collectis, (Slutning [conclusion]). 3. Familia Ariciaea - F. Sipunculacea and Index. Videnskabelige Meddelelser fra Dansk Naturhistorisk Forening for 1858: 105-120. Available from https://www.biodiversitylibrary.org/item/110675\#page/109/mode/1up [accessed 16 Sep. 2021].

Grube A.E. 1874 (1873). Die Familie der Lycorideen und die Aufstellung von Gruppen in der Gattung Nereis. Jahres-Bericht der schlesischen Gesellschaft für vaterländische Cultur 51: 56-73. Available from https://www.biodiversitylibrary.org/item/118508\#page/76/mode/1up [accessed 16 Sep. 2021]. 
Grube A.E. 1878. Annulata Semperiana. Beiträge zur Kenntnis der Annelidenfauna der Philippinen nach den von Herrn Prof. Semper mitgebrachten Sammlungen. Memoires de l'Académie impériale des Sciences de St. Pétersbourg, série 7 25: 1-300. https://doi.org/10.5962/bhl.title.85345

Hansen A. 1882. Recherches sur les annélides recueillies par M. le professeur Édouard van Beneden pendant son voyage au Brésil et à la Plata. Mémoires couronnés et Mémoires des Savants étrangers publiés par l'Académie royale des Sciences, des Lettres et des Beaux-Arts de Belgique 44 (3): 1-29. Available from https://www.biodiversitylibrary.org/page/5943290 [accessed 16 Sep. 2021].

Hartman O. 1936. New species of polychaetous annelids of the family Nereidae from California. Proceedings of the United States National Museum 83: 467-480.

https://doi.org/10.5479/si.00963801.83-2994.467

Hartman O. 1938. Annotated list of the types of polychaetous annelids in the Museum of Comparative Zoology. Bulletin of the Museum of Comparative Zoology at Harvard College 85: 1-31.

Hartman O. 1939. The polychaetous annelids collected on the Presidential Cruise of 1938. Smithsonian Miscellaneous Collections 98 (13): 1-22. Available from

https://www.biodiversitylibrary.org/item/35649\#page/371/mode/1up [accessed 16 Sep. 2021].

Hartman O. 1940. Polychaetous annelids, 2. Chrysopetalidae to Goniadidae. Allan Hancock Pacific Expeditions 7: 173-287. Available from

https://www.biodiversitylibrary.org/page/27822405\#page/191/mode/1 up [accessed 16 Sep. 2021].

Hartman O. 1944. Polychaetous annelids. Allan Hancock Atlantic Expedition 3: 1-33.

Hartman O. 1945. The marine annelids of North Carolina. Duke University Marine Station Bulletin 2: $1-54$.

Hartman O. 1948. The marine annelids erected by Kinberg. With some notes on some other types in the Swedish State Museum. Arkiv för Zoologi 42A: 1-137.

Hartman O. 1951. The littoral marine annelids of the Gulf of Mexico. Publications of the Institute of Marine Science, Port Aransas, Texas 2: 7-124.

Hartman O. 1954. Polychaetous annelids of the Gulf of Mexico. In: Galtsoff P.S. (ed.) Gulf of Mexico. Its Origin, Waters, and Marine Life: 413-417. Fishery Bulletin of the Fish and Wildlife Service, Washington DC.

Hartman O. 1956. Polychaetous annelids erected by Treadwell, 1891 to 1948, together with a brief chronology. Bulletin of the American Museum of Natural History 109: 239-310.

Hartman O. 1959. Catalogue of the polychaetous annelids of the World. Allan Hancock Foundation, Occasional Papers 23: 1-628.

Hartman O. 1964. Polychaeta Errantia of Antarctica. Antarctic Research Series 3: 1-131. https://doi.org/10.1029/AR003

Hartmann-Schröder G. 1960. Zur Polychaeten-Fauna von Peru. Beiträge zur neotropischen Fauna 11: 1-44. https://doi.org/10.1080/01650526009380621

Hartmann-Schröder G. 1962a. Zur Kenntnis der Nereiden Chiles (Polychaeta Errantia), mit Beschreibung epitoker Stadien einiger Arten und der Jugendentwicklung von Perinereis vallata (Grube). Zoologischer Anzeiger 168: 389-441.

Hartmann-Schröder G. 1962b. Zur Kenntnis des Eulitorals der chilenischen Pazifikküste und der argentinischen Küste Südpatagoniens unter besonderer Berücksichtigung der Polychaeten und Ostracoden, 2. Die Polychaeten des Eulitorals. Mitteilungen aus dem hamburgischen zoologischen Museum und Institut 60 (Suppl.): 57-270.

Hartmann-Schröder G. 1996. Annelida, Borstenwürmer, Polychaeta. Tierwelt Deutschlands 58: 1-648. 
Hartwich G. 1993. Die Polychaeten-Typen des Zoologisches Museums in Berlin. Mitteilungen aus dem zoologischen Museum in Berlin 69: 73-154. https://doi.org/10.1002/mmnz.19930690106

Hefferan M. 1900. Variation in the teeth of Nereis. Biological Bulletin 2: 129-143.

https://doi.org/10.2307/1535673

Heinen A. 1911. Die Nephtydeen und Lycorideen der Nord- und Ostsee einschließlich der verbindenden Meeresteile. Wissenschaftliche Meeresuntersuchungen, New Series 13: 1-85. Available from https://www.biodiversitylibrary.org/item/53069\#page/11/mode/1up [accessed 16 Sep. 2021].

Hoagland R.A. 1919. Polychaetous annelids from Porto Rico, the Florida Keys, and Bermuda. Bulletin of the American Museum of Natural History 41: 571-590.

Hutchings P. \& Kupriyanova E. 2018. Cosmopolitan polychaetes — fact or fiction? Personal and historical perspectives. Invertebrate Systematics 32: 1-9. https://doi.org/10.1071/IS17035

ICZN (International Commission on Zoological Nomenclature). 1999. International Code of Zoological Nomenclature. $4^{\text {th }}$ Edition. International Trust for Zoological Nomenclature in association with the British Museum (Natural History), London.

Imajima M. 1972. Review of the annelid worms of the family Nereididae of Japan, with descriptions of five new species or subspecies. Bulletin of the National Science Museum 15: 37-153.

Kinberg J.G.H. 1866. Annulata nova (Continuatio): Nereidum dispositio nova. Öfversigt av Kongliga Vetenskaps-Akademiens Förhandlingar 22: 167-179. Available from

https://www.biodiversitylibrary.org/item/100715\#page/181/mode/1up [accessed 16 Sep. 2021].

Kinberg J.G.H. 1910. Annulater. Kongliga Svenska Fregatten Eugenies Resa omkring Jorden under Befäl af C.A. Virgin Aren 1851-1853. Vetenskapliga Iakttagelser på Konung Oscar den Förstes Befallning utgifna af Kongliga Svenska Vetenskapsakademien. Part 2, Zoology 3. Almquist and Wicksells Boktryckeri A/B, Uppsala and Stockholm.

Khlebovich V.V. 1996. Polychaetous annelids 3. Polychaetes of the family Nereididae of the Russian seas and adjacent waters. Fauna of Russia and Neighbouring Countries, Zoological Institute, Russian Academy of Sciences, New Series 140: 1-223. [In Russian.]

Liñero-Arana I. \& Reyes-Vásquez G. 1979. Nereidae (Polychaeta, Errantia) del Golfo de Cariaco, Venezuela. Boletín del Instituto Oceanográfico, Universidad de Oriente 18: 3-12.

Malmgren A.J. 1867. Annulata Polychaeta Spetsbergiae, Groenlandiae, Islandiae et Scandinaviae hactenus cognita. Frenckelliana, Helsingsforsiae [Helsinki]. https://doi.org/10.5962/bhl.title.13358

McIntosh W.C. 1910. A Monograph of the British Annelids, volume 2, part 2. Polychaeta: Syllidae to Ariciidae: 233-444. Ray Society, London. Available from

https://www.biodiversitylibrary.org/item/118633\#page/13/mode/1up [accessed 16 Sep. 2021].

Mohammad M.B.M. 1981. Malformations in some polychaete annelids from Kuwait, Arabian Gulf. Hydrobiologia 78 (2): 129-131. https://doi.org/10.1007/BF00007586

Monro C.C.A. 1933. The Polychaeta Errantia collected by Dr. Crossland at Colón, in the Panama Region, and the Galapagos Islands during the expedition of the S.Y. "St. George." Proceedings of the Zoological Society of London 103 (1): 1-96. https://doi.org/10.1111/j.1096-3642.1933.tb01578.x

Müller O.F. 1771. Von Würmern des süssen und salzigen Wassers. Seinect und Faber, Copenhagen. Available from https://www.biodiversitylibrary.org/item/50349\#page/5/mode/1up [accessed 16 Sep. 2021].

Müller O.F. 1776. Zoologiae Danicae Prodromus, seu Animalium Daniae et Norvegiae Indigenarum Characters, Nomina, et Synonyma Imprimis Popularium. Hallageriis, Havniae [Copenhagen].

https://doi.org/10.5962/bhl.title.13268 
Müller O.F. 1800. Naturgeschichte einiger Wurm-Arten, des süssen und salzigen Wassers. Johann Heinrich Schubothe, Copenhagen. https://doi.org/10.5962/bhl.title.14413

Nonato E.F. \& Luna J.A.C. 1970. Anelídeos poliquetas do nordeste do Brasil, 1. Poliquetas bentónicos da costa de Alagoas e Sergipe. Boletim do Instituto Oceanográfico, São Paulo 19: 57-130.

https://doi.org/10.1590/S0373-55241970000100004

Núñez J. 2004. Familia Nereididae Savigny, 1822. Fauna Ibérica 25: 293-390.

Örsted A.S. 1843. Annulatorum Danicorum Conspectus, Fasc. 1. Maricolae. Wahlianae, Hafniae [Copenhagen]. Available from https:/www.biodiversitylibrary.org/item/44441\#page/3/mode/1up [accessed 16 Sep. 2021].

Oug E., Bakken T. \& Kongsrud J.A. 2014. Original specimens and type localities of early described polychaete species (Annelida) from Norway, with particular attention to species described by O.F. Müller and M. Sars. Memoirs of Museum Victoria 71: 217-236. https://doi.org/10.24199/j.mmv.2014.71.17

Pamungkas J. \& Glasby C.J. 2015. Taxonomy of reproductive Nereididae (Annelida) in multispecies swarms at Ambon Island, Indonesia. ZooKeys 520: 1-25. https://doi.org/10.3897/zookeys.520.9581

Pettibone M.H. 1956. Some polychaete worms of the families Hesionidae, Syllidae, and Nereidae from the east coast of North America, West Indies, and Gulf of Mexico. Journal of the Washington Academy of Sciences 46: 281-294. Available from

https://www.biodiversitylibrary.org/item/122693\#page/317/mode/1up [accessed 16 Sep. 2021].

Quatrefages A. de. 1866a. Histoire naturelle des Annéles marins et d'Eau douce. Annélides et Gephyriens. Vol. 1. Librarie Encyclopèdique de Roret, Paris. Available from

https://www.biodiversitylibrary.org/item/214290\#page/7/mode/1up [accessed 16 Sep. 2021].

Quatrefages A. de. 1866b. Histoire naturelle des Annéles marins et d'Eau douce. Annélides et Gephyriens. Vol. 2. Librarie Encyclopèdique de Roret, Paris. Available from https://www.biodiversitylibrary.org/item/214384\#page/7/mode/1up [accessed 16 Sep. 2021].

Rathke H. 1837a. Zur Fauna der Krym. Mémoires de l'Academie impériale des Sciences de St. Pétersbourg (Mémoirs des Savants étrangers) 3: 290-454. Available from http://www.biodiversitylibrary.org/bibliography/11609\#/summary [accessed 16 Sep. 2021].

Rathke H. 1837b. De Bopyro et Nereide: Commentationes Anatomico-Physiologicae Duae. Frantzen, Rigae and Dorpati [Riga and Tartu, Estonia]. https://doi.org/10.5962/bhl.title.14421

Read G. \& Fauchald K. (eds) 2020. World Polychaeta database. Nereis Linnaeus, 1758. Available from http://www.marinespecies.org/aphia.php?p=taxdetails\&id=129379 [accessed 21 Sep. 2021].

Reish D.J. 1954. Nomenclatural changes and redescription of two nereids (Annelida, Polychaeta) from the Eastern Pacific. Bulletin of the Southern California Academy of Sciences 53: 99-106. Available from https://www.biodiversitylibrary.org/item/106883\#page/267/mode/1up [accessed 16 Sep. 2021].

Reish D.J. 1968. A biological survey of Bahia de Los Angeles, Gulf of California, Mexico, 2. Benthic polychaetous annelids. Transactions of the San Diego Society of Natural History 15 (7): 67-106.

https://doi.org/10.5962/bhl.part.12054

Rioja E. 1960. Estudios anelidológicos, 23. Contribución al conocimiento de los anélidos poliquetos de las Islas de Revillagigedo. Anales del Instituto de Biología, México 30: 243-259.

Röhner M., Bastrop R. \& Jürss K. 1997. Genetic differentiation in Hediste diversicolor (Polychaeta: Nereididae) for the North Sea and the Baltic Sea. Marine Biology 130: 171-180.

https://doi.org/10.1007/s002270050236

Rozbaczylo N. \& Bolados J. 1980. Nereidos de Iquique, Chile (Polychaeta: Nereidae). Boletín del Museo Nacional de Historia Natural, Chile 37: 205-224. 
Rullier F. 1974. Quelques annélides polychètes de Cuba recueillies dans des éponges. Travaux du Muséum d'Histoire naturelle Grigore Antipa 14: 9-77.

Rullier F. \& Amoureux L. 1969. Nouvelle contribution a l'etude de la faune des annélides polychètes du Maroc. Bulletin de la Societé des Sciences naturelles du Maroc 49: 109-142.

Salazar-Vallejo S.I. 2020. Revision of Leocrates Kinberg, 1866 and Leocratides Ehlers, 1908 (Annelida, Errantia, Hesionidae). Zootaxa 4739: 1-114. https://doi.org/10.11646/zootaxa.4739.1.1

Salazar-Vallejo S.I. \& Eibye-Jacobsen D. 2012. Annulata örstediana: Publication dates, composition and annotated taxonomic list, with some comments on Hemipodus (Polychaeta: Glyceridae). Revista de Biología Tropical 60: 1391-1402. https://doi.org/10.15517/rbt.v60i3.1815

Salazar-Vallejo S.I. \& Jiménez-Cueto M.S. 1997. Neréididos (Polychaeta) del Caribe mexicano con una clave para las especies del Gran Caribe. Revista de Biología Tropical 44/45: 361-377.

Salazar-Vallejo S.I., Gillet P. \& Surugiu V. 2017. How false is Nereis falsa (Annelida, Phyllodocida, Nereididae)? Revista de Biología tropical 65: 847-857. https://doi.org/10.15517/rbt.v65i3.26635

Santos C.S.G. \& Lana P.C. 2003. Nereididae (Polychaeta) da costa nordeste do Brasil, 2. Gêneros Ceratonereis e Nereis. Iheringia, série Zoologia 93: 5-22.

https://doi.org/10.1590/S0073-47212003000100001

Schmarda L.K. 1861. Neue Turbellarien, Rotatorien und Anneliden beobachtet und gesammelt auf einer Reise um die Erde 1853 bis 1857. Wilhelm Engelmann, Leipzig.

Available from www.biodiversitylibrary.org/ia/neuewirbelloseth21861schm [accessed 16 Sep. 2021].

Schroeder P.C. \& Hermans C.O. 1975. Annelida: Polychaeta. In: Giese A.C. \& Pearse J.S. (eds) Reproduction of Marine Invertebrates 3: 1-213. Academic Press, New York.

https://doi.org/10.1016/B978-0-12-282503-3.50007-9

Smith R.I. 1959. The synonymy of the viviparous polychaete Neanthes lighti Hartman (1938) with Nereis limnicola Johnson (1903). Pacific Science 13: 349-350.

Sousa-Paula L.C. de, Pessoa F.A.C., Otranto D. \& Dantas-Torres F. 2021. Beyond taxonomy: species complexes in New World phlebotomine sand flies. Medical and Veterinary Entomology 35 (3): 267-283. https://doi.org/10.1111/mve.12510

Taylor J.L. 1984. Family Nereidae Johnston 1845. In: Uebelacker J.M. \& Vittor B.A. (eds) Taxonomic Guide to the Polychaetes (Annelida: Polychaeta) from the Northern Gulf of Mexico 5: 31.1-31.42. B.A. Vittor \& Assoc., Mobile, USA.

Tosuji H., Bastrop R., Götting M., Park T., Hong J.-S., Sato M. 2019. Worldwide molecular phylogeny of common estuarine polychaetes of the genus Hediste (Annelida: Nereididae), with special referenc to interspecific common haplotypes found in southern Japan. Marine Biodiversity 49: 1385-1402.

https://doi.org/10.1007/s12526-018-0917-2

Treadwell A.L. 1924. Polychaetous annelids collected by the Barbados-Antigua Expedition from the University of Iowa in 1918. University of Iowa Studies in Natural History 10: 3-23.

Treadwell A.L. 1928. Polychaetous annelids from the Arcturus Oceanographic Expedition. Zoologica 8: 449-485. https://doi.org/10.5962/p.190372

Treadwell A.L. 1932. Annelidos polychetos novos da Ilha de São Sebastião. Revista do Museu Paulista 17 (2): 1-20.

Treadwell A.L. 1937. The Templeton Crocker Expedition. VIII. Polychaetous annelids from the west coast of Lower California, the Gulf of California and Clarion Island. Zoologica, Scientific Contributions of the New York Zoological Society 22 (2): 139-160. https://doi.org/10.5962/p.184684 
Vasileiadou K., Pavloudi C., Sarropoulou E., Fragopoulou N., Kotoulas G. \& Arvanitidis C. 2016. Unique COI haplotypes in Hediste diversicolor populations in lagoons adjoining the Ionian Sea. Aquatic Biology 25: 7-15. https://doi.org/10.3354/ab00654

Villalobos-Guerrero T.F. \& Idris I. 2021. Reproductive morphology and redescriptions of some Neanthes Kinberg, 1865 (Annelida: Nereididae) species from the southeastern Asian seas, with comparative synoptic tables of accepted species. European Zoological Journal 88 (1): 556-594.

https://doi.org/10.1080/24750263.2021.1899318

Virgilio M., Backeljau T. \& Abbiati M. 2006. Mitochondrial DNA and allozyme patterns of Hediste diversicolor (Polychaeta: Nereididae): the importance of small scale genetic structuring. Marine Ecology Progress Series 326: 157-165. https://doi.org/10.3354/meps326157

Virgilio M., Fauvelot C., Constantini F., Abbiati M. \& Backeljau T. 2009. Phylogeography of the common ragworm Hediste diversicolor (Polychaeta: Nereididae) reveals cryptic diversity and multiple colonization events across its distribution. Molecular Ecology 18: 1980-1994.

https://doi.org/10.1111/j.1365-294X.2009.04170.x

von Marenzeller E. 1874. Zur Kenntnis der adriatischen Anneliden. Sitzungsberichte der kaiserliche Akademie der Wissenschaften, Mathematisch-Naturwissenschaftliche Classe, Wien 69: 407-482. Available from https://www.biodiversitylibrary.org/item/35268\#page/441 [accessed 16 Sep. 2021].

Wesenberg-Lund E. 1962. Reports of the Lund University Chile Expedition 1948-1949. 43. Polychaeta Errantia. Lunds Universitets Arsskrift, New Series 257 (12): 1-139.

Wiktor J. 1980. Type-specimens of Annelida Polychaeta in the Museum of Natural History of the Wroclaw University. Annales Zoologici 35: 267-283.

Willey A. 1905. Report on the Polychaeta collected by Professor Herdman, at Ceylon, in 1902. Report to the Government of Ceylon on the Pearl Oyster Fisheries of the Gulf of Manaar, with Supplementary Reports upon the Marine Biology of Ceylon by other Naturalists IV, Supplementary Reports 4: 243-324.

Winchell C.J., Valencia J.E. \& Jacobs D.K. 2010. Confocal analysis of nervous system architecture in direct-developing juveniles of Neanthes arenaceodentata (Annelida, Nereididae). Frontiers Zoology 7: e17. https://doi.org/10.1186/1742-9994-7-17

Wu B., Sun R. \& Yang D.J. 1985. The Nereidae (Polychaetous Annelids) of the Chinese Coast. China Ocean Press, Beijing.

Manuscript received: 28 December 2020

Manuscript accepted: 8 June 2021

Published on: 24 November 2021

Topic editor: Rudy C.A.M. Jocqué

Desk editors: Jeroen Venderickx, Danny Eibye-Jacobsen

Printed versions of all papers are also deposited in the libraries of the institutes that are members of the EJT consortium: Muséum national d'histoire naturelle, Paris, France; Meise Botanic Garden, Belgium; Royal Museum for Central Africa, Tervuren, Belgium; Royal Belgian Institute of Natural Sciences, Brussels, Belgium; Natural History Museum of Denmark, Copenhagen, Denmark; Naturalis Biodiversity Center, Leiden, the Netherlands; Museo Nacional de Ciencias Naturales-CSIC, Madrid, Spain; Real Jardín Botánico de Madrid CSIC, Spain; Zoological Research Museum Alexander Koenig, Bonn, Germany; National Museum, Prague, Czech Republic. 